University of Texas Rio Grande Valley

ScholarWorks @ UTRGV

$12-2021$

\title{
Exempting battery electric vehicles from traffic restrictions: Impacts on market and environment under Pigovian taxation
}

$\mathrm{Xu} \mathrm{Hu}$

Zhaojun Yang

Jun Sun

The University of Texas Rio Grande Valley, jun.sun@utrgv.edu

Yali Zhang

Follow this and additional works at: https://scholarworks.utrgv.edu/is_fac

Part of the Tourism and Travel Commons, and the Transportation Commons

\section{Recommended Citation}

Hu, X., Yang, Z., Sun, J., \& Zhang, Y. (2021). Exempting battery electric vehicles from traffic restrictions: Impacts on market and environment under Pigovian taxation. Transportation Research Part A: Policy and Practice, 154, 53-91. https://doi.org/10.1016/j.tra.2021.09.014

This Article is brought to you for free and open access by the Robert C. Vackar College of Business \& Entrepreneurship at ScholarWorks @ UTRGV. It has been accepted for inclusion in Information Systems Faculty Publications and Presentations by an authorized administrator of ScholarWorks @ UTRGV. For more information, please contact justin.white@utrgv.edu,william.flores01@utrgv.edu. 


\begin{abstract}
In busy metropolitan areas, traffic restrictions based on the last digits of license plates effectively ease traffic jams and improve air quality. Recently, policy-makers in China exempted battery electric vehicles (BEV) from traffic restrictions to promote their diffusion in place of conventional vehicles (CV). To examine the impacts of such an exemption on consumers and manufacturers as well as the environment, this study models the duopoly competition between $\mathrm{BEV}$ and $\mathrm{CV}$ manufacturers as a Cournot game. The numerical analyses compare three traffic restriction policies concerning $\mathrm{BEV}$ and $\mathrm{CV}$, and reveal the pros and cons of each. In particular, the BEV-exempted policy promotes customer adoption, industry development, and environment protection with the least consumer surplus loss. As supplementary measures, relevant vehicle purchase tax and carbon tax may make such a policy more effective, respectively, in short and long terms.
\end{abstract}

Keywords: Conventional vehicles (CV); Battery electric vehicles (BEV); Traffic restriction policies; Vehicle purchase tax; Carbon tax; Carbon emission. 


\section{Exempting Battery Electric Vehicles from Traffic Restrictions: Impacts on Market and Environment under Pigovian Taxation}

\section{Introduction}

Exhaust from vehicles using fossil fuels is a major source of carbon emission. In metropolitan areas, traffic congestions not only cost people time but also make air pollution worse. To alleviate the issues, major cities around the world keep some vehicles off the road on certain days. Known as traffic restriction (Fernandes et al., 2016; Shi, Guo, \& Hu, 2019), driving restriction (L. L. Wang, Xu, \& Qin, 2014; Yang, Lu, Liu, \& Guo, 2018), or restriction of car use (Gallego, Montero, \& Salas, 2013; Z. Y. Liu, Li, Wang, \& Shang, 2018), such a measure is a "necessary evil". At the cost of individual convenience, a traffic restriction enhances the wellbeing of the general public.

For instance, the traffic restriction helped Guangzhou, a megacity in China, reduce volatile organic compounds by $31 \%$ roadside and $34 \%$ rooftop on average (X. Y. Huang et al., 2017). Langfang is another severely-polluted city, and its enforcement improves air quality and significantly lowers the cancer risk level of its population (Zhao et al., 2018). To China's capital, Beijing, the measure brings tremendous public health benefits, especially for women and the elderly in winter (Y. Liu, Yan, \& Dong, 2016). It also reduces carbon emission by more than 35\%, or 15.5 million tons each year, in Beijing alone (P. H. Li \& Jones, 2015).

A typical traffic restriction covers all private cars but exempts public transport such as buses and taxis. In 2017, China further "whitelisted" new energy vehicles (NEV) to promote their diffusion (N. Wang, Pan, \& Zheng, 2017). In the regulations regarding such an exemption and other preferential policies (e.g., tax breaks), NEV include battery electric vehicles (BEV), plug-in hybrid electric vehicles (PHEV), and fuel cell electric vehicles (FCEV) (MI\&IT, 2020; MOF, 2020a, 2020b). By the same token, this study distinguishes these three types of NEV from conventional vehicles (CV) that run on internal combustion engines as the main power source (e.g., 
non-plug-in hybrid electric vehicles). In particular, BEV accounted for two-thirds (4.79 out of 7.2 million) of total NEV sold worldwide by the end of 2019 (IEA, 2020), and over $80 \%$ (4.49 out of 5.51 million) in the China market by the first quarter of 2021 (MPS, 2021). Thus, this study focuses on the effects of BEV-exempted traffic restriction in primary modeling, and includes PHEV and FCEV in extended robustness analyses.

As "traffic restriction policies address economic, social, and environmental issues at the local level but may have effects beyond their area of application" (Anciaes, 2015), exempting BEV from traffic restriction has implications beyond its original intent. This study attempts to investigate the question of how BEV-exempted traffic restriction helps promote BEV diffusion and reduce carbon emission along with Pigovian taxation. First, it reviews the current literature on

traffic restriction policies, BEV incentive programs and Pigovian taxation approaches to identify the research gap. Next, it sets up the mathematical model of a Cournot game between a BEV manufacturer and a CV manufacturer that compete for the same market, and compares BEVexempted traffic restriction with no restriction and uniform restriction. Then, numerical analyses are conducted to examine the effectiveness of EV-exempted traffic restriction under vehicle purchase tax and carbon tax, followed by extended robustness analyses. Finally, the implications of the findings are discussed.

\section{Research Background}

\subsection{Traffic Restriction}

Often called last-digit restriction (X. D. Zhang, Li, Feng, \& Chen, 2012) or license plate restriction (N. Jia, Zhang, He, \& Li, 2017; Pu, Yang, Liu, Chen, \& Chen, 2015), a typical traffic restriction policy determines when a car can be on the road based on the tail number of its license plate. Many cities of China, for instance, keep each private car off the road from one-day-out-of10 to odd-even-day, as shown in Table 1. Among the variants, one-day-per-week is the most 
common. An increasing number of restriction programs implemented in major cities worldwide (e.g., Paris, Rome, Mexico City, and London) now differentiate cars by their pollution levels: highpollution vehicles are prohibited or restricted in down-town areas, while low-pollution vehicles are not (Barahona, Gallego, \& Montero, 2020).

Table 1. Traffic Restriction in China

\begin{tabular}{ll}
\hline Restriction & \multicolumn{1}{c}{ City } \\
\hline One-day-out-of-10 & $\begin{array}{l}\text { Changchun } \\
\text { Beijing, Tianjin, Shijiazhuang, Tangshan, Qinhuangdao, Handan, Baoding, }\end{array}$ \\
$\begin{array}{l}\text { Cangzhou, Langfang, Zhengzhou, Kaifeng, Luoyang, Anyang, Hebi, } \\
\text { Xne-day-per-week } \\
\text { Chiang, Puyang, Luohe, Xi'an, Xianyang, Weinan, Hangzhou, Lanzhou, } \\
\text { Chengdu, Taiyuan. }\end{array}$ \\
$\begin{array}{l}\text { Odd-even-day } \\
\text { Four-days-on-road- } \\
\text { and-four-days-off }\end{array}$ & Guangzhou Xinzhou, Dalian, Zhuhai. \\
\hline
\end{tabular}

Note: It is a nationwide policy to exempt NEV from traffic restriction (MOF, 2020b).

The simplest odd-even-day traffic restriction keeps half of the cars home every week day. Delhi, one of the most polluted cities in the world, tried such a policy in 2016 (Chowdhury et al., 2017). Beijing, the capital of China, enforced it during the 2008 Olympic Games (Cai \& Xie, 2011). On a regular basis, more cities choose milder traffic restriction policies. The one-day-per-week restriction keeps a car off the road for one day every week, reducing about 20 percent of traffic each weekday. In addition to those in China, many major cities in the world also implement this policy, such as Milan (Invernizzi et al., 2011), Ramallah (Vermote, Macharis, Boeykens, Schoolmeester, \& Piutman, 2014), and Mexico City (Guerra \& Millard-Ball, 2017; Lyons, Lozano, Granados, \& Guzman, 2017).

The main difference across policy variants, especially between one-day-per-week and oddeven-day, lies in traffic restriction strength. Being the most stringent, odd-even-day traffic restriction is generally not welcomed by drivers, some of whom may even risk violating the policy (Z. Y. Liu et al., 2018). At a steep cost, its marginal benefit is not very convincing either: the traffic 
volume in Beijing only increased by $8.74 \%$ when it was replaced by one-day-per-week after the 2008 Olympic Games (Z. Y. Liu et al., 2018). One goal of this study, therefore, is to explore the relationship between traffic restriction strength and consumer surplus.

All traffic restriction policies are more effective in the short term than in the long term (Huang, Fu, \& Qi, 2017; Yang et al., 2018). To bypass the restriction, for example, many commuters buy a second car (Y. X. Liu, Hong, \& Liu, 2016). Even worse, some commuters choose to drive "illegally" on prohibited days (Z. Liu, Li, Wang, \& Shang, 2020). Others would rather change their travel plans than switching to public transport as per policy intent (Guerra \& MillardBall, 2017). For most drivers, therefore, the use of BEV is preferred if they are exempted from traffic restrictions (Klungboonkrong, Jaensirisak, \& Satirnnam, 2017). To gradually phase out CV

in big cities, China exempted NEV, dominantly BEV, from traffic restriction in 2017 as "a combination of traffic restriction policy and green technology" (NDRC, 2017). It is estimated that replacing $\mathrm{CV}$ with $\mathrm{BEV}$ can cut more than half of the carbon emission from transportation (Mro \& Lonza, 2018).

The effectiveness of traffic restriction is usually evaluated in terms of how it enhances traffic and environmental conditions, such as the increase of average speed (Z. Y. Liu et al., 2018) and the improvement of air quality (Fernandes et al., 2016; Lyons et al., 2017; Pu et al., 2015). Policy-makers often put more weight on the environment than the traffic as evidenced by the fact that many cities deploying one-day-per-week switch to temporary odd-even-day in response to smog (MEEC, 2018; SMG, 2018). Therefore, this study pays special attention to the effect of traffic restriction on emission control.

\subsection{Pigovian Taxation}

In countries like China (Hao, Ou, Du, Wang, \& Ouyang, 2016) and Norway (Bjerkan, Nørbech, \& Nordtømme, 2016), waiving vehicle purchase tax for BEV is one critical move to promote their diffusion (Mersky, Sprei, Samaras, \& Qian, 2016). This kind of Pigovian taxation 
serves as a negative incentive that "persuades" people to switch from CV to BEV. It is considered an effective green policy that reduces the total carbon emission from transportation in the long run (Fridstrøm \& Østli, 2017).

Meanwhile, applying fuel surcharge for $\mathrm{CV}$ is an alternative to waiving vehicle purchase tax for $\mathrm{BEV}$ in terms of emission control: purchase tax reduces the number of $\mathrm{CV}$ while fuel surcharge limits their use (Y. Liu \& Cirillo, 2015). Adding an extra burden on consumers, however, the fuel surcharge is not very popular in countries like the USA and China where people still rely heavily on CV (Hsu, Walters, \& Purgas, 2008). As another option for emission control, carbon tax is levied directly on automakers and largely avoids consumer complaints (Aldy, 2019). Therefore, this study examines the effects of BEV-exempted traffic restriction under two Pigovian taxation approaches: vehicle purchase tax (waived for BEV) and carbon tax.

\subsection{BEV Incentive Programs}

Either direct or indirect in nature, incentive programs play essential roles in BEV diffusion. Direct incentives such as price subsidies and tax breaks motivate consumers to purchase BEV in many countries (Sierzchula, Bakker, Maat, \& van Wee, 2014). Another direct incentive implemented in China, free vehicle license (worth 106,144 RMB on average), also stimulates BEV sales (Qian, Grisolia, \& Soopramanien, 2019). Nevertheless, the impact of such customer-side subsidies on the expansion of China's BEV market is not as strong as expected, considering alternative policies that support its continuous growth (L. Li et al., 2020). For instance, R\&D subsidization is effective in promoting BEV adoption and environment protection (Yan, 2018).

Although there are debates on financial incentives, it is generally agreed upon that public expenditure and regulatory measures play important roles in NEV diffusion (Berkeley, Jarvis, \& Jones, 2018; Biresselioglu, Kaplan, \& Yilmaz, 2018; L. Li et al., 2020; Lin \& Wu, 2018), such as the construction of BEV charging infrastructure to ease consumers' range concerns (Kim, Oh, Park, \& Joo, 2018; Neves, Marques, \& Fuinhas, 2019). As indirect incentives, supportive policies like 
toll waiver, free parking, and special lane access (e.g., HOV/carpool and bus lanes) increase people's incorporation of BEV in daily routines and consequently their purchase intention (Hardman, 2019).

Like direct incentives, indirect incentives come with a cost. For instance, toll waiver leads to a sizable loss of toll revenue despite its promotion of BEV adoption in Norway (Aasness \& Odeck, 2015). Attractive to potential BEV buyers in Netherlands (Wolbertus, Kroesen, van den Hoed, \& Chorus, 2018), USA (Krause, Carley, Lane, \& Graham, 2013), Japan (Khan, Yamamoto, \& Sato, 2020) and China (Ning Wang, Tang, \& Pan, 2017), free parking also causes a fall in the parking revenue, sometimes making a difference between surplus and deficit for local administrations (Bakker \& Trip, 2013). In places where detached dwellings allow more consumers to charge at home (e.g., USA, Switzerland), parking incentives do not stimulate BEV sales as much as home ownership (Bruckmann, Willibald, \& Blanco, 2021).

Though special lane access for BEV imposes little burden on the government budget, it is not problem-free either. For instance, granting BEV the access to a bus lane may slow down or even congest the traffic there and void its original purpose. Therefore, bus lane access is not very attractive to potential BEV buyers who generally care about public welfare (Y. Zhang, Qian, Sprei, $\& \mathrm{Li}, 2016)$. Removing the carpool requirement of high-occupancy vehicle (HOV) lanes for BEV drivers only promotes purchase intentions in those megacities where the highway infrastructure allows such lane dedications (Hackbarth \& Madlener, 2013; Krause et al., 2013).

The impacts of HOV and bus lane access on BEV sales depend on traffic congestion levels in the regions where they are deployed (Hardman, 2019). Though they may increase the likelihood of repeated purchases, most first-time BEV buyers pay more attention to technology, environment and performance (Hardman, Chandan, Tal, \& Turrentine, 2017). Even in the USA, HOV lane access is found an insignificant predictor of BEV sales due to limited HOV lane accessibility per capita (Wee, Coffman, \& La Croix, 2018). Similarly in Canada, China, and the Netherlands, HOV and bus lane access have no significant effects on BEV adoption (W. Jia \& Chen, 2021). 
Compared with the above indirect incentives, restrictive policies (i.e., registration limit and traffic restriction) on traditional vehicles promote NEV adoption far more effectively ( $\mathrm{Lu}$, Yao, Jin, $\&$ Pan, 2020). The policy to limit the number of new vehicle registrations significantly increased the sales of NEVs in major Chinese cities, for instance, by $73.4 \%, 87.5 \%, 87 \%$ and $65.5 \%$ respectively in Tianjin, Hangzhou, Shenzhen and Haikou (Chi, Wang, \& Xu, 2021). The similar license plate lottery program implemented in the Netherlands also outperforms the subsidy policy (Peters, van der Werff, \& Steg, 2018). Driving restriction shows great potential as well, ranked by consumers in China as the third important factor next to registration limit and bus lane access, surpassing charging convenience, purchase subsidy, vehicle use subsidy and other factors (Lu et al., 2020). NEV drivers appreciate both registration limit waiver and traffic restriction exemption as they supplement each other: the former reduces ownership cost and the latter increases usage value (Ning Wang et al., 2017).

As subsidy policies encounter diminishing marginal returns, it is logical for regulatory policies to step in (X. Liu, Xie, Wang, \& Xue, 2021). In addition to those on the consumer side, there are regulatory policies on the manufacturer side as well. China's dual-credit mechanism on automakers comprises the credit from NEV production and the credit based on the average fuel consumption level of $\mathrm{CV}$ manufactured (to be discussed in more details later). With such a mechanism, BEV sales are likely to increase by over 2 million units annually (Ou et al., 2018), and the total carbon emission from passenger vehicles is expected to peak in 2032 (He et al., 2020). In the USA, various federal and state regulations promote BEV diffusion, such as "greenhouse gas (GHG) emissions and fuel economy standards for light-duty vehicles" and "corporate average fuel economy (CAFE) standards" at the national level (Sen, Noori, \& Tatari, 2017), and California's "zero-emission vehicle (ZEV) program" (Sykes \& Axsen, 2017) and "low carbon fuel standard (LCFS)" (Lepitzki \& Axsen, 2018). 


\subsection{Research Gap}

Extant studies predict BEV sales with traffic restriction exemption along with other variables such as charging infrastructure, price subsidy, tax break and registration limit waiver, and the results based on official or non-governmental data support its relatively strong influence (Ma, Fan, \& Feng, 2017; Morton, Lovelace, \& Anable, 2017; N. Wang et al., 2017). To further understand how traffic restriction exemption affects people's intention to purchase and use BEV, researchers collected survey and experiment observations from consumers, and the findings also suggested that such a policy effectively boosts up people's willingness to purchase BEV (Ning Wang et al., 2017; Z. Wang, Zhao, Yin, \& Zhang, 2017). Nevertheless, researchers and practitioners are yet to find out how traffic restriction policies and other incentive programs together make differences in the decisions of consumers and automakers, the understanding of which is critical for holistic policy-making.

So far, only one publication examined the effectiveness of incentive programs on BEV diffusion with trade-off scenarios (Ning Wang, Tang, Zhang, \& Guo, 2019). The results of system dynamics modeling suggest that registration limit waiver, price subsidy, and traffic restriction exemption have stronger effects on BEV sales than the reductions in parking fee, road toll, insurance charge, and vehicle and vessel $(\mathrm{V} \& \mathrm{~V})$ tax. However, the study did not consider how the competition between $\mathrm{BEV}$ and $\mathrm{CV}$ manufacturers influences consumer behavior. Rather, it compared the scenarios in which each policy is enacted or not. For instance, the abrogation of the BEV subsidy is expected to result in a sharp decline of market share by $42 \%$.

When a person chooses between BEV and CV options, the decision is based on their relative pros and cons in context. The comparison is embedded in different incentive programs that distinguish the utilities of $\mathrm{BEV}$ and $\mathrm{CV}$ to consumers. In addition to traffic restriction exemption that lifts BEV usage value, people consider financial incentives at the time of purchase. As a negative incentive in contrast to price subsidy, Pigovian taxation on CV manufacturers or buyers 
makes BEV more market-competitive.

The modeling of $\mathrm{CV}$ and $\mathrm{BEV}$ as competitive alternatives makes it possible to accommodate both Pigovian taxation and traffic restriction exemption. Rooted in the same environmental consideration, they are synergistic in shaping BEV purchase decisions regarding one-time investment and life-time usage, respectively. The examination of how traffic restriction and Pigovian taxation interact with each other helps policy-makers identify the best practices that are environment-friendly as well as acceptable to both automakers and consumers.

\section{Methods}

This study attempts to fill in the research gap with game theory modeling, as the competition between a BEV manufacturer and a CV manufacturer for the same market is basically a Cournot game in which they make decisions independently. Describing how consumers choose between $\mathrm{BEV}$ and $\mathrm{CV}$ and how vehicle manufacturers price their products to maximize profitability, the benchmark model provides the basis for further evaluating different traffic restriction policies and taxation approaches. Table 2 summarizes model notations.

Table 2. Model Notations

\begin{tabular}{cl}
\hline Notation & Definition \\
\hline$i \in\{B E V, C V\}$ & Vehicle type subscript: BEV stands for "battery electric \\
& vehicles", and CV stands for "conventional vehicles". \\
$P_{i}$ & Retail price \\
$C_{i}$ & Marginal cost \\
$O_{i}$ & Operating cost \\
$v$ & Consumer valuation of CV \\
$\beta v$ & Consumer valuation of BEV, $0<\beta \leq 1$ \\
$r_{V P T}$ & Vehicle purchase tax rate \\
\hline
\end{tabular}




\begin{tabular}{cl}
\hline$s$ & Price subsidy on BEV \\
$l$ & Loss of consumer surplus (which reflects the strength of \\
& traffic restriction) \\
$U_{i}$ & Surplus utility \\
$q_{i}$ & Vehicle Sales \\
$\pi_{i}$ & Manufacturer profit \\
$e_{i}$ & Carbon emission \\
$c e_{i}$ & Carbon tax \\
& Traffic restriction superscript: NR stands for "no \\
& restriction", CVR stands for "CV restricted" (i.e., BEV- \\
& exempted restriction), and BR stands for "both CV and \\
& BEV restricted" (i.e., uniform restriction). \\
& Total carbon emission \\
&
\end{tabular}

\subsection{Consumer Behavior}

When purchasing vehicles, consumers have two options, BEV or CV. Most BEV use lithium batteries to store energy, making them pricier than $\mathrm{CV}\left(P_{B E V}>P_{C V}\right)$. To promote $\mathrm{BEV}$ diffusion, there is a price subsidy $s$ on BEV. In addition, consumers need to pay vehicle purchase tax for $\mathrm{CV}$, which is waived for BEV. The rate of vehicle purchase tax is $r_{V P T}$ for $\mathrm{CV}$, and 0 for BEV.

Operating cost mainly includes transportation cost and maintenance cost. In terms of transportation cost, BEV are more economical (as electricity is relatively affordable and can be obtained from new energy sources like solar and wind) than CV. The average fuel consumption of CV in China in 2017 was $6.76 \mathrm{~L} / 100 \mathrm{~km}$ (CATRC, 2018), and the goal set by the State Council of China is to reach $5 \mathrm{~L} / 100 \mathrm{~km}$ by 2020 (SCC, 2016a). The average gasoline price in China is 5-7 $\mathrm{RMB} / \mathrm{L}$, and the transportation cost of $\mathrm{CV}$ is about $25-35 \mathrm{RMB} / 100 \mathrm{~km}$. Meanwhile, BEV currently 
consume $14.7 \mathrm{kWh} / 100 \mathrm{~km}$ on average, which is expected to be lowered to $11.5 \mathrm{kWh} / 100 \mathrm{~km}$ by 2025 (ACNPMCCS, 2017). The electricity rate is $0.5-1 \mathrm{RMB} / \mathrm{kWh}$ in China, leading to the transportation cost of 5.75-14.7 RMB/100km. Compared with $\mathrm{CV}, \mathrm{BEV}$ are also less expensive to maintain due to fewer mechanical parts. For instance, the five-year maintenance cost of a Nissan Leaf was about $\$ 3,920$, in comparison to $\$ 4,268$ for its $\mathrm{CV}$ equivalent of a Toyota Corolla (Breetz $\&$ Salon, 2018). The gaps in transportation and maintenance costs are expected to widen as the $\mathrm{BEV}$ market becomes more mature. Therefore, the operating cost of BEV is set lower than that of $\mathrm{CV}: O_{B E V}<O_{C V}$.

To maximize the surplus utility, strategic consumers compare different vehicle options based on the valuation of cars. Due to technological bottlenecks (e.g., relatively short range, fast decay of battery, and time-consuming recharging) and insufficient recognition, consumers' valuation of $\mathrm{BEV}$ is generally lower than that of $\mathrm{CV}$. The ratio of valuation between $\mathrm{BEV}$ and $\mathrm{CV}$ is $\beta$, and $0<\beta<1$. The surplus utility is formulated below:

$$
\begin{gathered}
U_{B E V}=\beta v-P_{B E V}-O_{B E V}+s, \\
U_{C V}=v-\left(1+r_{V P T}\right) P_{C V}-O_{C V} .
\end{gathered}
$$

Consumers may purchase neither BEV nor $\mathrm{CV}$ if both options provide negative surplus utility. When at least one option provides positive surplus utility, they will choose the one of higher surplus utility. Heterogeneous consumers are evenly distributed between 0 and 1 . The identification of the indifferent consumer's location yields the functional relationship between sales and retail price, as formulated below:

$$
\begin{gathered}
q_{B E V}=\frac{\left(1+r_{V P T}\right) P_{C V}-P_{B E V}+O_{C V}-O_{B E V}+s}{1-\beta}-\frac{P_{B E V}+O_{B E V}-s}{\beta}, \\
q_{C V}=1-\frac{\left(1+r_{V P T}\right) P_{C V}-P_{B E V}+O_{C V}-O_{B E V}+s}{1-\beta}
\end{gathered}
$$

\subsection{Manufacturer Decisions}

There are two manufacturers that make BEV and CV, respectively. Pursuing profitability, 
they decide the retail prices of their own products independently. The two types of vehicles are produced at different marginal costs. At the present, batteries are still relatively expensive, raising the marginal cost of BEV above that of $\mathrm{CV}: C_{B E V}>C_{C V}$. A higher retail price is needed to make the BEV manufacturer profitable. In the foreseeable future, the difference in production scales between BEV and CV will sustain the price gap.

In addition to marginal cost and retail price, the profitability of automakers is also subject to environmental regulations. In China, the NEV credit mechanism awards NEV production with a positive credit $C R_{N E V}^{+}$of up to 6 points per vehicle, but penalizes $C V$ production with a negative credit $C R_{N E V}^{-}$of -0.12 point per vehicle (as per the most recent values in 2020). Based on such "NEV credit proportion requirement", the BEV manufacturer obtains the positive credit $C R_{N E V}^{+} q_{B E V}$, whereas the $\mathrm{CV}$ manufacturer accrues the negative credit $C R_{N E V}^{-} q_{C V}$. An automaker may purchase credit at the unit price of $P_{C R}$ to offset negative points, or pay a fine at the rate of fine $_{C R}$. To encourage corporate participation in NEV credit trading, fine $e_{C R}$ is set higher than $P_{C R}$, or all the automakers that accrue negative points will choose to pay fines.

Considering the NEV credit mechanism, the profit of manufacturer $i$ can be formulated as:

$$
\pi_{i}=P_{i} q_{i}-C_{i} q_{i}+T C R_{i}
$$

where $i \in\{B E V, C V\}$, corresponding to $\mathrm{BEV}$ and $\mathrm{CV}$ manufacturers respectively, and $T C R_{i}$ stands for credit trading income or expense. In particular, the BEV manufacturer profits from selling credit points: $T C R_{B E V}=\min \left\{C R_{N E V}^{+} q_{B E V}, C R_{N E V}^{-} q_{C V}\right\} P_{C R}$, and the CV manufacturer pays for credit points: $T C R_{C V}=-\min \left\{C R_{N E V}^{+} q_{B E V}, C R_{N E V}^{-} q_{C V}\right\} P_{C R}$. This study first focuses on the scenario $C R_{N E V}^{+} q_{B E V}>C R_{N E V}^{-} q_{C V}$, in which the NEV credit for transaction totals $C R_{N E V}^{-} q_{C V}$. In

the case $C R_{N E V}^{+} q_{B E V}<C R_{N E V}^{-} q_{C V}$, the $\mathrm{CV}$ manufacturer needs to pay an additional fine, which will be discussed in Section 4.4.4.

\subsection{Total Carbon Emission}

The life-cycle assessment of total carbon emission considers the direct carbon emission 
from $\mathrm{CV}$ as well as the indirect emission of BEV from electricity generation (Onn et al., 2018). In a grid with the carbon intensity of electricity lower than $700 \mathrm{~g} / \mathrm{kWh}, \mathrm{BEV}$ leave a smaller carbon footprint than CV at the same usage (IEA, 2016; Wu et al., 2018). The average carbon intensity of electricity in the world is $340 \mathrm{~g} / \mathrm{kWh}$ (IEA, 2019), and China's coal powerplants must meet the $550 \mathrm{~g} / \mathrm{kWh}$ standard or get phased out by 2020 (SCC, 2016b). For the same expected lifespan mileage (e.g., $300,000 \mathrm{~km}$ ), therefore, BEV yield less carbon emission than $\mathrm{CV}$ on average: $e_{B E V}<e_{C V}$. The total carbon emission (TCE) for all vehicles is:

$$
T C E=\sum_{i=B E V, C V} e_{i} q_{i}
$$

In the case of carbon tax, the unit amount is calculated based on the lifecycle emission of each vehicle produced:

$$
\begin{aligned}
c e_{B E V} & =\text { carbon tax rate } \cdot e_{B E V} \\
c e_{C V} & =\text { carbon tax rate } \cdot e_{C V}
\end{aligned}
$$

\subsection{Consumer Surplus}

The sum of surplus utility formulated previously is denoted as consumer surplus (CS). Under the ad hoc policy of no traffic restriction, a density function $f(v)$ can be specified based on Equations (1), (2), and Lemma 1:

$$
f(v)=\left\{\begin{array}{ccc}
0 & , & \max \left\{U_{B E V}(v), U_{C V}(v)\right\}<0 \\
U_{B E V}(v) & , & U_{B E V}(v)>U_{C V}(v) \text { and } U_{B E V}(v)>0 \\
U_{C V}(v) & , & U_{B E V}(v)<U_{C V}(v) \text { and } U_{C V}(v)>0
\end{array}\right.
$$

The integral of the density function $f(v)$ yields the value of CS:

$$
C S=\int_{0}^{1} f(v) d v
$$




\section{Results}

Based on the model setup above, Section 4.1 reports the equilibrium results under different restriction-taxation scenarios. The comparisons of these equilibria yield the optimal traffic restriction strategy in Section 4.2 and the optimal taxation approach in Section 4.3, respectively. In order to assess model robustness, Section 4.4 considers four extensions by relaxing relevant assumptions.

\subsection{Optimal Pricing}

This section derives the optimal pricing decisions made by the two manufacturers under three traffic restriction policies:

NR: No restriction policy;

CVR: BEV-exempted policy with only $\mathrm{CV}$ restricted;

BR: Uniform policy with both BEV and CV restricted.

In addition, two Pigovian taxation approaches are considered. The first is vehicle purchase tax (waived for BEV), which has been implemented in China and Norway. The second is carbon tax, a climate policy worldwide.

\subsubsection{No Traffic Restriction Scenario}

Two manufacturers price their vehicles independently. Consumers make purchase decisions based on the retail prices of BEV and CV. The backward induction is used to solve this game, and optimal solutions are summarized in Lemma 1.

Lemma 1. Where there is no traffic restriction, the optimal retail prices, sales volumes, and manufacturer profits are:

$$
P_{B E V}^{N R}=\frac{\beta\left(K_{1}+1-\beta\right)+2 K_{2}}{4-\beta}-O_{B E V}+s,
$$




$$
\begin{gathered}
q_{B E V}^{N R}=\frac{\beta\left(K_{1}+1-\beta\right)-(2-\beta) K_{2}}{(4-\beta)(1-\beta) \beta}, \\
\pi_{B E V}^{N R}=\frac{\left[\beta\left(K_{1}+1-\beta\right)-(2-\beta) K_{2}\right]^{2}}{(4-\beta)^{2}(1-\beta) \beta} \\
+C R_{N E V}^{-} P_{C R} \frac{2+\beta-2 K_{1}-K_{2}}{4-\beta}, \\
P_{C V}^{N R}=\frac{2\left(K_{1}+1-\beta\right)+K_{2}}{(4-\beta)\left(1+r_{V P T}\right)}-\frac{O_{C V}}{1+r_{V P T}}, \\
q_{C V}^{N R}=1-\frac{(2-\beta)\left(K_{1}+1-\beta\right)-K_{2}}{(4-\beta)(1-\beta)}, \\
\pi_{C V}^{N R}=\frac{\left[2(1-\beta)-(2-\beta) K_{1}+K_{2}\right]^{2}}{(4-\beta)^{2}(1-\beta)\left(1+r_{V P T}\right)} .
\end{gathered}
$$

Note: $\quad K_{1}=\left(1+r_{V P T}\right)\left(C_{C V}+C R_{N E V}^{-} P_{C R}\right)+O_{C V} \quad$ and $\quad K_{2}=C_{B E V}+\beta C R_{N E V}^{-} P_{C R}+$ $O_{B E V}-s$.

\section{Proof: See Appendix A.}

Table 3 summarizes how sales volumes, retail prices, manufacturer profits, consumer surplus, and total carbon emission vary with parameter values under vehicle purchase tax when there is no traffic restriction. The results are analytical, and Appendix B1 gives the derivatives.

Table 3. Sensitivity analysis for no traffic restriction under vehicle purchase tax

\begin{tabular}{ccccccccc}
\hline & $q_{B E V}^{N R}$ & $q_{C V}^{N R}$ & $P_{B E V}^{N R}$ & $P_{C V}^{N R}$ & $\pi_{B E V}^{N R}$ & $\pi_{C V}^{N R}$ & $C S^{N R}$ & $T C E^{N R}$ \\
\hline$r_{V P T}$ & + & - & + & - & Note 2 & - & - & - \\
$O_{B E V}$ & - & + & - & + & - & + & - & Note 1 \\
$O_{C V}$ & + & - & + & - & Note 2 & - & - & - \\
$\beta$ & + & + & + & - & + & - & + & + \\
\hline
\end{tabular}

Note 1. When $c e_{B E V}>\frac{\beta}{2-\beta} c e_{C V}$, it is "+"; otherwise, it is "-"; Note 2. When $\Lambda_{1}-(4-\beta)(1-\beta) C R_{N E V}^{-} P_{C R}>0$, it is “+”; otherwise, it is " -".

Corollary 1 gives the optimal solutions under carbon tax when there is no traffic restriction: 
Corollary 1. When there is no traffic restriction, the optimal retail prices, sales volumes, and manufacturer profits under carbon tax are:

$$
\begin{gathered}
\tilde{P}_{B E V}^{N R}=\frac{\beta\left(\widetilde{K}_{1}+1-\beta+c e_{C V}\right)+2\left(K_{2}+c e_{B E V}\right)}{4-\beta}-O_{B E V}+s, \\
\tilde{q}_{B E V}^{N R}=\frac{\beta\left(\widetilde{K}_{1}+1-\beta+c e_{C V}\right)-(2-\beta)\left(K_{2}+c e_{B E V}\right)}{(4-\beta)(1-\beta) \beta}, \\
\tilde{\pi}_{B E V}^{N R}=\mathrm{CR}_{\mathrm{NEV}}^{-} P_{C R} \frac{2+\beta-2\left(\widetilde{K}_{1}+c e_{C V}\right)-K_{2}-c e_{B E V}}{4-\beta} \\
+\frac{\left[\beta\left(\widetilde{K}_{1}+1-\beta+c e_{C V}\right)-(2-\beta)\left(K_{2}+c e_{B E V}\right)\right]^{2}}{(4-\beta)^{2}(1-\beta) \beta}, \\
\tilde{P}_{C V}^{N R}=\frac{2\left(\widetilde{K}_{1}+1-\beta+c e_{C V}\right)+K_{2}+c e_{B E V}}{4-\beta}-O_{C V}, \\
\tilde{q}_{C V}^{N R}=1-\frac{(2-\beta)\left(\widetilde{K}_{1}+1-\beta+c e_{C V}\right)-\left(K_{2}+c e_{B E V}\right)}{(4-\beta)(1-\beta)}, \\
\tilde{\pi}_{C V}^{N R}=\frac{\left[2(1-\beta)-(2-\beta)\left(\widetilde{K}_{1}+c e_{C V}\right)+K_{2}+c e_{B E V}\right]^{2}}{(4-\beta)^{2}(1-\beta)} .
\end{gathered}
$$

Note: $\widetilde{K}_{1}=C_{C V}+C R_{N E V}^{-} P_{C R}+O_{C V}$ and $K_{2}=C_{B E V}+\beta C R_{N E V}^{-} P_{C R}+O_{B E V}-s$.

Proof: See Appendix A.

Table 4 summarizes how sales volumes, retail prices, manufacturer profits, consumer surplus and total carbon emission vary with parameter values under carbon tax when there is no traffic restriction. The results are analytical, and Appendix B2 gives the derivatives.

Table 4. Sensitivity analysis for no traffic restriction under carbon tax

\begin{tabular}{ccccccccc}
\hline & $\tilde{q}_{B E V}^{N R}$ & $\tilde{q}_{C V}^{N R}$ & $\tilde{P}_{B E V}^{N R}$ & $\tilde{P}_{C V}^{N R}$ & $\tilde{\pi}_{B E V}^{N R}$ & $\tilde{\pi}_{C V}^{N R}$ & $\widetilde{C S}^{N R}$ & $\widetilde{T C E}^{N R}$ \\
\hline$O_{B E V}$ & - & + & - & + & - & + & - & Note 1 \\
$O_{C V}$ & + & - & + & - & Note 4 & - & - & - \\
$c e_{B E V}$ & - & + & + & + & - & + & - & Note 2 \\
$c e_{C V}$ & + & - & + & + & Note 4 & - & - & Note 3 \\
$\beta$ & + & - & + & - & + & - & + & $+/-$ \\
\hline
\end{tabular}


Note 1 . When $c e_{B E V}>\frac{\beta}{2-\beta} c e_{C V}$, it is “-”; otherwise, it is “+”. Note 2 . When $\frac{(2-\beta) c e_{B E V}+\beta c e_{C V}}{(4-\beta)(1-\beta) \beta}+\tilde{q}_{B E V}^{N R}>0$, it is “+”; otherwise, it is "- ". Note 3 . When $\frac{c e_{B E V}-(2-\beta) c e_{C V}}{(4-\beta)(1-\beta)}+\tilde{q}_{C V}^{N R}>0$, it is "+"; otherwise, it is "- ". Note 4 . When $\widetilde{\Lambda}_{1}-$ $(4-\beta)(1-\beta) C R_{N E V}^{-} P_{C R}>0$, it is "+"; otherwise, it is "-—".

Several conclusions can be drawn from the sensitivity analyses in Table 3 and Table 4. First, reducing vehicle operating costs enables a manufacturer to sell more cars at a higher retail price and make more profit. Second, the decrease in operating costs leads to more consumer surplus. Third, increasing the operating cost of $\mathrm{CV}$ reduces total carbon emission, but lowering the operating cost of BEV may not. When BEV are undervalued or the emission advantage is weak $\left(c e_{B E V}>\frac{\beta}{2-\beta} c e_{C V}\right)$, reducing their operating cost actually increases total carbon emission. Only when BEV have a relatively high valuation or big emission advantage $\left(c e_{B E V}<\frac{\beta}{2-\beta} c e_{C V}\right)$ does their lower operating cost lead to less total carbon emission, as shown in Fig. 1.

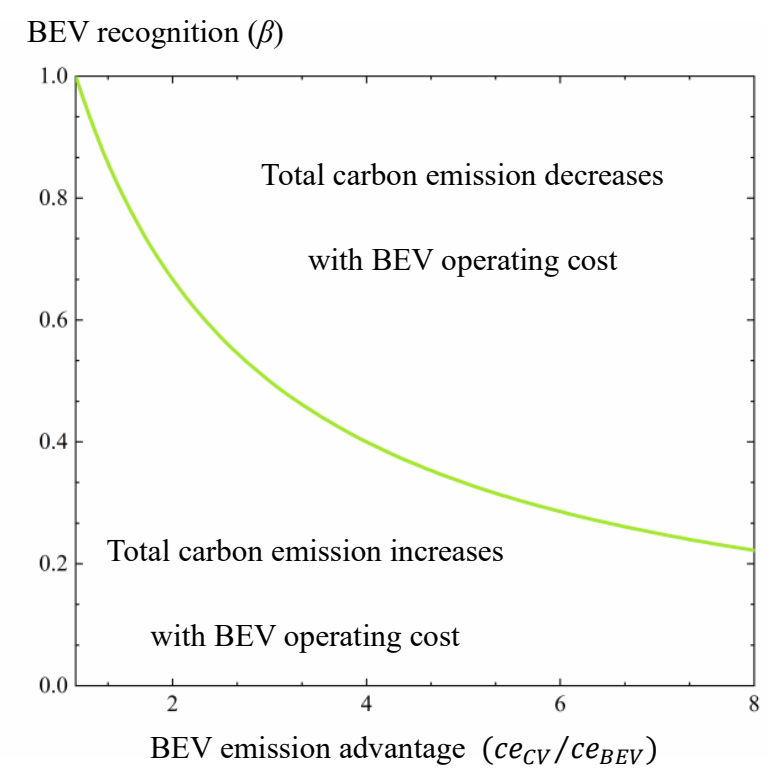

Fig.1. BEV operating cost and total carbon emission under BEV recognition and emission advantage 
Nevertheless, reducing the operating cost of BEV promotes their diffusion and industry development, as well as consumer surplus. One way to reduce the operating cost of BEV is to facilitate their charging, such as by constructing more public charging stations. Yet such an effort is not very effective until the BEV industry is mature enough $c e_{B E V}>\frac{\beta}{2-\beta} c e_{C V}$. Before that, increasing the operating cost of $\mathrm{CV}$ (e.g., with fuel surcharge) is more viable for reducing their environmental impacts.

The two Pigovian taxation approaches perform differently. Vehicle purchase tax has almost no effect on the BEV market but makes differences in $\mathrm{CV}$ retail price and manufacturer profit. Carbon tax, however, affects the whole market by raising the retail prices of both BEV and CV. In other words, a consumer pays for the expected lifecycle emission of a vehicle through its manufacturer.

Although the derivatives of $\mathrm{BEV}$ recognition $\beta$ are analytical, the expressions are very long and complicated, which renders qualitative insights nearly impossible. Therefore, Fig.2 and Fig.3 numerically illustrate different trends under vehicle purchase tax (VPT) and carbon tax (CT) based on the parameters below. $r_{V P T}=0.1, l=0.05, O_{B E V}=0.15, O_{C V}=0.2, C_{B E V}=0.25, C_{C V}=$ $0.2, c e_{B E V}=0.05, c e_{C V}=0.1, s=0.02, C R_{N E V}^{-}=0.1, P_{C R}=0.005$. 


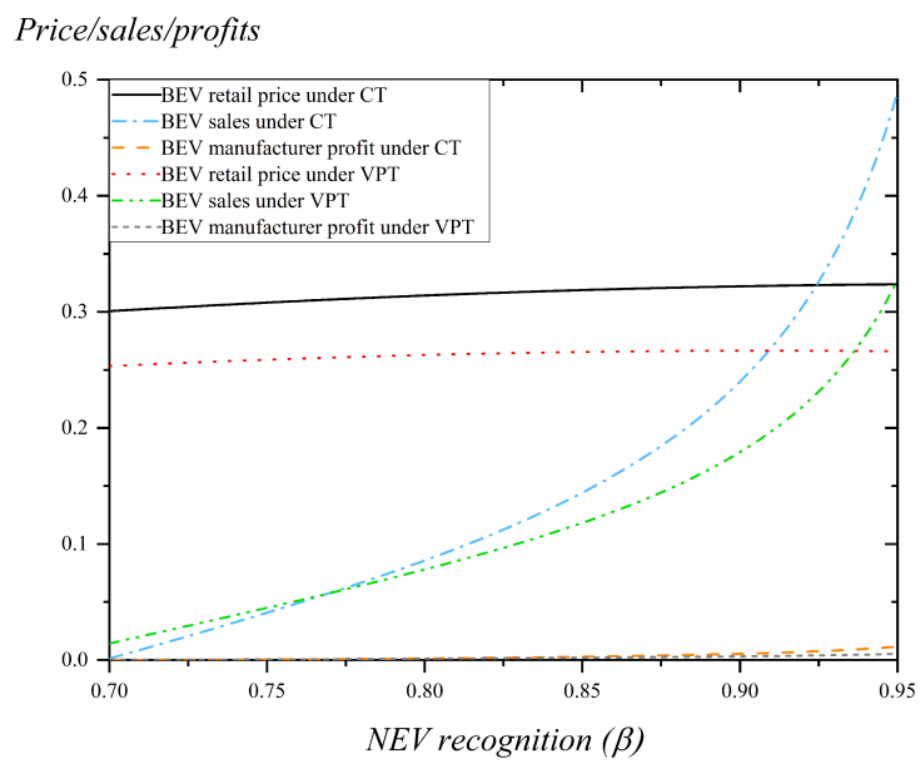

Fig.2. (a) The impacts of BEV recognition on BEV sales, retail price and manufacturer profit

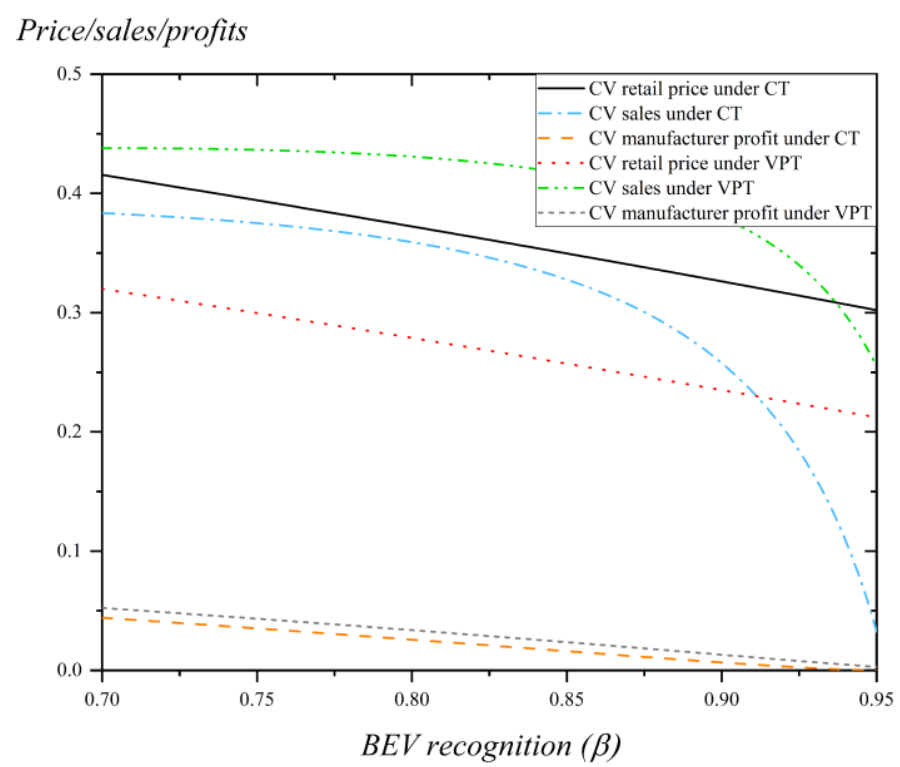

Fig.2. (b) The impacts of BEV recognition on CV sales, retail price and manufacturer profit 


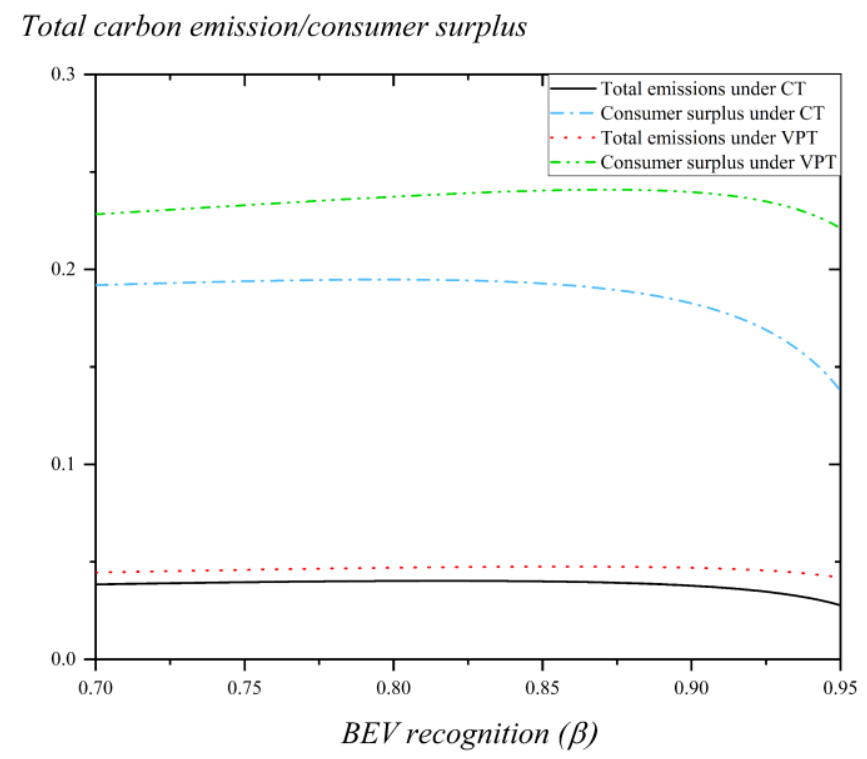

Fig. 3. The impacts of BEV recognition on consumer surplus and total carbon emission

Compared with vehicle purchase tax, carbon tax works in favor of BEV over CV. The increase of $\beta$ enables the $\mathrm{BEV}$ manufacturer to capture more sales at a higher retail price and make more profit, all at the cost of the $\mathrm{CV}$ manufacturer. In addition, the increase in $\beta$ will promote consumer surplus. Moving beyond 0.9 (when consumers value BEV and CV nearly equally), $\beta$ is also negatively correlated with total carbon emission.

When vehicle purchase tax is levied instead, BEV that enjoy the waiver actually lose some ground to $\mathrm{CV}$. The rise of $\beta$ induces price competition, which benefits consumers. However, this increases total carbon emission due to the sales of more vehicles. Compared with carbon tax, therefore, vehicle purchase tax makes the emission advantage of BEV obscure. The contrast between the two taxation approaches becomes even bigger at a higher BEV recognition level. Compared with carbon tax, vehicle purchase tax narrows the consumer surplus gap between $\mathrm{CV}$ and BEV and lengthens their substitution process. 


\subsubsection{BEV-exempted Traffic Restriction Scenario}

With traffic restriction, commuters cannot access the road all the time, which brings them a loss, denoted $l$. When BEV are exempted, this loss only applies to CV commuters. Strategic consumers consider the BEV-exempted traffic restriction when making vehicle purchasing decisions. The surplus utility derived from purchasing CV can be reformulated as:

$$
U_{C V}=v-\left(1+r_{V P T}\right) P_{C V}-O_{C V}-l .
$$

Solving the indifferent consumer's location yields the demand function:

$$
\begin{gathered}
q_{B E V}=\frac{\left(1+r_{V P T}\right) P_{C V}-P_{B E V}+l+O_{C V}-O_{B E V}+s}{1-\beta}-\frac{P_{B E V}+O_{B E V}-s}{\beta}, \\
q_{C V}=1-\frac{\left(1+r_{V P T}\right) P_{C V}-P_{B E V}+l+O_{C V}-O_{B E V}+s}{1-\beta} .
\end{gathered}
$$

The game sequence remains the same, and optimal solutions are summarized in Lemma 2.

Lemma 2. When CV rather than BEV are subject to traffic restriction, optimal retail prices, sales volumes, and manufacturer profits are:

$$
\begin{gathered}
P_{B E V}^{C V R}=\frac{\beta\left(K_{1}+1-\beta+l\right)+2 K_{2}}{4-\beta}-O_{B E V}+s, \\
q_{B E V}^{C V R}=\frac{\beta\left(K_{1}+1-\beta+l\right)-(2-\beta) K_{2}}{(4-\beta)(1-\beta) \beta}, \\
\pi_{B E V}^{C V R}=\mathrm{CR}_{\mathrm{NEV}}^{-} P_{C R} \frac{2+\beta-2 K_{1}-2 l-K_{2}}{4-\beta} \\
+\frac{\left[\beta\left(K_{1}+1-\beta+l\right)-(2-\beta) K_{2}\right]^{2}}{(4-\beta)^{2}(1-\beta) \beta}, \\
P_{C V}^{C V R}=\frac{2\left(K_{1}+1-\beta+l\right)+K_{2}}{(4-\beta)\left(1+r_{C V}+l\right.}-\frac{\left.O_{V P}\right)}{1+r_{V P T}} \\
q_{C V}^{C V R}=1-\frac{(2-\beta)\left(K_{1}+1-\beta+l\right)-K_{2}}{(4-\beta)(1-\beta)}, \\
\pi_{C V}^{C V R}=\frac{\left[2(1-\beta)-(2-\beta)\left(K_{1}+l\right)+K_{2}\right]^{2}}{(4-\beta)^{2}(1-\beta)\left(1+r_{V P T}\right)} .
\end{gathered}
$$

Note: $\quad K_{1}=\left(1+r_{V P T}\right)\left(C_{C V}+C R_{N E V}^{-} P_{C R}\right)+O_{C V} \quad$ and $\quad K_{2}=C_{B E V}+\beta C R_{N E V}^{-} P_{C R}+$ $O_{B E V}-S$.

Proof: See Appendix A. 
Table 5 summarizes how retail prices, sales volumes, manufacturer profits, consumer surplus, and total carbon emission vary with parameter values under vehicle purchase tax when $\mathrm{BEV}$ are exempted from traffic restriction. The results are analytical, and Appendix B3 gives the derivatives.

Table 5. Sensitivity analysis for BEV-exempted traffic restriction under vehicle purchase tax

\begin{tabular}{ccccccccc}
\hline & $q_{B E V}^{C V R}$ & $q_{C V}^{C V R}$ & $P_{B E V}^{C V R}$ & $P_{C V}^{C V R}$ & $\pi_{B E V}^{C V R}$ & $\pi_{C V}^{C V R}$ & $C S^{C V R}$ & $T C E^{C V R}$ \\
\hline$l$ & + & - & + & - & Note 2 & - & - & - \\
$r_{V P T}$ & + & - & + & - & Note 2 & - & - & - \\
$O_{B E V}$ & - & + & - & + & - & + & - & Note 1 \\
$O_{C V}$ & + & - & + & - & Note 2 & - & - & - \\
$\beta$ & + & - & + & - & + & - & + & $+1-$ \\
\hline
\end{tabular}

Note 1. When $c e_{B E V}>\frac{\beta}{2-\beta} c e_{C V}$, it is "-"; otherwise, it is "+". Note 2. When $\Lambda_{2}-(4-\beta)(1-\beta) C R_{N E V}^{-} P_{C R}>0$, it is “+”; otherwise, it is "-”".

Corollary 2 gives the optimal solutions under carbon tax when BEV are exempted from travel restriction:

Corollary 2. When only $C V$ are subject to travel restriction, optimal retail prices, sales volumes, and manufacturer profits under carbon tax are:

$$
\begin{gathered}
\tilde{P}_{B E V}^{C V R}=\frac{\beta\left(\widetilde{K}_{1}+1-\beta+l+c e_{C V}\right)+2\left(K_{2}+c e_{B E V}\right)}{4-\beta}-O_{B E V}+s, \\
\tilde{q}_{B E V}^{C V R}=\frac{\beta\left(\widetilde{K}_{1}+1-\beta+l+c e_{C V}\right)-(2-\beta)\left(K_{2}+c e_{B E V}\right)}{(4-\beta)(1-\beta) \beta}, \\
\tilde{\pi}_{B E V}^{C V R}=\mathrm{CR}_{\mathrm{NEV}}^{-} P_{C R} \frac{2+\beta-2\left(\widetilde{K}_{1}+l+c e_{C V}\right)-K_{2}-c e_{B E V}}{4-\beta} \\
+\frac{\left[\beta\left(\widetilde{K}_{1}+1-\beta+l+c e_{C V}\right)-(2-\beta)\left(K_{2}+c e_{B E V}\right)\right]^{2}}{(4-\beta)^{2}(1-\beta) \beta}
\end{gathered}
$$




$$
\begin{aligned}
& \tilde{P}_{C V}^{C V R}=\frac{2\left(\widetilde{K}_{1}+1-\beta+l+c e_{C V}\right)+K_{2}+c e_{B E V}}{4-\beta}-\left(O_{C V}+l\right), \\
& \tilde{q}_{C V}^{C V R}=1-\frac{(2-\beta)\left(\widetilde{K}_{1}+1-\beta+l+c e_{C V}\right)-\left(K_{2}+c e_{B E V}\right)}{(4-\beta)(1-\beta)}, \\
& \tilde{\pi}_{C V}^{C V R}=\frac{\left[2(1-\beta)-(2-\beta)\left(\widetilde{K}_{1}+l+c e_{C V}\right)+K_{2}+c e_{B E V}\right]^{2}}{(4-\beta)^{2}(1-\beta)} .
\end{aligned}
$$

Note: $\widetilde{K}_{1}=C_{C V}+C R_{N E V}^{-} P_{C R}+O_{C V}$ and $K_{2}=C_{B E V}+\beta C R_{N E V}^{-} P_{C R}+O_{B E V}-s$.

Proof: See Appendix A.

Table 6 summarizes how retail prices, sales volumes, manufacturer profits, consumer surplus, and total carbon emission vary with parameter values under carbon tax when BEV are exempted from traffic restriction. The results are analytical, and Appendix B4 gives the derivatives.

Table 6. Sensitivity analysis for BEV-exempted traffic restriction under carbon tax

\begin{tabular}{ccccccccc}
\hline & $\tilde{q}_{B E V}^{C V R}$ & $\tilde{q}_{C V}^{C V R}$ & $\tilde{P}_{B E V}^{C V R}$ & $\tilde{P}_{C V}^{C V R}$ & $\tilde{\pi}_{B E V}^{C V R}$ & $\tilde{\pi}_{C V}^{C V R}$ & $\widetilde{C S}^{C V R}$ & $\widetilde{T C E}^{C V R}$ \\
\hline$l$ & + & - & + & - & Note 4 & - & - & - \\
$O_{B E V}$ & - & + & - & + & - & + & - & Note 1 \\
$O_{C V}$ & + & - & + & - & Note 4 & - & - & - \\
$c e_{B E V}$ & - & + & + & + & - & + & - & Note 2 \\
$c e_{C V}$ & + & - & + & + & + & - & - & Note 3 \\
$\beta$ & + & - & + & - & + & - & + & $+/-$ \\
\hline
\end{tabular}

Note 1. When $c e_{B E V}>\frac{\beta}{2-\beta} c e_{C V}$, it is "-”; otherwise, it is "+". Note 2. When $\frac{(2-\beta) c e_{B E V}+\beta c e_{C V}}{(4-\beta)(1-\beta) \beta}+q_{B E V}>0$, it is "+"; otherwise, it is "-". Note 3 . When $\frac{c e_{B E V}-(2-\beta) c e_{C V}}{(4-\beta)(1-\beta)}+q_{C V}>0$, it is " + "; otherwise, it is "-”. Note 4. When $\widetilde{\Lambda}_{2}-$ $(4-\beta)(1-\beta) C R_{N E V}^{-} P_{C R}>0$, it is "+"; otherwise, it is " -"

The results in Table 5 and Table 6 indicate that the BEV manufacturer benefits from BEVexempted traffic restriction. First, increasing the loss of consumer surplus $l$ through strengthening traffic restriction enables the BEV manufacturer to increase sales at a higher price and make more 
profit. In contrast, the sales and price of CV fall, ruining the CV manufacturer's profitability. As expected, the BEV manufacturer favors BEV-exempted traffic restriction, but the CV manufacturer dislikes it. Second, increasing $l$ reduces total carbon emission, albeit at the cost of consumer surplus: $\mathrm{CV}$ consumers suffer traffic restriction, and BEV consumers need to pay for a higher retail price. In addition, the insights on how operating cost and Pigovian taxation interact with each other in Section 4.1.1 still hold here.

Reflected by the loss of consumer surplus, the strength of traffic restriction makes differences in traffic condition and air quality. Thus, many cities are in the process of further increasing the strength of traffic restriction, such as "four days on road and four days off" implemented in Guangzhou. However, is it always a good idea to strengthen traffic restriction? To answer this question, a set of numerical experiments were conducted using the parameters in section 4.1.1. Fig. 4 shows that the negative impacts of vehicle purchase tax (waived for BEV) and carbon tax on consumer surplus stabilizes and weakens, respectively, as traffic restriction strengthens.

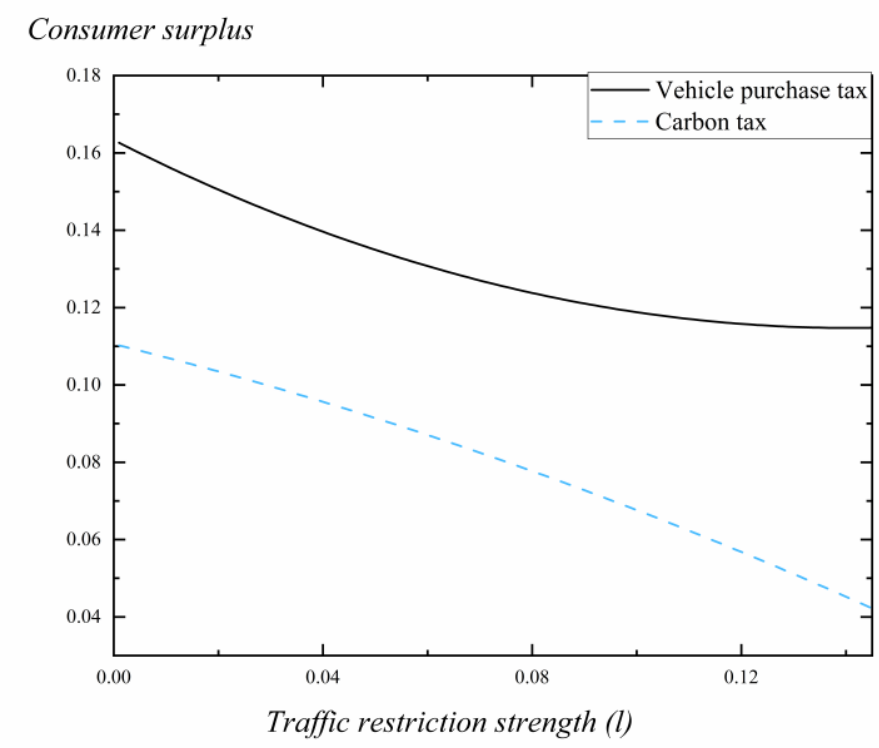

Fig. 4. The impacts of traffic restriction strength on consumer surplus under different taxations 
The results in Fig. 5 and Fig. 6 suggest that BEV outperform CV under both taxation approaches. While higher BEV recognition enhances consumer surplus, and total carbon emission first increases slowly but then decreases quickly. Consistent with the finding in Section 4.1.1, BEVexempted traffic restriction positively interacts with BEV adoption.

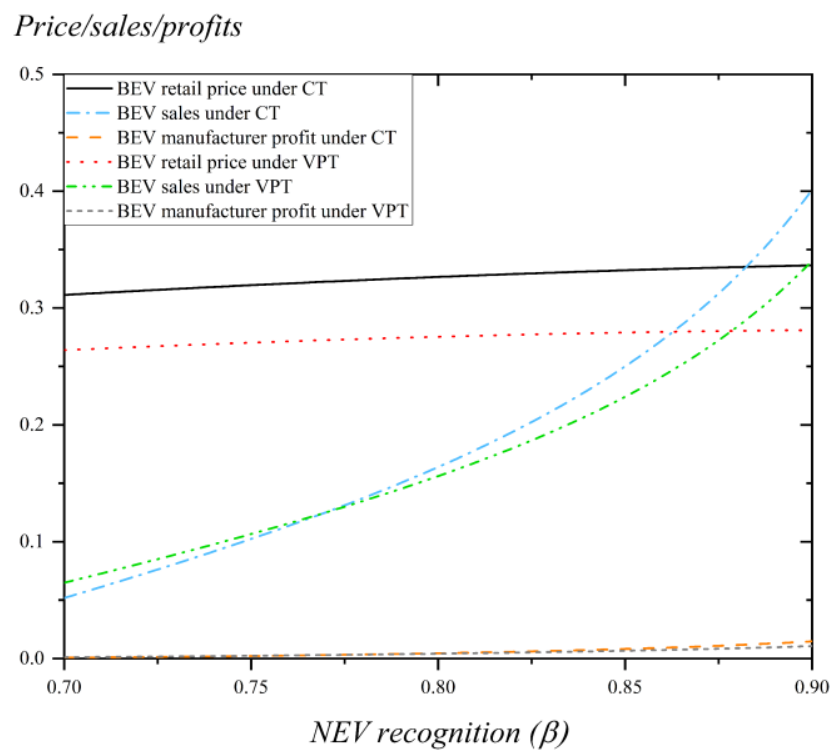

Fig. 5. (a) The impacts of BEV recognition on BEV sales, retail price, and manufacturer profit

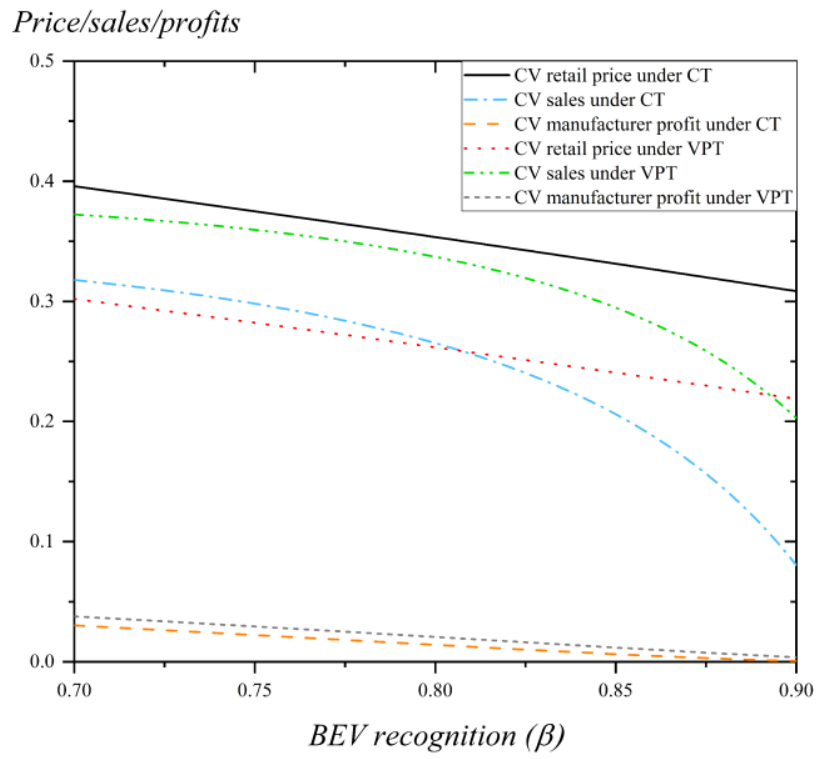

Fig. 5. (b) The impacts of BEV recognition on $\mathrm{CV}$ sales, retail price, and manufacturer profit 


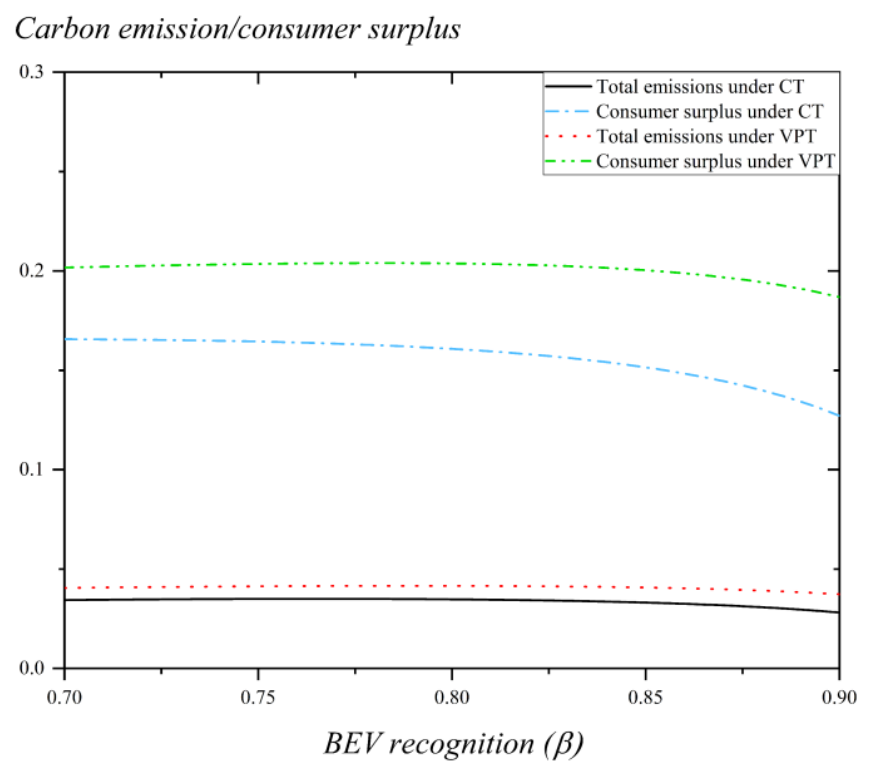

Fig. 6. The impacts of BEV recognition on consumer surplus and total carbon emission.

\subsubsection{Uniform Traffic Restriction Scenario}

In most countries, $\mathrm{BEV}$ are treated the same as $\mathrm{CV}$ when traffic restriction is implemented. This subsection focuses on such a uniform policy that applies to both CV and BEV. When consumers evaluate the BEV option, the surplus utility derived from the purchase can be reformulated as:

$$
U_{B E V}=\beta v-P_{B E V}-O_{B E V}+s-l .
$$

By solving the indifferent consumer's location, the demand function is derived. The game sequence remains the same, and optimal solutions are summarized in Lemma 3.

Lemma 3. When both BEV and CV are subject to traffic restriction, the optimal retail prices, sales volumes, and manufacturer profits are given below:

$$
\begin{gathered}
P_{B E V}^{B R}=\frac{\beta\left(K_{1}+1-\beta+l\right)+2\left(K_{2}+l\right)}{4-\beta}-O_{B E V}-l+s, \\
q_{B E V}^{B R}=\frac{\beta\left(K_{1}+1-\beta+l\right)-(2-\beta)\left(K_{2}+l\right)}{(4-\beta)(1-\beta) \beta},
\end{gathered}
$$




$$
\begin{gathered}
\pi_{B E V}^{B R}=\mathrm{CR}_{\mathrm{NEV}}^{-} P_{C R} \frac{2+\beta-2 K_{1}-K_{2}-3 l}{4-\beta} \\
+\frac{\left[\beta\left(K_{1}+1-\beta+l\right)-(2-\beta)\left(K_{2}+l\right)\right]^{2}}{(4-\beta)^{2}(1-\beta) \beta}, \\
P_{C V}^{B R}=\frac{2\left(K_{1}+1-\beta+l\right)+K_{2}+l}{(4-\beta)\left(1+r_{V P T}\right)}-\frac{O_{C V}+l}{1+r_{V P T}}, \\
q_{C V}^{B R}=1-\frac{(2-\beta)\left(K_{1}+1-\beta+l\right)-K_{2}-l}{(4-\beta)(1-\beta)}, \\
\pi_{C V}^{B R}=\frac{\left[2(1-\beta)-(2-\beta)\left(K_{1}+l\right)+K_{2}+l\right]^{2}}{(4-\beta)^{2}(1-\beta)\left(1+r_{V P T}\right)} .
\end{gathered}
$$

Note: $\quad K_{1}=\left(1+r_{V P T}\right)\left(C_{C V}+C R_{N E V}^{-} P_{C R}\right)+O_{C V} \quad$ and $\quad K_{2}=C_{B E V}+\beta C R_{N E V}^{-} P_{C R}+$ $O_{B E V}-s$.

Proof: See Appendix A.

Table 7 summarizes how retail prices, sales volumes, manufacturer profits, consumer surplus, and total carbon emission vary with parameter values under vehicle purchase tax when both $\mathrm{BEV}$ and $\mathrm{CV}$ are subject to traffic restriction (i.e., uniform restriction). The results are analytical, and Appendix B5 gives the derivatives.

Table 7. Sensitivity analysis for uniform traffic restriction under vehicle purchase tax

\begin{tabular}{ccccccccc}
\hline & $q_{B E V}^{B R}$ & $q_{C V}^{B R}$ & $P_{B E V}^{B R}$ & $P_{C V}^{B R}$ & $\pi_{B E V}^{B R}$ & $\pi_{C V}^{B R}$ & $C S^{B R}$ & $T C E^{B R}$ \\
\hline$l$ & + & - & + & - & Note 2 & - & - & - \\
$r_{V P T}$ & + & - & + & - & Note 2 & - & - & - \\
$O_{B E V}$ & - & + & - & + & - & + & - & Note 1 \\
$O_{C V}$ & + & - & + & - & Note 2 & - & - & - \\
$\beta$ & + & + & + & - & + & - & + & + \\
\hline
\end{tabular}

Note 1. When $c e_{B E V}>\frac{\beta}{2-\beta} c e_{C V}$, it is "-"; otherwise, it is "+"; Note 2. When $\Lambda_{3}-(4-\beta)(1-\beta) C R_{N E V}^{-} P_{C R}>0$, it is “+”; otherwise, it is "-".

Corollary 3 gives the optimal solutions under carbon tax when both BEV and $\mathrm{CV}$ are 
subject to traffic restriction (i.e., uniform restriction):

Corollary 3. When both BEV and CV are subject to traffic restriction, optimal retail prices, sales volumes, and manufacturer profits under carbon tax are:

$$
\begin{gathered}
\tilde{P}_{B E V}^{B R}=\frac{\beta\left(\widetilde{K}_{1}+1-\beta+l+c e_{C V}\right)+2\left(K_{2}+l+c e_{B E V}\right)}{4-\beta}-O_{B E V}-l+s, \\
\tilde{q}_{B E V}^{B R}=\frac{\beta\left(\widetilde{K}_{1}+1-\beta+l+c e_{C V}\right)-(2-\beta)\left(K_{2}+l+c e_{B E V}\right)}{(4-\beta)(1-\beta) \beta}, \\
\tilde{\pi}_{B E V}^{B R}=\mathrm{CR}_{\mathrm{NEV}}^{-} P C R \frac{2+\beta-2\left(\widetilde{K}_{1}+l+c e_{C V}\right)-K_{2}-c e_{B E V}-l}{4-\beta} \\
+\frac{\left[\beta\left(\widetilde{K}_{1}+1-\beta+l+c e_{C V}\right)-(2-\beta)\left(K_{2}+l+c e_{B E V}\right)\right]^{2}}{(4-\beta)^{2}(1-\beta) \beta}, \\
\tilde{P}_{C V}^{B R}=\frac{2\left(\widetilde{K}_{1}+1-\beta+l+c e_{C V}\right)+K_{2}+l+c e_{B E V}}{4-\beta}-\left(O_{C V}+l\right), \\
\tilde{q}_{C V}^{B R}=1-\frac{(2-\beta)\left(\widetilde{K}_{1}+1-\beta+l+c e_{C V}\right)-K_{2}-l-c e_{B E V}}{(4-\beta)(1-\beta)}, \\
\tilde{\pi}_{C V}^{B R}=\frac{\left[2(1-\beta)-(2-\beta)\left(\widetilde{K}_{1}+l+c e_{C V}\right)+K_{2}+l+c e_{B E V}\right]^{2}}{(4-\beta)^{2}(1-\beta)} .
\end{gathered}
$$

Note: $\widetilde{K}_{1}=C_{C V}+C R_{N E V}^{-} P_{C R}+O_{C V}$ and $K_{2}=C_{B E V}+\beta C R_{N E V}^{-} P_{C R}+O_{B E V}-s$.

Proof: See Appendix A.

Table 8 summarizes how retail prices, sales volumes, enterprise profits, consumer surplus, and total carbon emission vary with parameter values under carbon tax when both BEV and CV are subject to traffic restriction (i.e., uniform restriction). The results are analytical, and Appendix B6 gives the derivatives.

Table 8 . Sensitivity analysis for uniform traffic restriction under carbon tax

\begin{tabular}{ccccccccc}
\hline & $\tilde{q}_{B E V}^{B R}$ & $\tilde{q}_{C V}^{B R}$ & $\tilde{P}_{B E V}^{B R}$ & $\tilde{P}_{C V}^{B R}$ & $\tilde{\pi}_{B E V}^{B R}$ & $\tilde{\pi}_{C V}^{B R}$ & $\widetilde{C S}^{B R}$ & $\widetilde{T C E}^{B R}$ \\
\hline$l$ & + & - & + & - & Note 4 & - & - & - \\
$O_{B E V}$ & - & + & - & + & - & + & - & Note 1 \\
$O_{C V}$ & + & - & + & - & Note 4 & - & - & -
\end{tabular}




\begin{tabular}{ccccccccc}
$c e_{B E V}$ & - & + & + & + & - & + & - & Note 2 \\
$c e_{C V}$ & + & - & + & + & + & - & - & Note 3 \\
$\beta$ & + & - & + & - & + & - & + & $+1-$ \\
\hline
\end{tabular}

Note 1. When $c e_{B E V}>\frac{\beta}{2-\beta} c e_{C V}$, it is "- "; otherwise, it is " + ". Note 2 . When $\frac{(2-\beta) c e_{B E V}+\beta c e_{C V}}{(4-\beta)(1-\beta) \beta}+q_{B E V}>0$, it is " + "; otherwise, it is "-". Note 3 . When $\frac{c e_{B E V}-(2-\beta) c e_{C V}}{(4-\beta)(1-\beta)}+q_{C V}>0$, it is "+"; otherwise, it is " - ". Note 4 . When $\widetilde{\Lambda}_{3}-$ $(4-\beta)(1-\beta) C R_{N E V}^{-} P_{C R}>0$, it is " $+" ;$ otherwise, it is " -".

The results in Table 7 and Table 8 corroborate those in Section 4.1.1 and Section 4.1.2.

Fig.7 shows that when traffic restriction strength $l$ increases, its negative impact on consumer surplus stabilizes, no matter which taxation approach is employed. Under the uniform traffic restriction, the difference in consumer surplus narrows as $l$ increases, which is different from the pattern in Section 4.1.2 under the BEV-exempted traffic restriction.

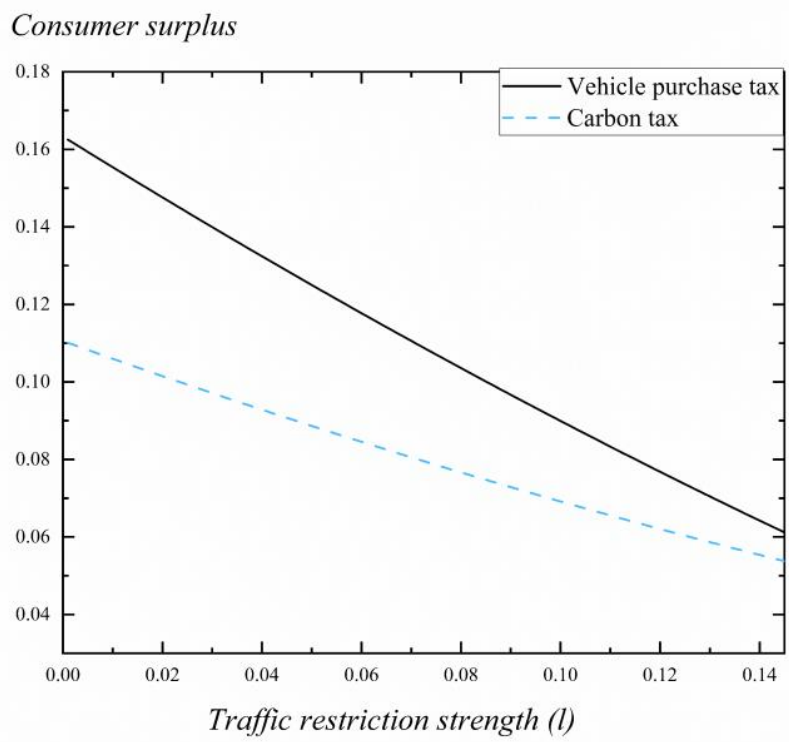

Fig. 7. The impacts of traffic restriction strength on consumer surplus under different taxations 
The results in Fig. 8 and Fig. 9 are consistent with those in Section 4.1.1. When the vehicle purchase tax is levied, there will be price competition as well. If carbon tax is levied, BEV outperforms CV quickly. The conclusion in Section 4.1.1 is verified: carbon tax highlights the emission advantage of $\mathrm{BEV}$, and $\mathrm{BEV}$ recognition magnifies this advantage.

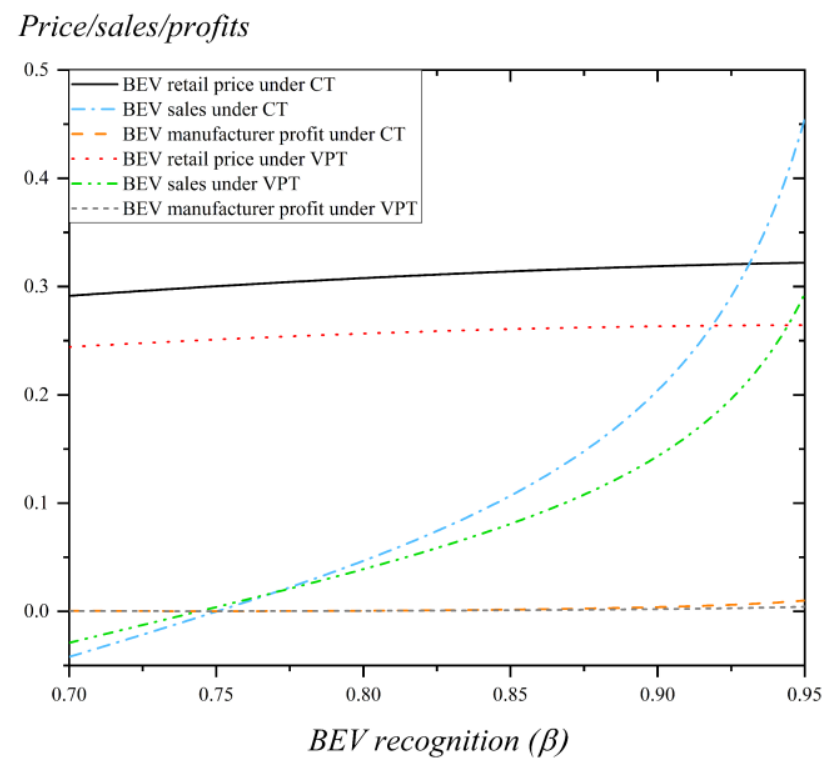

Fig. 8 (a). The impacts of BEV recognition on BEV sales, retail price and manufacturer profit

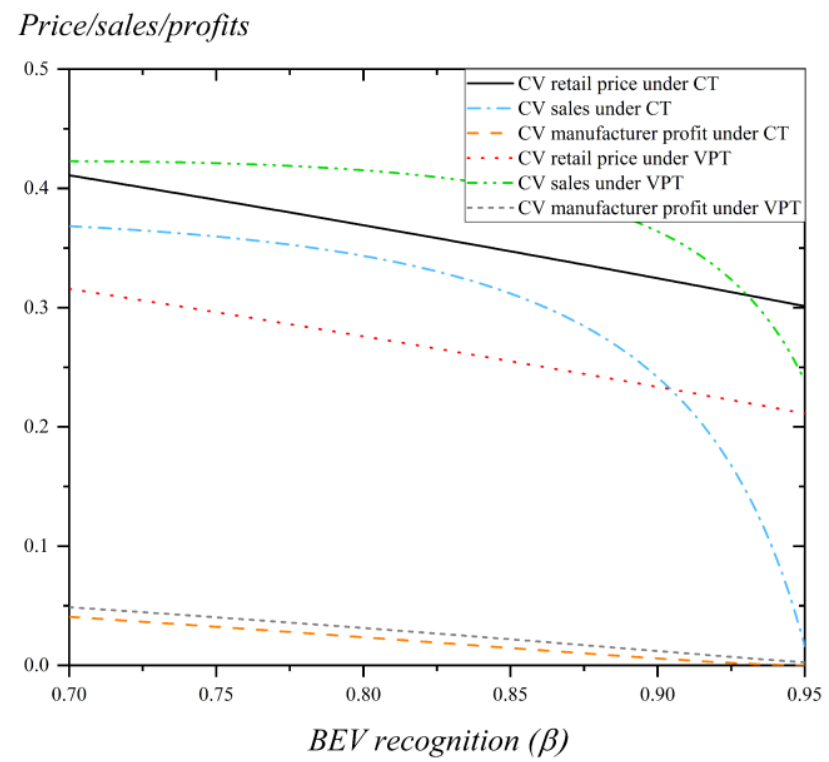

Fig. 8 (b). The impacts of BEV recognition on CV sales, retail price and manufacturer profit. 


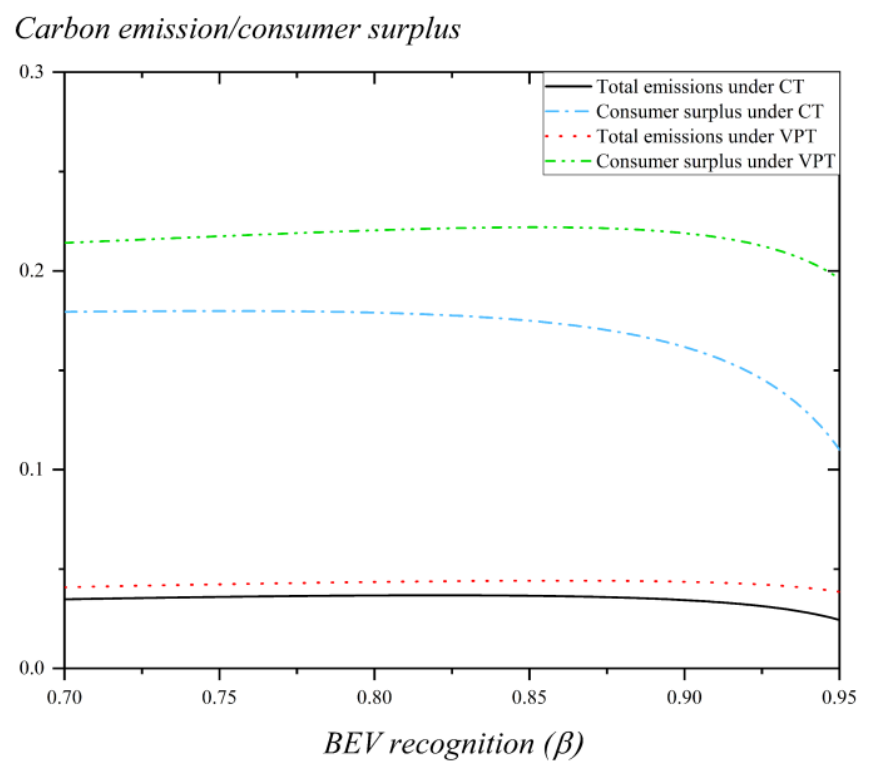

Fig. 9. The impacts of BEV recognition on consumer surplus and total carbon emission

\subsection{Optimal Traffic Restriction Policy}

For more insights on policy-making that typically involves different measures, this section compares three traffic restriction policies under the scenarios of vehicle purchase tax and carbon tax in Sections 4.2.1 and 4.2.2, respectively.

\subsubsection{Vehicle Purchase Tax Scenario}

Under vehicle purchase tax (waived for BEV), three traffic restriction policies, namely no restriction, BEV-exempted restriction, and uniform restriction, lead to different results from manufacturer, consumer, and environment perspectives. Proposition 1, Proposition 2, and Proposition 3 summarize the comparisons based on Lemma 1, Lemma 2, and Lemma 3, respectively. 
Proposition 1. The BEV manufacturer favors BEV-exempted traffic restriction, but the $C V$ manufacturer favors no traffic restriction.

(a) The retail price, sales volume of the BEV manufacturer are the highest under BEVexempted traffic restriction, followed by no traffic restriction, but the lowest under uniform traffic restriction. The enterprise profit of the BEV manufacturer is the lowest under uniform traffic restriction, and the profit is highest under BEV-exempted traffic restriction if and only if the restricting ratio is relatively high $\frac{l}{2 \beta}>C R_{N E V}^{-} P_{C R}(4-\beta)(1-\beta)-\Lambda_{1}$, where $\Lambda_{1}=\beta\left(K_{1}+1-\beta\right)-(2-\beta) K_{2}$.

(b) The retail price, sales volume, and manufacturer profit of the CV manufacturer are highest under no traffic restriction, followed by uniform traffic restriction, but the lowest under BEV-exempted traffic restriction.

Proof: See Appendix A.

Whereas Proposition 1 focuses on the profitability of automakers, Proposition 2 compares total carbon emission across three traffic restriction policies.

\section{Proposition 2.}

(a) BEV-exempted traffic restriction and uniform traffic restriction lead to less emission than no traffic restriction.

(b) Uniform traffic restriction does not always make the least emission. If $e_{B E V}<$ $\frac{\beta}{2-\beta} e_{C V}, B E V$-exempted traffic restriction leads to less emission.

Proof: See Appendix A. 


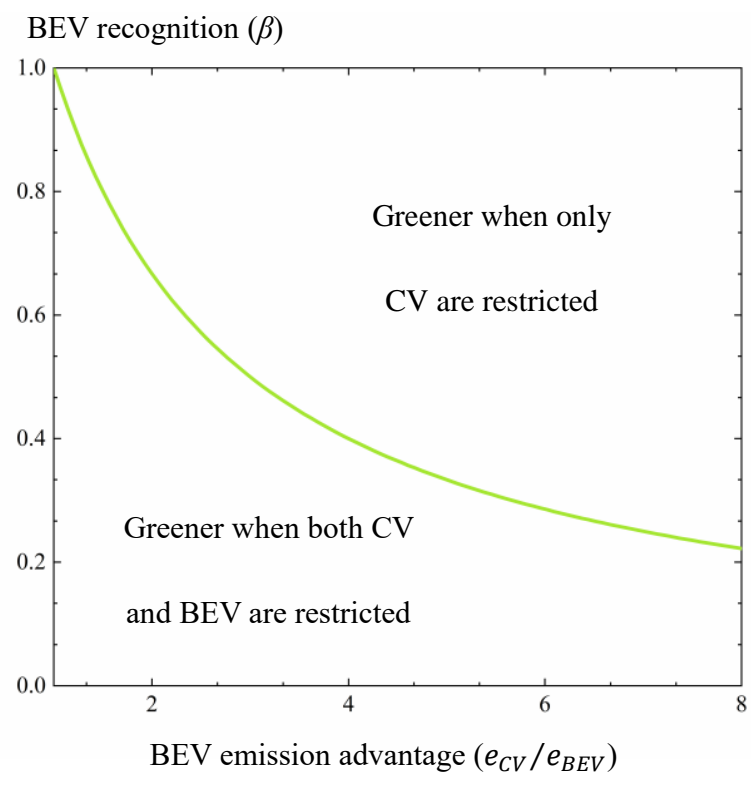

Fig. 10. Environmental effectiveness of traffic restriction policies with vehicle purchase tax

Fig. 10 confirms that uniform traffic restriction does not always make the least emission. When $\mathrm{BEV}$ have a strong advantage over $\mathrm{CV}$ in emission, or $\mathrm{BEV}$ recognition is high $\left(e_{B E V}<\right.$ $\left.\frac{\beta}{2-\beta} e_{C V}\right)$, BEV-exempted traffic restriction leads to less emission than uniform traffic restriction. Proposition 3 compares consumer surplus across different traffic restriction policies.

Proposition 3. Traffic restrictions reduce consumer surplus, but BEV-exempted traffic restriction is more moderate than uniform traffic restriction.

Proof: See Appendix A.

As explained in Appendix A, the comparison of consumer surplus is based on function $f(v)$. Fig.11 plots the function for each traffic restriction policy. 


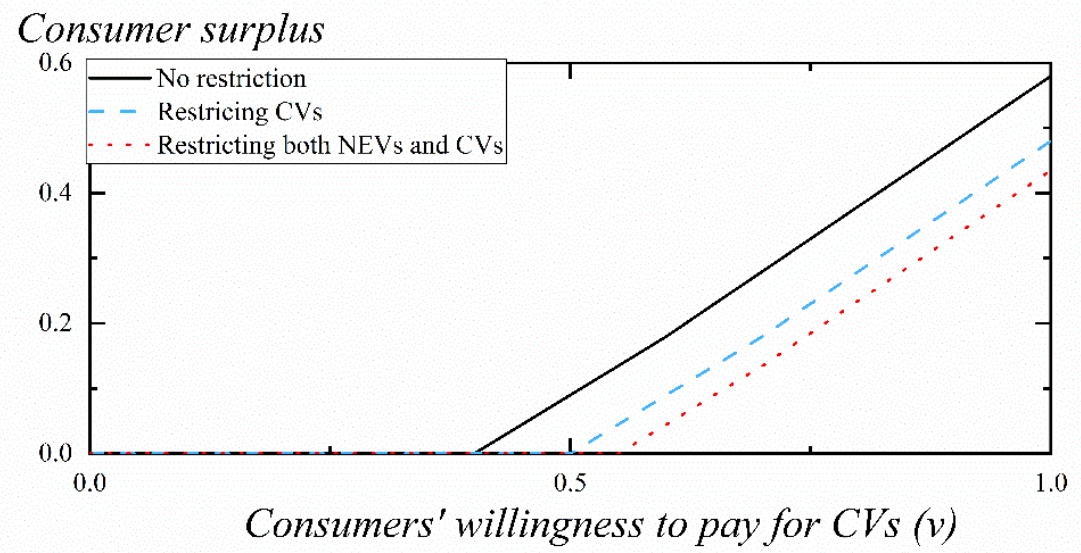

Fig. 11. Consumer surplus across different traffic restriction policies under vehicle purchase tax

Fig. 11 shows that consumer surplus decreases when traffic restriction applies to more vehicles, which verifies Proposition 3. Compared with no traffic restriction and uniform traffic restriction, BEV-exempted traffic restriction promotes environment protection (as well as public health) while not hurting consumer surplus too much.

\subsubsection{Carbon Tax Scenario}

Under carbon tax, three traffic restriction policies are also compared from manufacturer, consumer and environment perspectives. Proposition 4, Proposition 5, and Proposition 6 summarize the comparisons based on Corollary 1, Corollary 2, and Corollary 3, respectively. Propositions 4, 5 and 6 under carbon tax are consistent with Propositions 1, 2, and 3 under vehicle purchase tax (waived for BEV), respectively, except for the condition of Proposition 4 (a).

Proposition 4. Under carbon tax, the BEV manufacturer favors BEV-exempted traffic restriction, but the $C V$ manufacturer favors no traffic restriction.

(a) The retail price, sales volume of the BEV manufacturer are the highest under BEVexempted traffic restriction, followed by no traffic restriction, but the lowest under uniform traffic restriction. The enterprise profit of the BEV manufacturer is the lowest under 
uniform traffic restriction, and the profit is highest under BEV-exempted traffic restriction if and only if the restricting ratio is relatively high $\frac{l}{2 \beta}>C R_{N E V}^{-} P_{C R}(4-\beta)(1-\beta)-\widetilde{\Lambda}_{1}$, where $\widetilde{\Lambda}_{1}=\beta\left(\widetilde{K}_{1}+1-\beta+c e_{C V}\right)-(2-\beta)\left(K_{2}+c e_{B E V}\right)$

(b) The retail price, sales volume, and manufacturer profit of the CV manufacturer are highest under no traffic restriction, followed by uniform traffic restriction, but the lowest under BEV-exempted traffic restriction.

Proof: See Appendix A.

Under carbon tax, therefore, strengthening traffic restriction while exempting BEV will expedite $\mathrm{CV}$ phaseout once $\mathrm{BEV}$ are well recognized by consumers.

Proposition 5. Under carbon tax,

(a) BEV-exempted traffic restriction and uniform traffic restriction lead to less emission than no traffic restriction.

(b) Uniform traffic restriction does not always make the least emission. If $e_{B E V}<$ $\frac{\beta}{2-\beta} e_{C V}, B E V$-exempted traffic restriction leads to less emission.

Proof: See Appendix A.

Under carbon tax, BEV-exempted traffic restriction outperforms uniform traffic restriction in terms of total carbon emission when BEV have clear emission advantage over CV. In this sense, BEV-exempted traffic restriction provides a viable environmental solution in the long term.

Proposition 6. Under carbon tax, traffic restrictions reduce consumer surplus, but BEVexempted traffic restriction is more moderate than uniform traffic restriction.

Proof: See Appendix A.

Under carbon tax, consumer surplus remains the lowest when both BEV and CV are subject to traffic restriction (i.e., uniform restriction) but the highest when there is no traffic restriction. Meanwhile, BEV-exempted traffic restriction strikes a balance between benefits and costs. 


\subsection{Optimal Taxation Approach}

Finally, two taxation approaches are directly compared from manufacturer, consumer and environment perspectives. Proposition 7, Proposition 8, and Proposition 9 summarize the comparisons based on Lemma 1, Lemma 2, Lemma 3, Corollary 1, Corollary 2, and Corollary 3.

Proposition 7. Under carbon tax, BEV sales are higher than under vehicle purchase tax if and only if $c e_{B E V}<\frac{\beta}{2-\beta}\left[c e_{C V}-r_{V P T}\left(C_{C V}+C R_{N E V}^{-} P_{C R}\right)\right]$, and $C V$ sales are lower if and only if $c e_{B E V}<(2-\beta)\left[c e_{C V}-r_{V P T}\left(C_{C V}+C R_{N E V}^{-} P_{C R}\right)\right]$.

Proof: See Appendix A.

Proposition 8. Carbon tax leads to less emission than vehicle purchase tax if and only if $c e_{B E V}<\frac{(2-\beta) e_{C V}-e_{B E V}}{\beta e_{C V}-(2-\beta) e_{B E V}} \beta\left[c e_{C V}-r_{V P T}\left(C_{C V}+C R_{N E V}^{-} P_{C R}\right)\right]$

Proof: See Appendix A.

Proposition 9. Under carbon tax, consumers pay more than half of it indirectly, and consumer surplus is lower than under vehicle purchase tax.

Proof: See Appendix A.

Under carbon tax, automakers raise car prices to let consumers pay for the majority of it, which is understandable as drivers are ultimately responsible for the carbon emission from their vehicles. Whereas vehicle purchase tax (waived for BEV) is preferred when the BEV industry is in its infancy, carbon tax is more favorable when the industry becomes mature enough.

\subsection{Robustness Analyses}

The aforementioned modeling is based on several assumptions that are not always true in the real world. This section relaxes some major assumptions to assess the robustness of findings. 


\subsubsection{Higher BEV Valuation}

It is assumed that consumers have a lower valuation of BEV than $\mathrm{CV}$ in previous analyses. However, some consumers who care about environmental impact and driving experience (smooth and quiet driving) may hold a higher valuation of BEV than CV. In places where the charging infrastructure is well established, people's range anxiety is reduced. Furthermore, the introduction of long-range $\mathrm{BEV}$ boosts up their valuation of $\mathrm{BEV}$. Therefore, more and more consumers are expected to value $\mathrm{BEV}$ higher than $\mathrm{CV}$.

This subsection assumes $\beta_{H}>1$ to denote that $\mathrm{BEV}$ valuation exceeds $\mathrm{CV}$ valuation. As shown in Appendix C, consumers' utility function remains the same, but their demand function changes as they are more willing to pay for BEV but hesitant to buy $\mathrm{CV}$, leading to different outcomes. In particular, the extended analyses address how each traffic restriction policy promotes BEV diffusion, curbs total carbon emission, and enhances manufacturer profitability.

First, the analysis indicates that BEV sales are highest but CV sales are lowest under BEVexempted traffic restriction. When consumers' valuation of BEV exceeds that of $\mathrm{CV}$, therefore, $\mathrm{BEV}$-exempted traffic restriction will maximize BEV diffusion but suppress $\mathrm{CV}$ sales. In terms of sales, the BEV manufacturer favors BEV-exempted traffic restriction, whereas the $\mathrm{CV}$ manufacturer dislikes it the most. As for profitability, the BEV manufacturer still prefers BEVexempted traffic restriction to uniform traffic restriction in all circumstances, and to no traffic restriction only at relatively high traffic restriction strength. All the above are consistent with the original case in which consumers value $\mathrm{BEV}$ lower than $\mathrm{CV}$.

At a closer look, when consumers value CV higher than BEV, the threshold of traffic restriction strength within which the profit of BEV manufacturer under BEV-exempted traffic restriction is higher than that under no traffic restriction is: $l>2 \beta\left[C R_{N E V}^{-} P_{C R}(4-\beta)(1-\beta)-\right.$ $\Lambda_{1}$ ] . When consumers value $\mathrm{BEV}$ higher than $\mathrm{CV}$, this threshold becomes: $l>$ $\frac{2}{\beta_{H}}\left[C R_{N E V}^{-} P_{C R}\left(4 \beta_{H}-1\right)\left(\beta_{H}-1\right)-\beta_{H} \Lambda_{1}^{C}\right]$. 
From the perspective of total carbon emission, there is a threshold of BEV emission under which BEV-exempted traffic restriction outperforms uniform traffic restriction. When consumers value $\mathrm{CV}$ higher than $\mathrm{BEV}$, this threshold is: $e_{B E V}<\frac{\beta}{2-\beta} e_{C V}$. When consumers value $\mathrm{BEV}$ higher than $\mathrm{CV}$, it becomes $e_{B E V}<\frac{\beta_{H}}{2 \beta_{H}-1} e_{C V}$. When $\beta$ falls between 0 and 1 , this threshold will gradually increase to $e_{C V}$; when $\beta$ moves beyond 1 , this threshold will decline but remain above $\frac{1}{2} e_{C V}$. Therefore, when $\mathrm{BEV}$ recognition and $\mathrm{CV}$ recognition differ greatly ( $\beta$ close to 0 or far above 1), $\mathrm{BEV}$ emission must be much lower than $\mathrm{CV}$ emission in order to make the total carbon emission under BEV-exempted traffic restriction lower than that under uniform traffic restriction. When the recognition levels are close, as long as BEV emission is lower than $\mathrm{CV}$ emission, the total carbon emission under BEV-exempted traffic restriction is lower than that under uniform traffic restriction.

Therefore, all the results still hold qualitatively when consumers value BEV higher than $\mathrm{CV}$. As for the case in which consumers are heterogeneous in BEV valuation (i.e., $\beta$ is randomly distributed between 0 to 2) due to different environmental awareness levels and driving experience preferences, the conclusions hold qualitatively as well.

\subsubsection{Other NEV Types}

The previous modeling is based on BEV, and this subsection further considers the other two types of NEV: plug-in hybrid electric vehicles (PHEV) and fuel-cell electric vehicles (FCEV). As per China's new energy regulations and California's ZEV Act, for instance, PHEV and FCEV enjoy almost the same treatment as BEV in terms of purchase tax breaks, purchase subsidies, traffic restriction exemption, and manufacturer production credit. Thus, all relevant assumptions in the previous modeling are still applicable.

Compared with BEV, PHEV can use regular gasoline in addition to electricity, mitigating consumers' range anxiety and concerns over charging station accessibility as well as waiting time. 
In most situations, PHEV drivers still prefer electricity for similar benefits of BEV in terms of lower operating cost and carbon emission than those of CV. Enjoying the benefits, consumers are likely to form a higher valuation of PHEV than BEV as well as $\mathrm{CV}$, which makes the analyses in Section 4.4.1 applicable here (just regard PHEV as more highly-valued BEV in Appendix C's analyses).

In contrast, FCEV use hydrogen as an energy source. At the present, hydrogen refueling stations are not as easy to find as gas stations for $\mathrm{CV}$, lowering the consumer valuation of FCEV. Moreover, the operating cost of FCEV is relatively high in many countries. In China, for example, CV cost drivers 25-40RMB for every 100 kilometers, whereas FCEV cost 70-100RMB for the same distance. Thus, the assumption that NEV have a relatively low operating cost no longer holds for FCEV in those countries. For the case in which the operating cost of FCEVs exceeds that of $\mathrm{CVS}$, the analysis in Appendix E identifies the threshold, $\bar{O}_{F C E V}=\frac{\beta\left(K_{1}+1-\beta+l\right)}{2-\beta}-C_{F C E V}-$ $\beta C R_{N E V}^{-} P_{C R}+s$. When the operating cost of FCEVs exceeds the threshold, $O_{F C E V} \geq \bar{O}_{F C E V}$ uncompetitive FCEVs lose their market share. When the operating cost of FCEVs only exceeds the operating cost of CVs but not the threshold, $O_{C V} \leq O_{F C E V} \leq \bar{O}_{F C E V}$, all the conclusions still hold qualitatively.

\subsubsection{Dual-Credit Mechanism}

China's dual-credit mechanism (mentioned in Section 2.3) comprises NEV credit and corporate average fuel consumption (CAFC) credit, the latter based on the actual consumption rate of each vehicle brand of a manufacturer and calculates the weighted average based on the production volume (MI\&IT, 2020). When the average consumption rate exceeds the standard, there will be negative $\mathrm{CAFC}$ credit for each vehicle produced: $C R_{C A F C}^{-}=$ average consumption rate-government standard. Otherwise, there will be positive CAFC credit. Negative CAFC credit can be offset by positive NEV credit, but positive CAFC 
credit cannot be traded or used for offsetting negative NEV credit.

In this study, the BEV manufacturer generates positive NEV credit, but the $\mathrm{CV}$ manufacturer yields negative NEV credit. As for the CAFC credit, there are two possibilities for the $\mathrm{CV}$ manufacturer. When the average fuel consumption rate is below the standard, it meets the CAFC requirement, and only need to purchase NEV credit from the BEV manufacturer to offset its negative NEV credit $C R_{N E V}^{-} q_{C V}$. Otherwise, it accrues negative CAFC credit $C R_{C A F C}^{-} q_{C V}$ as well, and need to purchase more credit $\left(C R_{N E V}^{-}+C R_{C A F C}^{-}\right) q_{C V}$. Therefore, the negative CAFC credit imposes an extra penalty on the CV manufacturer on top of the negative NEV credit for each vehicle produced. Basically, the dual-credit mechanism reinforces the production of more environment-friendly vehicles, and the findings still hold qualitatively.

\subsubsection{Regulatory Fine}

The previous modeling is based on the assumption that the NEV credit available for trading is sufficient for offsetting the negative credit accrued by the $\mathrm{CV}$ manufacturer: $C R_{N E V}^{+} q_{B E V}>$ $C R_{N E V}^{-} q_{C V}$. In case that the $\mathrm{CV}$ manufacturer cannot purchase enough NEV credit to offset its negative credit, or $C R_{N E V}^{+} q_{B E V}<C R_{N E V}^{-} q_{C V}$, it has to pay for a higher regulatory fine. The purpose of this penalty is to ensure the continuance of credit trading. In places like California that enforce the ZEV regulation and alike, the penalty takes the form of a monetary fine. In China, such a fine rarely gets incurred as there is plenty of positive NEV credit available for trading. If a manufacturer did not offset its negative credit, its quota for producing high-emission vehicles would be restrained.

This extended analysis employs the monetary fine that is more quantifiable: fine $=$ $\left(C R_{N E V}^{-} q_{C V}-C R_{N E V}^{+} q_{B E V}\right) \cdot$ fine $_{C R}$. This leads to the updated profit function of the $\mathrm{CV}$ manufacturer: $\pi_{C V}=P_{C V} q_{C V}-C_{C V} q_{C V}+T C R_{C V}-$ fine.

The results based on the updated profit function remain largely stable. First, BEV sales

remain the highest under BEV-exempted traffic restriction, while $\mathrm{CV}$ sales get hurt the most as 
expected. In terms of profitability, the BEV manufacturer is always more profitable under BEVexempted traffic restriction than under no traffic restriction without the need to consider the precondition of traffic restriction strength $l$ as in the no-fine scenario. As for the CV manufacturer, now only when $l$ is low enough will it continue profiting more under no traffic restriction than under BEV-exempted traffic restriction and uniform traffic restriction. These changes indicate that the possibility to trigger the fine mechanism due to limited NEV credit supply will make the BEV manufacturer more inclined toward BEV-exempted traffic restriction, whereas the $\mathrm{CV}$ manufacturer will prefer uniform traffic restriction to no traffic restriction. In a market where there is plenty of NEV credit available for trading, both BEV and CV manufacturers may favor no traffic restriction. Finally, the total carbon emission remains the highest under no traffic restriction but the lowest under BEV-exempted traffic restriction when $e_{B E V}<\frac{\beta}{2-\beta} e_{C V}$, or under uniform traffic restriction otherwise.

\section{Conclusion and Implications}

This study presents an analytical model that examines the competition between BEV and CV manufacturers under different traffic restriction policies and Pigovian taxation approaches. The modeling also incorporates the variations of major assumptions in extended analyses, such as the dual-credit regulatory mechanism and other types of NEV. Compared with no traffic restriction and uniform traffic restriction, BEV-exempted traffic restriction has the greatest potential to promote BEV diffusion and reduce the total carbon emission. Its effectiveness is strengthened to various degrees under two Pigovian taxation scenarios, vehicle purchase tax (waived for BEV) and carbon tax. The investigation of the interaction between traffic restriction and Pigovian taxation helps researchers and practitioners optimize policy-making for greener transportation.

This study contributes to the literature with a few insights into BEV-exempted traffic restriction and relevant Pigovian taxation. The benchmark model corroborates the relationship 
between traffic restriction exemption and BEV diffusion from the game theory perspective. Compared with existing studies that reach a similar conclusion under simplified scenarios $(\mathrm{N}$. Wang et al., 2017; Ning Wang et al., 2017; Ning Wang et al., 2019), this study further examines the relationship in the context of Pigovian taxation. The findings reveal the commonality between vehicle purchase tax and carbon tax as well as their distinctness: the substitution of the former with the latter leads to increased BEV sales, higher automaker profitability, more consumer surplus, and lower total carbon emission in the long term.

For policy makers and corporate managers, the findings yield some helpful implications. First, BEV-exempted traffic restriction is found optimal to promote BEV diffusion in all circumstances, which explains why it becomes a widespread policy in major cities of China. Most existing studies on traffic restriction apply empirical methods to show that BEV-exempted traffic restriction facilitates innovation diffusion (Ma et al., 2017; Morton et al., 2017; N. Wang et al., 2017). The lack of data on both uniform traffic restriction and BEV-exempted traffic restriction in the same region, however, makes it difficult to directly compare two policies in terms of their impacts on BEV adoption. So far, only one study used the simulation approach with system dynamics modeling to assess their effects, and made the similar conclusion that BEV-exempted traffic restriction outperforms the uniform one in promoting BEV adoption (Ning Wang et al., 2019). Based on game theory modeling, this study further takes Pigovian taxation approaches (especially, carbon tax) into account to examine their interactions with traffic restriction policies for striking a balance between consumer surplus and environmental impact.

Second, BEV valuation must be relatively high for traffic restriction exemption to be effective in lowering total carbon emission beyond uniform traffic restriction. Policy makers cannot just rely on the fact that BEV are advantageous in leaving smaller carbon footprints, but need to actively advance relevant public recognition and cleaner power generation in order to minizine total carbon emission. Consistent with the claim of other researchers (F. Li et al., 2019), the findings of this study imply that reducing BEV emission in the whole life cycle (by establishing 
the cleaner power grid, reducing production energy consumption, improving BEV efficiency, and recycling both batteries and vehicles) is essential to the achievement of environmental goals. Equally important for traffic emission reduction, the results highlight the necessity to improve BEV recognition, which is by far mainly achieved through the enhancement of charging infrastructure accessibility (Ye, Kang, Li, \& Wang, 2021). This study advocates the two-legged approach, reducing BEV life-cycle emission while increasing BEV recognition, as it can be claimed either way in terms of which one comes first, like the chicken or the egg.

Third, uniform traffic restriction always leads to a bigger loss of consumer surplus than $\mathrm{BEV}$-exempted traffic restriction. On the end-user side, therefore, exempting BEV from traffic restriction strikes a balance between individual interests and public benefits. Under the conditions of insufficient public transport, long commuting distance, and inadequate license plate, drivers can be greatly affected by uniform traffic restriction and may risk driving "illegally" (Z. Liu et al., 2020; Z. Y. Liu et al., 2018; L. L. Wang et al., 2014). BEV-exempted traffic restriction provides them an alternative, leading to higher consumer surplus as well as reduced traffic emission. In this way, the new policy guides the directions of automobile market restructuring and NEW industry development.

Fourth, BEV manufacturer is more competitive under BEV-exempted traffic restriction than under uniform traffic restriction at relatively high restriction strength. It is known that ZEV regulation in California and Dual Credit regulation in China benefit automakers like Tesla and BYD that make profits from selling positive points. This study further recognizes the advantage brought by the BEV-exempted traffic restriction policy to BEV automakers through boosted consumer preference. After BEV diffusion reaches a critical mass, policy makers may strengthen traffic restriction but exempt $\mathrm{BEV}$ to expedite $\mathrm{CV}$ phaseout without hurting consumer surplus much. Countries that cultivate higher public recognition of BEV and establish cleaner power grids are readier for BEV-exempted traffic restriction to promote their diffusion and cut total carbon emission. 
Finally, as for Pigovian taxation, it is recommended that policy makers replace vehicle purchase tax with carbon tax when the BEV industry becomes mature enough. As the public recognition and life-cycle emission of BEV continue their upward and downward trends beyond a certain point, carbon tax will outperform vehicle purchase tax in terms of BEV diffusion and total carbon emission. The theoretical justification for shifting from vehicle purchase tax to carbon tax lies in the fact that vehicle purchase tax is based on the retail prices of $\mathrm{CV}$ alone, but carbon tax is based on the life-cycle emission of all vehicles. In this sense, carbon tax is more capable of differentiating different types of NEV in terms of their "green" levels. For instance, BEV and PHEV are both waived from vehicle purchase tax, but BEV is less pollutive than PHEV. The use of carbon tax can tap such differences and encourages automakers and consumers to pursue cleaner options. As the vehicle purchase tax exemption policy becomes less efficient over time (Yan, 2018), this study does not suggest its immediate conversion to carbon tax. Before automakers establish low life-cycle emission and high recognition for BEV, the combination of vehicle purchase tax waiver and BEV-exempted traffic restriction is still effective for traffic emission reduction. Regions with cleaner power grids and higher BEV recognition may pilot carbon taxation in place of vehicle purchase tax exemption, and others can gradually follow suit when they are ready.

The model development is based on a few assumptions, which are relaxed in extended analyses. This study initially examines the situation where consumers value BEV lower than CV, and further explores the case in which consumers value BEV higher than CV in Section 4.4.1. The major finding remains the same that $\mathrm{BEV}$-exempted restriction outperforms no restriction and uniform restriction in promoting BEV diffusion and reducing total carbon emission. Section 4.4.2 discusses PHEV and FCEV, the other two major types of NEV, and suggests that most conclusions still hold, especially for PHEV that are more closely related to BEV than FCEV. Section 4.4.3 accommodates CAFC credit along with the NEV credit mechanism in the dual-credit mechanism, and Section 4.4.4 explores the possibility that the supply of positive credit is short of demand, both of which give the BEV manufacturer more advantage over the $\mathrm{CV}$ manufacturer. 
This study has several limitations that point to future research directions. On the supply side, it only considers the rivalry between two automakers that produce BEV and CV respectively. In the real world, however, there are many BEV and CV manufacturers, and some make both BEV and CV. Furthermore, this study does not incorporate the ranges of different BEV into modeling. On the demand side, this study assumes that each consumer buys one vehicle, but it is possible for a commuter to purchase a second vehicle to bypass the traffic restriction. In addition, fuel surcharge as a consumer-end climate policy is not included in the modeling. Future research may accommodate such conditions on both sides to make the analyses more realistic. 


\section{Reference}

Aasness, M. A., \& Odeck, J. (2015). The increase of electric vehicle usage in Norway-incentives and adverse effects. Eur. Transp. Res. Rev., 7(4). doi:10.1007/s12544-015-0182-4

Aldy, J. E. (2019). Carbon Tax Review and Updating: Institutionalizing an Act-Learn-Act Approach to U.S. Climate Policy. Rev. Environ. Econ. Policy, 14(1), 76-94. doi:10.1093/reep/rez019

Anciaes, P. R. (2015). Area-wide traffic restriction in Lisbon city center: opportunity lost or mistake avoided? Transport Research Procedia, 8, 237-246. doi:10.1016/j.trpro.2015.06.058

Bakker, S., \& Trip, J. (2013). Policy options to support the adoption of electric vehicles in the urban environment. Transp. Res. Part D Transp. Environ., 25, 18-23. doi:https://doi.org/10.1016/j.trd.2013.07.005

Barahona, N., Gallego, F. A., \& Montero, J. P. (2020). Vintage-Specific Driving Restrictions. Review of Economic Studies, 87(4), 1646-1682. doi:10.1093/restud/rdz031

Berkeley, N., Jarvis, D., \& Jones, A. (2018). Analysing the take up of battery electric vehicles: An investigation of barriers amongst drivers in the UK. Transportation Research Part DTransport and Environment, 63, 466-481. doi:10.1016/j.trd.2018.06.016

Biresselioglu, M. E., Kaplan, M. D., \& Yilmaz, B. K. (2018). Electric mobility in Europe: A comprehensive review of motivators and barriers in decision making processes. Transportation Research Part a-Policy and Practice, 109, 1-13. doi:10.1016/j.tra.2018.01.017

Bjerkan, K. Y., Nørbech, T. E., \& Nordtømme, M. E. (2016). Incentives for promoting Battery Electric Vehicle (BEV) adoption in Norway. Transp. Res. Part D Transp. Environ., 43, 169180. doi:10.1016/j.trd.2015.12.002

Breetz, H. L., \& Salon, D. (2018). Do electric vehicles need subsidies? Ownership costs for conventional, hybrid, and electric vehicles in 14 U.S. cities. Energy Policy, 120, 238-249. doi:10.1016/j.enpol.2018.05.038

Bruckmann, G., Willibald, F., \& Blanco, V. (2021). Battery Electric Vehicle adoption in regions without strong policies. Transportation Research Part D-Transport and Environment, 90. doi:10.1016/j.trd.2020.102615

Cai, H., \& Xie, S. D. (2011). Traffic-related air pollution modeling during the 2008 Beijing Olympic Games: The effects of an odd-even day traffic restriction scheme. Sci. Total Environ., 409, 1935-1948. doi:10.1016/j.scitotenv.2011.01.025

CATRC. (2018). The causes and trends behind the change of oil consumption in the industry. Beijing: China Automotive Technology \& Research Center, Retrieved from http://www.catarc.info/news/3363.cshtml

Chi, Y.-Y., Wang, Y.-Y., \& Xu, J.-H. (2021). Estimating the impact of the license plate quota policy 
for ICEVs on new energy vehicle adoption by using synthetic control method. Energy Policy, 149. doi:10.1016/j.enpol.2020.112022

Chowdhury, S., Dey, S., Tripathi, S. N., Beig, G., Mishra, A. K., \& Sharma, S. (2017). "Traffic intervention" policy fails to mitigate air pollution in megacity Delhi. Environ. Sci. Policy, 74, 8-13. doi:10.1016/j.envsci.2017.04.018

Fernandes, P., Bandeira, J. M., Fontes, T., Pereira, S. R., Schroeder, B. J., Rouphail, N. M., \& Coelho, M. C. (2016). Traffic Restriction Policies in an Urban Avenue: A Methodological Overview for a Trade-Off Analysis of Traffic and Emission Impacts Using Microsimulation. Int. J. Sustain. Transp., 10(3), 201-215. doi:10.1080/15568318.2014.885622

Fridstrøm, L., \& Østli, V. (2017). The vehicle purchase tax as a climate policy instrument. Transp. Res. Part A Policy Pract., 96, 168-189. doi:10.1016/j.tra.2016.12.011

Gallego, F., Montero, J. P., \& Salas, C. (2013). The effect of transport policies on car use: A bundling model with applications. Energ. Econ., 40, S85-S97. doi:10.1016/j.eneco.2013.09.018

Guerra, E., \& Millard-Ball, A. (2017). Getting around a license-plate ban: Behavioral responses to Mexico City's driving restriction. Transp. Res. Part D Transp. Environ., 55, 113-126. doi:10.1016/j.trd.2017.06.027

Hackbarth, A., \& Madlener, R. (2013). Consumer Preferences for Alternative Fuel Vehicles: A discrete Choice Analysis. SSRN Electronic Journal. doi:10.2139/ssrn.2236286

Hao, H., Ou, X. M., Du, J. Y., Wang, H. W., \& Ouyang, M. G. (2016). China's electric vehicle subsidy scheme: Rationale and impacts. Energy Policy, 73, 722-732. doi:10.1016/j.enpol.2014.05.022

Hardman, S. (2019). Understanding the impact of reoccurring and non-financial incentives on plug-in electric vehicle adoption - A review. Transp. Res. Part A Policy Pract., 119, 1-14. doi:10.1016/j.tra.2018.11.002

Hardman, S., Chandan, A., Tal, G., \& Turrentine, T. (2017). The effectiveness of financial purchase incentives for battery electric vehicles - A review of the evidence. Renew. Sust. Energ. Rev., 80, 1100-1111. doi:10.1016/j.rser.2017.05.255

He, X., Ou, S. Q., Gan, Y., Lu, Z. F., Przesmitzki, S., Bouchard, J. L., . . Wang, M. (2020). Greenhouse gas consequences of the China dual credit policy. Nat. commun., 11, 5212. doi:10.1038/s41467-020-19036-w

Hsu, S., Walters, J., \& Purgas, A. (2008). Pollution tax heuristics: An empirical study of willingness to pay higher gasoline taxes. Energy Policy, 36, 3612-3619. doi:10.1016/j.enpol.2008.06.010

Huang, H. J., Fu, D. Y., \& Qi, W. (2017). Effect of driving restrictions on air quality in Lanzhou, China: Analysis integrated with internet data source. J. Clean. Prod., 142, 1013-1020. doi:10.1016/j.jclepro.2016.09.082

Huang, X. Y., Zhang, Y. L., Yang, W. Q., Huang, Z. Z., Wang, Y. J., Zhang, Z., . . Wang, X. M. (2017). Effect of traffic restriction on reducing ambient volatile organic compounds 
(VOCs): Observation-based evaluation during a traffic restriction drill in Guangzhou, China. Atmos. Environ., 161, 61-70. doi:10.1016/j.atmosenv.2017.04.035

IEA. (2016). Global EV Outlook 2016. IEA, Paris, Retrieved from https://www.iea.org/reports/global-ev-outlook-2016

IEA. (2019). Global Energy \& CO2 Status Report 2019. IEA, Paris, Retrieved from https://www.iea.org/reports/global-energy-co2-status-report-2019

IEA. (2020). Global EV Outlook 2020. IEA, Paris, Retrieved from https://www.iea.org/reports/global-ev-outlook-2020

Invernizzi, G., Ruprecht, A., Mazza, R., De Marco, C., Mocnik, G., Sioutas, C., \& Westerdahl, D. (2011). Measurement of black carbon concentration as an indicator of air quality benefits of traffic restriction policies within the ecopass zone in Milan, Italy. Atmos. Environ., 45, 3522-3527. doi:10.1016/j.atmosenv.2011.04.008

Jia, N., Zhang, Y. D., He, Z. B., \& Li, G. (2017). Commuters' acceptance of and behavior reactions to license plate restriction policy: A case study of Tianjin, China. Transp. Res. Part D Transp. Environ., 52, 428-440. doi:10.1016/j.trd.2016.10.035

Jia, W., \& Chen, T. D. (2021). Are Individuals' stated preferences for electric vehicles (EVs) consistent with real-world EV ownership patterns? Transportation Research Part DTransport and Environment, 93. doi:10.1016/j.trd.2021.102728

Khan, U., Yamamoto, T., \& Sato, H. (2020). Consumer preferences for hydrogen fuel cell vehicles in Japan. Transportation Research Part D-Transport and Environment, 87. doi:10.1016/j.trd.2020.102542

Kim, M.-K., Oh, J., Park, J.-H., \& Joo, C. (2018). Perceived value and adoption intention for electric vehicles in Korea: Moderating effects of environmental traits and government supports. Energy, 159, 799-809. doi:10.1016/j.energy.2018.06.064

Klungboonkrong, P., Jaensirisak, S., \& Satirnnam, T. (2017). Potential performance of urban land use and transport strategies in reducing greenhouse gas emissions: Khon Kaen case study, Thailand. Int. J. Sustain. Transp., 11(1), 36-48. doi:10.1080/15568318.2015.1106249

Krause, R. M., Carley, S. R., Lane, B. W., \& Graham, J. D. (2013). Perception and reality: public knowledge of plug-in electric vehicles in 21 U.S. cities. Energy Policy, 63, 433-440. doi:https://doi.org/10.1016/j.enpol.2013.09.018

Lepitzki, J., \& Axsen, J. (2018). The role of a low carbon fuel standard in achieving long-term GHG reduction targets. Energy Policy, 119, 423-440. doi:10.1016/j.enpol.2018.03.067

Li, F., Ou, R., Xiao, X., Zhou, K., Xie, W., Ma, D., . . Song, Z. (2019). Regional comparison of electric vehicle adoption and emission reduction effects in China. Resources Conservation and Recycling, 149, 714-726. doi:10.1016/j.resconrec.2019.01.038

Li, L., Guo, S., Cai, H., Wang, J., Zhang, J., \& Ni, Y. (2020). Can China's BEV market sustain without government subsidies?: An explanation using cues utilization theory. Journal of Cleaner Production, 272. doi:10.1016/j.jclepro.2020.122589

Li, P. H., \& Jones, S. (2015). Vehicle restrictions and CO2 emissions in Beijing - A simple 
projection using available data. Transp. Res. Part D Transp. Environ., 41, 467-476. doi:10.1016/j.trd.2015.09.020

Lin, B., \& Wu, W. (2018). Why people want to buy electric vehicle: An empirical study in firsttier cities of China. Energy Policy, 112, 233-241. doi:10.1016/j.enpol.2017.10.026

Liu, X., Xie, F., Wang, H., \& Xue, C. (2021). The impact of policy mixes on new energy vehicle diffusion in China. Clean Technologies and Environmental Policy. doi:10.1007/s10098021-02040-Z

Liu, Y., \& Cirillo, C. (2015). Model System to Evaluate Impacts of Vehicle Purchase Tax and Fuel Tax on Household Greenhouse Gas Emissions. Transp. Res. Rec., 2503(1), 51-59. doi:10.3141/2503-06

Liu, Y., Yan, Z. J., \& Dong, C. (2016). Health implications of improved air quality from Beijing's driving restriction policy. Environ. Pollut., 219, 323-328. doi:10.1016/j.envpol.2016.10.049

Liu, Y. X., Hong, Z. S., \& Liu, Y. (2016). Do driving restriction policies effectively motivate commuters to use public transportation? Energy Policy, 90, 253-261. doi:10.1016/j.enpol.2015.12.038

Liu, Z., Li, R., Wang, X., \& Shang, P. (2020). Noncompliance behavior against vehicle restriction policy: A case study of Langfang, China. Transportation Research Part a-Policy and Practice, 132, 1020-1033. doi:10.1016/j.tra.2020.01.005

Liu, Z. Y., Li, R. M., Wang, X. K., \& Shang, P. (2018). Effects of vehicle restriction policies: Analysis using license plate recognition data in Langfang, China. Transp. Res. Part A Policy Pract., 118, 89-103. doi:10.1016/j.tra.2018.09.001

Lu, T., Yao, E., Jin, F., \& Pan, L. (2020). Alternative Incentive Policies against Purchase Subsidy Decrease for Battery Electric Vehicle (BEV) Adoption. Energies, 13(7). doi:10.3390/en13071645

Lyons, L., Lozano, A., Granados, F., \& Guzman, A. (2017). Impacts of time restriction on heavy truck corridors: The case study of Mexico City. Transp. Res. Part A Policy Pract., 102, 119-129. doi:10.1016/j.tra.2017.03.012

Ma, S. C., Fan, Y., \& Feng, L. (2017). An evaluation of government incentives for new energy vehicles in China focusing on vehicle purchasing restrictions. Energy Policy, 110, 609-618. doi:10.1016/j.enpol.2017.07.057

MEEC. (2018). Action Plan for Comprehensive Control of Air pollution in autumn and Winter from 2018 to 2019 in Beijing, Tianjin, Hebei and its surrounding areas. Beijing: Ministry of Ecological Environment of China, Retrieved from http://www.mee.gov.cn/gkml/sthjbgw/sthjbwj/201809/t20180927 630570.htm

Mersky, A. C., Sprei, F., Samaras, C., \& Qian, Z. (2016). Effectiveness of incentives on electric vehicle adoption in Norway. Transp. Res. Part D Transp. Environ., 46, 56-68. doi:10.1016/j.trd.2016.03.011

MI\&IT. (2020). Parallel management method of average fuel consumption of passenger car 
enterprises and new energy vehicle points. Beijing: Ministry of Industry and Information

Technology of the People's Republic of China, Retrieved from https:/www.miit.gov.cn/jgsj/zfs/bmgz/art/2020/art bb9aff09c02d44cf87dfce83fc5df7d5. $\underline{\mathrm{html}}$

MOF. (2020a). Announcement on relevant policies for exemption of vehicle purchase tax for new energy vehicles. Beijing: Ministry of Finance of the People's Republic of China, Retrieved from http://jx.mof.gov.cn/xxgk/zhengcefagui/202004/t20200427 3504998.htm

MOF. (2020b). Notice on improving the financial subsidy policy for the promotion and application of new energy vehicles. Beijing: Ministry of Finance of the People's Republic of China, Retrieved from http://jx.mof.gov.cn/xxgk/zhengcefagui/202004/t20200427 3505000.htm

Morton, C., Lovelace, R., \& Anable, J. (2017). Exploring the effect of local transport policies on the adoption of low emission vehicles: Evidence from the London Congestion Charge and Hybrid Electric Vehicles. Transp. Policy, 60, 34-46. doi:10.1016/j.tranpol.2017.08.007

MPS. (2021). 9.66 Million Newly Registered Motor Vehicles in the First Quarter of 2021. Available at: https://app.mps.gov.cn/gdnps/pc/content.jsp?id=7829360. Retrieved on 410.

Mro, A., \& Lonza, L. (2018). Electricity carbon intensity in European Member States: Impacts on GHG emissions of electric vehicles. Transp. Res. Part D Transp. Environ., 64, 5-14. doi:10.1016/j.trd.2017.07.012

NDRC. (2017). Implementation Act on promoting the Renewal and upgrading of key Consumer goods and the Recycling of Resources (2019-2020). Beijing: National Development and Reform Commission of China, Retrieved from http://www.gov.cn/xinwen/201906/07/5398219/files/ecedbc8eba5947d789e7e60aa02ed062.pdf

Neves, S. A., Marques, A. C., \& Fuinhas, J. A. (2019). Technological progress and other factors behind the adoption of electric vehicles: Empirical evidence for EU countries. Research in Transportation Economics, 74, 28-39. doi:10.1016/j.retrec.2018.12.001

Onn, C. C., Mohd, N. S., Yuen, C. W., Loo, S. C., Koting, S., Abd Rashid, A. F., . . Yusoff, S. (2018). Greenhouse gas emissions associated with electric vehicle charging: The impact of electricity generation mix in a developing country. Transportation Research Part DTransport and Environment, 64, 15-22. doi:10.1016/j.trd.2017.06.018

Ou, S. Q., Lin, Z. H., Qi, L., Li, J., He, X., \& Przesmitzki, S. (2018). The dual-credit policy: Quantifying the policy impact on plug-in electric vehicle sales and industry profits in China Energy Policy. doi:10.1016/j.enpol.2018.06.017

Peters, A. M., van der Werff, E., \& Steg, L. (2018). Beyond purchasing: Electric vehicle adoption motivation and consistent sustainable energy behaviour in The Netherlands. Energy Research \& Social Science, 39, 234-247. doi:10.1016/j.erss.2017.10.008

$\mathrm{Pu}$, Y. C., Yang, C., Liu, H. B., Chen, Z., \& Chen, A. (2015). Impact of license plate restriction policy on emission reduction in Hangzhou using a bottom-up approach. Transp. Res. Part D Transp. Environ., 34, 281-292. doi:10.1016/j.trd.2014.11.007 
Qian, L., Grisolia, J. M., \& Soopramanien, D. (2019). The impact of service and governmentpolicy attributes on consumer preferences for electric vehicles in China. Transportation Research Part a-Policy and Practice, 122, 70-84. doi:10.1016/j.tra.2019.02.008

SCC. (2016a). the 13th Five-Year Plan for Energy Saving and Emission Reduction. Beijing: General Office of the State Council of the People's Republic of China, Retrieved from http:/www.gov.cn/zhengce/content/2017-01/05/content 5156789.htm

SCC. (2016b). Notice of the State Council on printing and distributing the work plan for controlling greenhouse gas emissions during the 13th Five Year Plan Period. Beijing: General Office of the State Council of the People's Republic of China, Retrieved from http:/www.gov.cn/zhengce/content/2016-11/04/content 5128619.htm

Sen, B., Noori, M., \& Tatari, O. (2017). Will Corporate Average Fuel Economy (CAFE) Standard help? Modeling CAFE's impact on market share of electric vehicles. Energy Policy, 109, 279-287. doi:10.1016/j.enpol.2017.07.008

Shi, J., Guo, X. S., \& Hu, X. N. (2019). Engaging Stakeholders in Urban Traffic Restriction Policy Assessment Using System Dynamics: The Case Study of Xi'an City, China. Sustainability, 11, 3930. doi:10.3390/su11143930

Sierzchula, W., Bakker, S., Maat, K., \& van Wee, B. (2014). The influence of financial incentives and other socio-economic factors on electric vehicle adoption. Energy Policy, 68, 183-194. doi:10.1016/j.enpol.2014.01.043

SMG. (2018). Action Plan for Comprehensive Control of Air pollution in autumn and Winter in Shijiazhuang City from 2018 to 2019. Shijiazhuang, China: Shijiazhuang Municipal people's Government, Retrieved from http://www.sjz.gov.cn/col/1516346012153/2018/11/13/1542090336637.html

Sykes, M., \& Axsen, J. (2017). No free ride to zero-emissions: Simulating a region's need to implement its own zero-emissions vehicle (ZEV) mandate to achieve $2050 \mathrm{GHG}$ targets. Energy Policy, 110, 447-460. doi:10.1016/j.enpol.2017.08.031

Vermote, L., Macharis, C., Boeykens, F., Schoolmeester, C., \& Piutman, K. (2014). Trafficrestriction in Ramallah (Palestine): Participatory sustainability assessment of pedestrian scenarios using a simplified transport model. Land Use Policy, 41, 453-464. doi:10.1016/j.landusepol.2014.06.005

Wang, L. L., Xu, J. T., \& Qin, P. (2014). Will a driving restriction policy reduce car trips? — The case study of Beijing, China. Transp. Res. Part A Policy Pract., 67, 279-290. doi:10.1016/j.tra.2014.07.014

Wang, N., Pan, H. Z., \& Zheng, W. H. (2017). Assessment of the incentives on electric vehicle promotion in China. Transp. Res. Part A Policy Pract., 101, 177-189. doi:10.1016/j.tra.2017.04.037

Wang, N., Tang, L., \& Pan, H. (2017). Effectiveness of policy incentives on electric vehicle acceptance in China: A discrete choice analysis. Transp. Res. Part A Policy Pract., 105, 210-218. doi:10.1016/j.tra.2017.08.009 
Wang, N., Tang, L., Zhang, W., \& Guo, J. (2019). How to face the challenges caused by the abolishment of subsidies for electric vehicles in China? Energy, 166, 359-372. doi:10.1016/j.energy.2018.10.006

Wang, Z., Zhao, C., Yin, J., \& Zhang, B. (2017). Purchasing intentions of Chinese citizens on new energy vehicles: How should one respond to current preferential policy? J. Clean. Prod., 161, 1000-1010. doi:10.1016/j.jclepro.2017.05.154

Wee, S., Coffman, M., \& La Croix, S. (2018). Do electric vehicle incentives matter? Evidence from the 50 U.S. states. Res. Policy, 47(9), 1601-1610. doi:10.1016/j.respol.2018.05.003

Wolbertus, R., Kroesen, M., van den Hoed, R., \& Chorus, C. G. (2018). Policy effects on charging behaviour of electric vehicle owners and on purchase intentions of prospective owners: Natural and stated choice experiments. Transportation Research Part D-Transport and Environment, 62, 283-297. doi:10.1016/j.trd.2018.03.012

Wu, Z. X., Wang, M., Zheng, J. H., Sun, X., Zhao, M. N., \& Wang, X. (2018). Life cycle greenhouse gas emission reduction potential of battery electric vehicle. J. Clean. Prod., 190, 462-470. doi:10.1016/j.jclepro.2018.04.036

Yan, S. (2018). The economic and environmental impacts of tax incentives for battery electric vehicles in Europe. Energy Policy, 123, 53-63. doi:10.1016/j.enpol.2018.08.032

Yang, J., Lu, F. W., Liu, Y., \& Guo, J. F. (2018). How does a driving restriction affect transportation patterns? The medium-run evidence from Beijing. J. Clean. Prod., 204, 270-281. doi:10.1016/j.jclepro.2018.08.069

Ye, F., Kang, W., Li, L., \& Wang, Z. (2021). Why do consumers choose to buy electric vehicles? A paired data analysis of purchase intention configurations. Transportation Research Part a-Policy and Practice, 147, 14-27. doi:10.1016/j.tra.2021.02.014

Zhang, X. D., Li, H. N., Feng, X. T., \& Chen, Z. H. (2012). Research on the Influence of Last Digit Restriction to the Traffic Flow Characteristics Appl. Mech. Mater., 253-255, 1976-1981. doi:https://doi.org/10.4028/www.scientific.net/AMM.253-255.1976

Zhang, Y., Qian, Z. S., Sprei, F., \& Li, B. (2016). The impact of car specifications, prices and incentives for battery electric vehicles in Norway: choices of heterogeneous consumers. Transp. Res. Part C Emerg. Technol., 69, 386-401. doi:10.1016/j.trc.2016.06.014

Zhao, J. B., Zhang, J., Sun, L. N., Liu, Y., Lin, Y. C., Li, Y. N., . . . Mao, H. J. (2018). Characterization of PM2.5-bound nitrated and oxygenated polycyclic aromatic hydrocarbons in ambient air of Langfang during periods with and without traffic restriction. Atmos. Res., 213, 302-308. doi:10.1016/j.atmosres.2018.06.015 


\section{Appendix A: Proof of Lemmas and Propositions}

\section{Proof of Lemma 1}

Substituting $q_{B E V}$ and $q_{C V}$ in Equation (3) and (4) into Equation (5) and using the first-order conditions, $d \pi_{B E V} / d P_{B E V}=0$ and $d \pi_{C V} / d P_{C V}=0$, derive the best response functions as follows:

$$
\begin{aligned}
& P_{B E V}=\frac{1}{2}\left[\left(1+r_{V P T}\right) \beta P_{C V}+C_{B E V}-O_{B E V}+O_{C V}-s\right] \\
& P_{C V}=\frac{1}{2}\left(\frac{P_{B E V}}{1+r_{V P T}}+C_{C V}+\frac{O_{B E V}-O_{C V}-s+1-\beta}{1+r_{V P T}}\right)
\end{aligned}
$$

It can be verified that the second-order derivatives are negative. Solving these two equations yields the equilibrium prices of $P_{B E V}$ and $P_{C V}$ in the lemma. Substituting the equilibrium prices into $q_{B E V}$ and $q_{C V}$ in Equation (3) and (4) and into the profit functions in Equation (5) yields the equilibrium demands and equilibrium profits in the lemma.

The equilibrium prices, demands, and profits in the Lemma 2, Lemma 3, Corollary 1, Corollary 2, and Corollary 3 can be obtained using similar methods.

\section{Proof of Proposition 1}

(a) Based on Equations (11), (26), (39), there are:

$$
\begin{aligned}
P_{B E V}^{C V R}-P_{B E V}^{N R}=l \frac{\beta}{4-\beta}> & 0, P_{B E V}^{B R}-P_{B E V}^{N R}=-2 l \frac{1-\beta}{4-\beta}<0, \\
& P_{B E V}^{C V R}-P_{B E V}^{B R}=P_{B E V}^{C V R}-P_{B E V}^{N R}-\left(P_{B E V}^{B R}-P_{B E V}^{N R}\right)>0 .
\end{aligned}
$$

Based on Equations (14), (29), (42), there are:

$$
\begin{gathered}
P_{C V}^{C V R}-P_{C V}^{N R}=-l \frac{2-\beta}{(4-\beta)\left(1+r_{V P T}\right)}<0, P_{C V}^{B R}-P_{C V}^{N R}=-l \frac{1-\beta}{(4-\beta)\left(1+r_{V P T}\right)}<0, \\
P_{C V}^{C V R}-P_{C V}^{B R}=\frac{-l}{(4-\beta)\left(1+r_{V P T}\right)}<0 .
\end{gathered}
$$

(b) Based on Equations (12), (27), (40), there are:

$$
\begin{aligned}
& q_{B E V}^{C V R}-q_{B E V}^{N R}=\frac{l}{(4-\beta)(1-\beta)}>0, q_{B E V}^{B R}-q_{B E V}^{N R}=\frac{-2 l}{(4-\beta) \beta}<0, \\
& q_{B E V}^{C V R}-q_{B E V}^{B R}=q_{B E V}^{C V R}-q_{B E V}^{N R}-\left(q_{B E V}^{B R}-q_{B E V}^{N R}\right)>0 .
\end{aligned}
$$


Based on Equations (15), (30), (43), there are:

$q_{C V}^{C V R}-q_{C V}^{N R}=-l \frac{2-\beta}{(4-\beta)(1-\beta)}<0, q_{C V}^{B R}-q_{C V}^{N R}=\frac{-l}{4-\beta}<0, q_{C V}^{C V R}-q_{C V}^{B R}=\frac{-l}{(4-\beta)(1-\beta)}<0$.

(c) Based on Equations (13), (28), (41), there are:

$$
\pi_{B E V}^{C V R}-\pi_{B E V}^{N R}=l \frac{\Lambda_{1}+\Lambda_{2}}{(4-\beta)^{2}(1-\beta)}-\frac{2 l C R_{N E V}^{-} P_{C R}}{4-\beta},
$$

Therefore $\pi_{B E V}^{C V R}-\pi_{B E V}^{N R}>0$ if and only if $\frac{l}{2 \beta}>C R_{N E V}^{-} P_{C R}(4-\beta)(1-\beta)-\Lambda_{1}$.

$$
\begin{gathered}
\pi_{B E V}^{B R}-\pi_{B E V}^{N R}=-2 l \frac{\Lambda_{1}+\Lambda_{3}}{(4-\beta)^{2} \beta}-\frac{3 l C R_{N E V}^{-} P_{C R}}{4-\beta}<0, \\
\pi_{B E V}^{C V R}-\pi_{B E V}^{B R}=(2-\beta) l \frac{\Lambda_{2}+\Lambda_{3}}{(4-\beta)^{2}(1-\beta) \beta}+\frac{l C R_{N E V}^{-} P_{C R}}{4-\beta}>0,
\end{gathered}
$$

where $\Lambda_{1}=\beta\left(K_{1}+1-\beta\right)-(2-\beta) K_{2}>0, \Lambda_{2}=\beta\left(K_{1}+1-\beta+l\right)-(2-\beta) K_{2}>0$, and $\Lambda_{3}=\beta\left(K_{1}+1-\beta+l\right)-(2-\beta)\left(K_{2}+l\right)>0$.

Based on Equations (16), (31), (44), there are:

$$
\pi_{C V}^{C V R}-\pi_{C V}^{N R}=-(2-\beta) l \frac{\Lambda_{4}+\Lambda_{5}}{(4-\beta)^{2}(1-\beta)\left(1+r_{V P T}\right)}<0,
$$

$\pi_{C V}^{B R}-\pi_{C V}^{N R}=-l \frac{\Lambda_{4}+\Lambda_{6}}{(4-\beta)^{2}\left(1+r_{V P T}\right)}<0, \pi_{C V}^{C V R}-\pi_{C V}^{B R}=-l \frac{\Lambda_{5}+\Lambda_{6}}{(4-\beta)(1-\beta)\left(1+r_{V P T}\right)}<0$,

where $\Lambda_{4}=2(1-\beta)-(2-\beta) K_{1}+K_{2}>0, \Lambda_{5}=2(1-\beta)-(2-\beta)\left(K_{1}+l\right)+K_{2}>0$, and $\Lambda_{6}=2(1-\beta)-(2-\beta)\left(K_{1}+l\right)+K_{2}+l>0$.

\section{Proof of Proposition 2}

Substituting Equations (12), (15), (27), (30), (40), and (43) into Equation (6) yields the total carbon emission under different traffic restriction policies, as shown below

$$
\begin{gathered}
T C E^{N R}=\frac{\beta\left(K_{1}+1-\beta\right)-(2-\beta) K_{2}}{(4-\beta)(1-\beta) \beta} e_{B E V}+\left[1-\frac{(2-\beta)\left(K_{1}+1-\beta\right)-K_{2}}{(4-\beta)(1-\beta)}\right] e_{C V}, \quad(A .3) \\
T C E^{C V R}=\frac{\beta\left(K_{1}+1-\beta+l\right)-(2-\beta) K_{2}}{(4-\beta)(1-\beta) \beta} e_{B E V}+\left[1-\frac{(2-\beta)\left(K_{1}+1-\beta+l\right)-K_{2}}{(4-\beta)(1-\beta)}\right] e_{C V},(A .4) \\
T C E^{B R}=\frac{\beta\left(K_{1}+1-\beta+l\right)-(2-\beta)\left(K_{2}+l\right)}{(4-\beta)(1-\beta) \beta} e_{B E V}+\left[1-\frac{(2-\beta)\left(K_{1}+1-\beta+l\right)-K_{2}-l}{(4-\beta)(1-\beta)}\right] e_{C V},(A
\end{gathered}
$$

Based on Equations (A.3), (A.4), and (A.5), there are:

$$
T C E^{C V R}-T C E^{N R}=\frac{l}{(4-\beta)(1-\beta)}\left[e_{B E V}-(2-\beta) e_{C V}\right]<0,
$$




$$
\begin{gathered}
T C E^{B R}-T C E^{N R}=\frac{-l}{(4-\beta) \beta}\left(2 e_{B E V}+\beta e_{C V}\right)<0, \\
T C E^{C V R}-T C E^{B R}=\frac{l}{(4-\beta)(1-\beta) \beta}\left[(2-\beta) e_{B E V}-\beta e_{C V}\right] .
\end{gathered}
$$

Therefore, $T C E^{C V R}<T C E^{B R}$ if and only if $e_{B E V}<\frac{\beta}{2-\beta} e_{C V}$.

\section{Proof of Proposition 3}

Substituting utility surplus Equations (1), (2), (23) and (38), and optimal prices in Equations (11), (14), (17), (20), (26), (29), (32), (35), (39), (42), (45), and (48) into Equations (9) yields the consumer surplus functions under different traffic restriction policies:

$$
f(v)^{N R}=\left\{\begin{array}{cc}
0 & 0<v<v_{1}^{N R} \\
\beta v-\frac{\beta\left(K_{1}+1-\beta\right)+2 K_{2}}{4-\beta}, & v_{1}^{N R}<v<v_{2}^{N R} \\
v-\frac{2\left(K_{1}+1-\beta\right)+K_{2}}{4-\beta}, & v_{2}^{N R}<v<1
\end{array}\right.
$$

where $v_{1}^{N R}=\frac{\beta\left(K_{1}+1-\beta\right)+2 K_{2}}{(4-\beta) \beta}$, and $v_{2}^{N R}=\frac{(2-\beta)\left(K_{1}+1-\beta\right)-K_{2}}{(4-\beta)(1-\beta)}$.

$$
f(v)^{C V R}=\left\{\begin{array}{cc}
0 & 0<v<v_{1}^{C V R} \\
\beta v-\frac{\beta\left(K_{1}+1-\beta+l\right)+2 K_{2}}{4-\beta}, & v_{1}^{C V R}<v<v_{2}^{C V R} \\
v-\frac{2\left(K_{1}+1-\beta+l\right)+K_{2}}{4-\beta}, & v_{2}^{C V R}<v<1
\end{array},\right.
$$

where $v_{1}^{C V R}=\frac{\beta\left(K_{1}+1-\beta+l\right)+2 K_{2}}{(4-\beta) \beta}$, and $v_{2}^{C V R}=\frac{(2-\beta)\left(K_{1}+1-\beta+l\right)-K_{2}}{(4-\beta)(1-\beta)}$.

$$
f(v)^{B R}=\left\{\begin{array}{cc}
0 & 0<v<v_{1}^{B R} \\
\beta v-\frac{\beta\left(K_{1}+1-\beta+l\right)+2 K_{2}+2 l}{4-\beta}, & v_{1}^{B R}<v<v_{2}^{B R} \\
v-\frac{2\left(K_{1}+1-\beta+l\right)+K_{2}+l}{4-\beta}, & v_{2}^{B R}<v<1
\end{array}\right.
$$

where $v_{1}^{B R}=\frac{\beta\left(K_{1}+1-\beta+l\right)+2 K_{2}+2 l}{(4-\beta) \beta}$, and $v_{2}^{B R}=\frac{(2-\beta)\left(K_{1}+1-\beta+l\right)-K_{2}-l}{(4-\beta)(1-\beta)}$.

It can be verified that curve $f(v)^{N R}$ is above curve $f(v)^{C V R}$, and curve $f(v)^{C V R}$ is above $f(v)^{B R}$. Consumer surplus is the integral of the curve $f(v)$ between 0 and 1 , or the area between the curve $f(v)$ and the x-axis. Through the curve position relationship shown in Figure 9, the relationship of consumer surplus in each traffic restriction policy can be determined, as 
summarized in Proposition 3.

\section{Proof of Proposition 4}

(a) Based on Equations (17), (32), and (45), there are:

$$
\begin{aligned}
\tilde{P}_{B E V}^{C V R}-\tilde{P}_{B E V}^{N R}=l \frac{\beta}{4-\beta}>0, & \tilde{P}_{B E V}^{B R}-\tilde{P}_{B E V}^{N R}=-2 l \frac{1-\beta}{4-\beta}<0, \\
& \tilde{P}_{B E V}^{C V R}-\tilde{P}_{B E V}^{B R}=\tilde{P}_{B E V}^{C V R}-\tilde{P}_{B E V}^{N R}-\left(\tilde{P}_{B E V}^{B R}-\tilde{P}_{B E V}^{N R}\right)>0 .
\end{aligned}
$$

Based on Equations (20), (35), and (48), there are:

$$
\tilde{P}_{C V}^{C V R}-\tilde{P}_{C V}^{N R}=-l \frac{2-\beta}{4-\beta}<0, \tilde{P}_{C V}^{B R}-\tilde{P}_{C V}^{N R}=-l \frac{1-\beta}{4-\beta}<0, \tilde{P}_{C V}^{C V R}-\tilde{P}_{C V}^{B R}=\frac{-l}{4-\beta}<0 .
$$

(b) Based on Equations (18), (33), and (46), there are:

$$
\begin{aligned}
& \tilde{q}_{B E V}^{C V R}-\tilde{q}_{B E V}^{N R}=\frac{l}{(4-\beta)(1-\beta)}>0, \tilde{q}_{B E V}^{B R}-\tilde{q}_{B E V}^{N R}=\frac{-l}{(4-\beta) \beta}<0, \\
& \tilde{q}_{B E V}^{C V R}-\tilde{q}_{B E V}^{B R}=\tilde{q}_{B E V}^{C V R}-\tilde{q}_{B E V}^{N R}-\left(\tilde{q}_{B E V}^{B R}-\tilde{q}_{B E V}^{N R}\right)>0 .
\end{aligned}
$$

Based on Equations (21), (36), and (49), there are:

$\tilde{q}_{C V}^{C V R}-\tilde{q}_{C V}^{N R}=-l \frac{2-\beta}{(4-\beta)(1-\beta)}<0, \quad \tilde{q}_{C V}^{B R}-\tilde{q}_{C V}^{N R}=\frac{-l}{4-\beta}<0, \quad \tilde{q}_{C V}^{C V R}-\tilde{q}_{C V}^{B R}=\frac{-l}{(4-\beta)(1-\beta)}<0$.

(c) Based on Equations (19), (34), and (47), there are:

$$
\tilde{\pi}_{B E V}^{C V R}-\tilde{\pi}_{B E V}^{N R}=l \frac{\widetilde{\Lambda}_{1}+\tilde{\Lambda}_{2}}{(4-\beta)^{2}(1-\beta)}-\frac{2 l C R_{N E V}^{-} P_{C R}}{4-\beta},
$$

Therefore $\tilde{\pi}_{B E V}^{C V R}-\tilde{\pi}_{B E V}^{N R}>0$ if and only if $\frac{l}{2 \beta}>C R_{N E V}^{-} P_{C R}(4-\beta)(1-\beta)-\widetilde{\Lambda}_{1}$

$$
\begin{gathered}
\tilde{\pi}_{B E V}^{B R}-\tilde{\pi}_{B E V}^{N R}=-2 l \frac{\widetilde{\Lambda}_{1}+\widetilde{\Lambda}_{3}}{(4-\beta)^{2} \beta}-\frac{3 l C R_{N E V}^{-} P_{C R}}{4-\beta}<0, \\
\tilde{\pi}_{B E V}^{C V R}-\tilde{\pi}_{B E V}^{B R}=(2-\beta) l \frac{\widetilde{\Lambda}_{2}+\widetilde{\Lambda}_{3}}{(4-\beta)^{2} \beta}+\frac{l C R_{N E V}^{-} P_{C R}}{4-\beta}>0,
\end{gathered}
$$

where $\widetilde{\Lambda}_{1}=\beta\left(\widetilde{K}_{1}+1-\beta+c e_{C V}\right)-(2-\beta)\left(K_{2}+c e_{B E V}\right)>0, \quad \widetilde{\Lambda}_{2}=\beta\left(\widetilde{K}_{1}+1-\beta+l+\right.$ $\left.c e_{C V}\right)-(2-\beta)\left(K_{2}+c e_{B E V}\right)>0$, and $\widetilde{\Lambda}_{3}=\beta\left(\widetilde{K}_{1}+1-\beta+l+c e_{C V}\right)-(2-\beta)\left(K_{2}+l+\right.$ $\left.c e_{B E V}\right)>0$.

Based on Equations (24), (37), and (50), there are:

$$
\tilde{\pi}_{C V}^{C V R}-\tilde{\pi}_{C V}^{N R}=-(2-\beta) l \frac{\tilde{\Lambda}_{4}+\tilde{\Lambda}_{5}}{(4-\beta)^{2}(1-\beta)}<0,
$$


$\tilde{\pi}_{C V}^{B R}-\tilde{\pi}_{C V}^{N R}=-l \frac{\widetilde{\Lambda}_{4}+\widetilde{\Lambda}_{6}}{(4-\beta)^{2}}<0, \tilde{\pi}_{C V}^{C V R}-\tilde{\pi}_{C V}^{B R}=-l \frac{\widetilde{\Lambda}_{5}+\widetilde{\Lambda}_{6}}{(4-\beta)(1-\beta)}<0$,

where $\quad \widetilde{\Lambda}_{4}=2(1-\beta)-(2-\beta)\left(\widetilde{K}_{1}+c e_{C V}\right)+K_{2}+c e_{B E V}>0 \quad, \quad \widetilde{\Lambda}_{5}=2(1-\beta)-(2-$ $\beta)\left(\widetilde{K}_{1}+c e_{C V}+l\right)+K_{2}+c e_{B E V}>0$, and $\widetilde{\Lambda}_{6}=2(1-\beta)-(2-\beta)\left(\widetilde{K}_{1}+l+c e_{C V}\right)+K_{2}+$ $c e_{B E V}+l>0$.

\section{Proof of Proposition 5}

Substituting Equations (18), (21), (33), (36), (46), and (49) into Equation (6) yields the total economic cost of emissions under different traffic restriction policies:

$$
\begin{gathered}
\widetilde{T C E}^{N R}=\frac{\beta\left(\widetilde{K}_{1}+1-\beta+c e_{C V}\right)-(2-\beta)\left(K_{2}+c e_{B E V}\right)}{(4-\beta)(1-\beta) \beta} e_{B E V} \\
+\left[1-\frac{(2-\beta)\left(\widetilde{K}_{1}+1-\beta+c e_{C V}\right)-K_{2}-c e_{B E V}}{(4-\beta)(1-\beta)}\right] e_{C V} \\
\widetilde{T C E}^{C V R}=\frac{\beta\left(\widetilde{K}_{1}+1-\beta+l+c e_{C V}\right)-(2-\beta)\left(K_{2}+c e_{B E V}\right)}{(4-\beta)(1-\beta) \beta} e_{B E V} \\
+\left[1-\frac{\left.(2-\beta)\left(\widetilde{K}_{1}+1-\beta+l+c e_{C V}\right)-K_{2}-c e_{B E V}\right]}{(4-\beta)(1-\beta)}\right] e_{C V} \\
\widetilde{T C E}^{B R}=\frac{\beta\left(\widetilde{K}_{1}+1-\beta+l+c e_{C V}\right)-(2-\beta)\left(K_{2}+l+c e_{B E V}\right)}{(4-\beta)(1-\beta) \beta} e_{B E V} \\
+\left[1-\frac{(2-\beta)\left(\widetilde{K}_{1}+1-\beta+l+c e_{C V}\right)-K_{2}-l-c e_{B E V}}{(4-\beta)(1-\beta)}\right] e_{C V},
\end{gathered}
$$

Based on Equations (A.9), (A.10), and (A.11), there are:

$$
\begin{gathered}
\widetilde{T C E}^{C V R}-\widetilde{T C E}^{N R}=\frac{l}{(4-\beta)(1-\beta)}\left[e_{B E V}-(2-\beta) e_{C V}\right]<0, \\
\widetilde{T C E}^{B R}-\widetilde{T C E}^{N R}=\frac{-l}{(4-\beta) \beta}\left(2 e_{B E V}+\beta e_{C V}\right)<0, \\
\widetilde{T C E}^{C V R}-\widetilde{T C E}^{B R}=\frac{l}{(4-\beta)(1-\beta) \beta}\left[(2-\beta) e_{B E V}-\beta e_{C V}\right] .
\end{gathered}
$$

Therefore, $\widetilde{T C E}^{C V R}<\widetilde{T C E}^{B R}$ if and only if $e_{B E V}<\frac{\beta}{2-\beta} e_{C V}$.

\section{Proof of Proposition 6}

Proposition 6 can be obtained using the method similar to the proof of Proposition 3, based on the 
following $\widetilde{f(v)^{B R}}, \widetilde{f(v)^{C V R}}$, and $\widetilde{f(v)^{N R}}$.

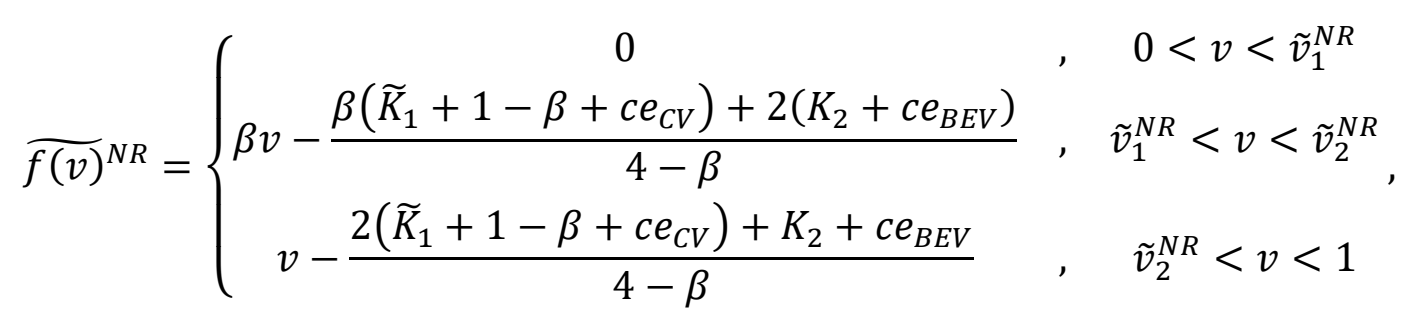

where $\tilde{v}_{1}^{N R}=\frac{\beta\left(\widetilde{K}_{1}+1-\beta+c e_{C V}\right)+2\left(K_{2}+c e_{B E V}\right)}{(4-\beta) \beta}$, and $\tilde{v}_{2}^{N R}=\frac{(2-\beta)\left(\widetilde{K}_{1}+1-\beta+c e_{C V}\right)-K_{2}-c e_{B E V}}{(4-\beta)(1-\beta)}$.

$$
\widetilde{f(v)}^{C V R}=\left\{\begin{array}{cc}
0 & 0<v<\tilde{v}_{1}^{C V R} \\
\beta v-\frac{\beta\left(\widetilde{K}_{1}+1-\beta+c e_{C V}+l\right)+2\left(K_{2}+c e_{B E V}\right)}{4-\beta}, & \tilde{v}_{1}^{C V R}<v<\tilde{v}_{2}^{C V R}, \\
v-\frac{2\left(\widetilde{K}_{1}+1-\beta+c e_{C V}+l\right)+K_{2}+c e_{B E V}}{4-\beta} & , \quad \tilde{v}_{2}^{C V R}<v<1
\end{array},\right.
$$

where $\tilde{v}_{1}^{C V R}=\frac{\beta\left(\widetilde{K}_{1}+1-\beta+c e_{C V}+l\right)+2\left(K_{2}+c e_{B E V}\right)}{(4-\beta) \beta}$, and $\tilde{v}_{2}^{C V R}=\frac{(2-\beta)\left(\widetilde{K}_{1}+1-\beta+c e_{C V}+l\right)-K_{2}-c e_{B E V}}{(4-\beta)(1-\beta)}$.

$$
\widetilde{f(v)^{B R}}=\left\{\begin{array}{cc}
0 & 0<v<\widetilde{v}_{1}^{B R} \\
\beta v-\frac{\beta\left(\widetilde{K}_{1}+1-\beta+c e_{C V}+l\right)+2\left(K_{2}+c e_{B E V}+l\right)}{4-\beta}, & \tilde{v}_{1}^{B R}<v<\tilde{v}_{2}^{B R} \\
v-\frac{2\left(\widetilde{K}_{1}+1-\beta+c e_{C V}+l\right)+K_{2}+c e_{B E V}+l}{4-\beta}, & \tilde{v}_{2}^{B R}<v<1
\end{array},\right.
$$

where $\tilde{v}_{1}^{B R}=\frac{\beta\left(\widetilde{K}_{1}+1-\beta+c e_{C V}+l\right)+2\left(K_{2}+c e_{B E V}+l\right)}{(4-\beta) \beta}$, and $\tilde{v}_{2}^{B R}=\frac{(2-\beta)\left(\widetilde{K}_{1}+1-\beta+c e_{C V}+l\right)-K_{2}-c e_{B E V}-l}{(4-\beta)(1-\beta)}$.

\section{Proof of Proposition 7}

Based on Equations (12), (18), (27), (33), (40), and (46), there are:

$$
\begin{aligned}
& \tilde{q}_{B E V}^{N R}-q_{B E V}^{N R}=\frac{\beta c e_{C V}-(2-\beta) c e_{B E V}-\beta r_{V P T}\left(C_{C V}+C R_{N E V}^{-} P_{C R}\right)}{(4-\beta)(1-\beta) \beta}, \\
& \tilde{q}_{B E V}^{C V R}-q_{B E V}^{C V R}=\frac{\beta c e_{C V}-(2-\beta) c e_{B E V}-\beta r_{V P T}\left(C_{C V}+C R_{N E V}^{-} P_{C R}\right)}{(4-\beta)(1-\beta) \beta}, \\
& \tilde{q}_{B E V}^{B R}-q_{B E V}^{B R}=\frac{\beta c e_{C V}-(2-\beta) c e_{B E V}-\beta r_{V P T}\left(C_{C V}+C R_{N E V}^{-} P_{C R}\right)}{(4-\beta)(1-\beta) \beta} .
\end{aligned}
$$

Therefore, $\tilde{q}_{B E V}^{N R}-q_{B E V}^{N R}>0, \tilde{q}_{B E V}^{C V R}-q_{B E V}^{C V R}>0$, and $\tilde{q}_{B E V}^{B R}-q_{B E V}^{B R}>0$, if and only if

$$
c e_{B E V}<\frac{\beta}{2-\beta}\left[c e_{C V}-r_{V P T}\left(C_{C V}+C R_{N E V}^{-} P_{C R}\right)\right] .
$$

Based on Equations (15), (21), (30), (36), (43), and (49), there are: 


$$
\begin{aligned}
\tilde{q}_{C V}^{N R}-q_{C V}^{N R} & =\frac{c e_{B E V}-(2-\beta) c e_{C V}+(2-\beta) r_{V P T}\left(C_{C V}+C R_{N E V}^{-} P_{C R}\right)}{(4-\beta)(1-\beta)}, \\
\tilde{q}_{C V}^{C V}-q_{C V}^{C V R} & =\frac{c e_{B E V}-(2-\beta) c e_{C V}+(2-\beta) r_{V P T}\left(C_{C V}+C R_{N E V}^{-} P_{C R}\right)}{(4-\beta)(1-\beta)}, \\
\tilde{q}_{C V}^{B R}-q_{C V}^{B R} & =\frac{c e_{B E V}-(2-\beta) c e_{C V}+(2-\beta) r_{V P T}\left(C_{C V}+C R_{N E V}^{-} P_{C R}\right)}{(4-\beta)(1-\beta)} .
\end{aligned}
$$

Therefore, $\tilde{q}_{C V}^{N R}-q_{C V}^{N R}<0, \tilde{q}_{C V}^{C V R}-q_{C V}^{C V R}<0, \tilde{q}_{C V}^{B R}-q_{C V}^{B R}<0$ if and only if

$$
c e_{B E V}<(2-\beta)\left[c e_{C V}-\left(C_{C V}+C R_{N E V}^{-} P_{C R}\right)\right] .
$$

\section{Proof of Proposition 8}

Based on Equations (A.3), (A.4), (A.5), (A.9), (A.10), and (A.11), there are:

$$
\begin{aligned}
\widetilde{T C E}^{N R}- & T C E^{N R}=\frac{\left[c e_{B E V}-(2-\beta) c e_{C V}+(2-\beta) r_{V P T}\left(C_{C V}+C R_{N E V}^{-} P_{C R}\right)\right] \beta e_{C V}}{(4-\beta)(1-\beta) \beta} \\
+ & \frac{\left[\beta c e_{C V}-(2-\beta) c e_{B E V}-\beta r_{V P T}\left(C_{C V}+C R_{N E V}^{-} P_{C R}\right)\right] e_{B E V}}{(4-\beta)(1-\beta) \beta}, \\
\widetilde{T C E}^{B R}- & T C E^{B R}=\frac{\left[c e_{B E V}-(2-\beta) c e_{C V}+(2-\beta) r_{V P T}\left(C_{C V}+C R_{N E V}^{-} P_{C R}\right)\right] \beta e_{C V}}{(4-\beta)(1-\beta) \beta} \\
+ & {\left[\frac{\left[\beta c e_{C V}-(2-\beta) c e_{B E V}-\beta r_{V P T}\left(C_{C V}+C R_{N E V}^{-} P_{C R}\right)\right] e_{B E V}}{(4-\beta)(1-\beta) \beta},\right.} \\
\widetilde{T C E}^{C V R}- & T C E^{C V R}=\frac{\left[c e_{B E V}-(2-\beta) c e_{C V}+(2-\beta) r_{V P T}\left(C_{C V}+C R_{N E V}^{-} P_{C R}\right)\right] \beta e_{C V}}{(4-\beta)(1-\beta) \beta} \\
+ & \frac{\left[\beta c e_{C V}-(2-\beta) c e_{B E V}-\beta r_{V P T}\left(C_{C V}+C R_{N E V}^{-} P_{C R}\right)\right] e_{B E V}}{(4-\beta)(1-\beta) \beta} .
\end{aligned}
$$

Therefore, $\widetilde{T C E}^{N R}-T C E^{N R}>0, \widetilde{T C E}^{B R}-T C E^{B R}>0$, and $\widetilde{T C E}^{C V R}-T C E^{C V R}>0$ if and only if $c e_{B E V}<\frac{(2-\beta) e_{C V}-e_{B E V}}{\beta e_{C V}-(2-\beta) e_{B E V}} \beta\left[c e_{C V}-r_{V P T}\left(C_{C V}+C R_{N E V}^{-} P_{C R}\right)\right]$.

\section{Proof of Proposition 9}

Based on Equations (A.6), (A.7), (A.8), (A.12), (A.13), and (A.14), using the method similar to the Proof of Proposition 3, yields the relationship of consumers surplus when different taxes are levied, as summarized in Proposition 9. 


\section{Appendix B: Explicit Expressions}

\section{Appendix B1}

The explicit expressions of the derivatives are as follow:

$$
\begin{aligned}
& \frac{\partial q_{B E V}^{N R}}{\partial r_{V P T}}=\frac{C_{C V}+C R_{N E V}^{-} P_{C R}}{(4-\beta)(1-\beta)}>0, \frac{\partial q_{C V}^{N R}}{\partial r_{V P T}}=-(2-\beta) \frac{C_{C V}+C R_{N E V}^{-} P_{C R}}{(4-\beta)(1-\beta)}<0, \frac{\partial T C E^{N R}}{\partial r_{V P T}}=-\frac{C_{C V}+C R_{N E V}^{-} P_{C R}}{(4-\beta)}<0, \\
& \frac{\partial P_{B E V}^{N R}}{\partial r_{V P T}}=\frac{\beta}{4-\beta}\left(C_{C V}+C R_{N E V}^{-} P_{C R}\right)>0, \frac{\partial \pi_{B E V}^{N R}}{\partial r_{V P T}}=\frac{2\left(C_{C V}+C R_{N E V}^{-} P_{C R}\right)\left[\Lambda_{1}-(4-\beta)(1-\beta) C R_{N E V}^{-} P_{C R}\right]}{(4-\beta)^{2}(1-\beta)}, \\
& \frac{\partial P_{C V}^{N R}}{\partial r_{V P T}}=-\frac{K_{2}-(2-\beta) O_{C V}+2(1-\beta)}{(4-\beta)\left(1+r_{V P T}\right)^{2}}=-\frac{1}{1+r_{V P T}}\left[P_{C V}-\frac{2}{4-\beta}\left(C_{C V}+C R_{N E V}^{-} P_{C R}\right)\right]<0, \\
& \frac{\partial \pi_{C V}^{N R}}{\partial r_{V P T}}=-\frac{\Lambda_{4}\left[2(2-\beta)\left(1+r_{V P T}\right)\left(C_{C V}+C R_{N E V} P_{C R}\right)+\Lambda_{4}\right]}{(4-\beta)^{2}(1-\beta)\left(1+r_{V P T}\right)^{2}}<0, \quad \text { where } \quad \Lambda_{1}=\beta\left(K_{1}+1-\beta\right)-(2-\beta) K_{2}, \\
& \Lambda_{4}=2(1-\beta)-(2-\beta) K_{1}+K_{2}>0 . \\
& \frac{\partial q_{B E V}^{N R}}{\partial O_{B E V}}=\frac{\beta-2}{(4-\beta)(1-\beta) \beta}<0, \frac{\partial q_{C V}^{N R}}{\partial O_{B E V}}=\frac{1}{(4-\beta)(1-\beta)}>0, \quad \frac{\partial P_{B E V}^{N R}}{\partial O_{B E V}}=\frac{\beta-2}{4-\beta}<0, \quad \frac{\partial P_{C V}^{N R}}{\partial O_{B E V}}=\frac{1}{(4-\beta)\left(1+r_{V P T}\right)}> \\
& 0, \frac{\partial \pi_{B E V}^{N R}}{\partial O_{B E V}}=-(2-\beta) \frac{2\left(\beta\left(K_{1}+1-\beta\right)-(2-\beta) K_{2}\right)}{(4-\beta)^{2}(1-\beta) \beta}-\frac{C R_{N E V}^{-} P_{C R}}{4-\beta}<0, \frac{\partial \pi_{C V}^{N R}}{\partial O_{B E V}}=\frac{2\left(2(1-\beta)-(2-\beta) K_{1}+K_{2}\right)}{(4-\beta)^{2}(1-\beta)\left(1+r_{V P T}\right)}>0 . \\
& \frac{\partial q_{B E V}^{N R}}{\partial O_{C V}}=\frac{1}{(4-\beta)(1-\beta) \beta}>0, \frac{\partial q_{C V}^{N R}}{\partial O_{C V}}=\frac{\beta-2}{(4-\beta)(1-\beta)}<0, \quad \frac{\partial P_{B E V}^{N R}}{\partial O_{C V}}=\frac{\beta}{4-\beta}>0, \quad \frac{\partial P_{C V}^{N R}}{\partial O_{C V}}=\frac{\beta-2}{(4-\beta)\left(1+r_{V P T}\right)}<0, \\
& \frac{\partial \pi_{B E V}^{N R}}{\partial O_{C V}}=\frac{2\left(\beta\left(K_{1}+1-\beta\right)-(2-\beta) K_{2}\right)}{(4-\beta)^{2}(1-\beta)}-\frac{2 C R_{N E V}^{-} P_{C R}}{4-\beta}, \frac{\partial \pi_{C V}^{N R}}{\partial O_{C V}}=-(2-\beta) \frac{2\left(2(1-\beta)-(2-\beta) K_{1}+K_{2}\right)}{(4-\beta)^{2}(1-\beta)\left(1+r_{V P T}\right)}<0 . \\
& \frac{\partial C S^{N R}}{\partial O_{B E V}}=\frac{\Delta C S^{N R}-C S^{N R}}{\Delta O_{B E V}}, \text { where } \Delta C S^{N R} \text { represents an increment. }
\end{aligned}
$$

By comparing $f(v)^{N R}$ and $\Delta f(v)^{N R}, \Delta C S^{N R}-C S^{N R}$ can be determined.

$$
\Delta f(v)^{N R}=\left\{\begin{array}{cc}
0 & 0<v<\Delta v_{1}^{N R} \\
\beta v-\frac{\beta\left(K_{1}+1-\beta\right)+2 K_{2}+2 \Delta O_{B E V}}{4-\beta}, & \Delta v_{1}^{N R}<v<\Delta v_{2}^{N R} \\
v-\frac{2\left(K_{1}+1-\beta\right)+K_{2}+\Delta O_{B E V}}{4-\beta} & , \quad \Delta v_{2}^{N R}<v<1
\end{array}\right.
$$

where $\Delta v_{1}^{N R}=\frac{\beta\left(K_{1}+1-\beta\right)+2 K_{2}}{(4-\beta) \beta}$, and $\Delta v_{2}^{N R}=\frac{(2-\beta)\left(K_{1}+1-\beta\right)-K_{2}}{(4-\beta)(1-\beta)}$.

Based on (A.3) and (A.15), there are: $\triangle C S^{N R}-C S^{N R}<0$, and $\frac{\partial C S^{N R}}{\partial O_{B E V}}<0$.

All derivatives with respect to $C S$ in Appendices B1, B2, B3, B4, B5, and B6 can be obtained in the same way. 


\section{Appendix B2}

The explicit expressions of the derivatives are as follow:

$$
\begin{aligned}
& \frac{\partial \tilde{q}_{C V}^{N R}}{\partial O_{B E V}}=\frac{1}{(4-\beta)(1-\beta)}>0, \quad \frac{\partial \tilde{P}_{C V}^{N R}}{\partial O_{B E V}}=\frac{1}{4-\beta}>0, \quad \frac{\partial \widetilde{\pi}_{C V}^{N R}}{\partial O_{B E V}}=\frac{2\left(2(1-\beta)-(2-\beta)\left(\widetilde{K}_{1}+c e_{C V}\right)+K_{2}+c e_{B E V}\right)}{(4-\beta)^{2}(1-\beta)}>0, \\
& \frac{\partial \tilde{q}_{B E V}^{N R}}{\partial O_{B E V}}=\frac{\beta-2}{(4-\beta)(1-\beta) \beta}<0, \frac{\partial \tilde{P}_{B E V}^{N R}}{\partial O_{B E V}}=\frac{\beta-2}{4-\beta}<0, \\
& \frac{\partial \widetilde{\pi}_{B E V}^{N R}}{\partial O_{B E V}}=-(2-\beta) \frac{2\left(\beta\left(\widetilde{K}_{1}+1-\beta+c e_{C V}\right)-(2-\beta)\left(K_{2}+c e_{B E V}\right)\right)}{(4-\beta)^{2}(1-\beta) \beta}-\frac{C R_{N E V}^{-} P_{C R}}{4-\beta}<0 . \\
& \frac{\partial \tilde{q}_{B E V}^{N R}}{\partial O_{C V}}=\frac{1}{(4-\beta)(1-\beta) \beta}>0, \frac{\partial \widetilde{\pi}_{B E V}^{N R}}{\partial O_{C V}}=\frac{2\left(\beta\left(\widetilde{K}_{1}+1-\beta+c e_{C V}\right)-(2-\beta)\left(K_{2}+c e_{B E V}\right)\right)}{(4-\beta)^{2}(1-\beta)}-\frac{2 C R_{N E V}^{-} P_{C R}}{4-\beta}, \\
& \frac{\partial \tilde{q}_{C V}^{N R}}{\partial O_{C V}}=\frac{\beta-2}{(4-\beta)(1-\beta)}<0, \frac{\partial \widetilde{\pi}_{C V}^{N R}}{\partial O_{C V}}=-(2-\beta) \frac{2\left(2(1-\beta)-(2-\beta)\left(\widetilde{K}_{1}+c e_{C V}\right)+K_{2}+c e_{B E V}\right)}{(4-\beta)^{2}(1-\beta)}<0, \\
& \frac{\partial \tilde{P}_{B E V}^{N R}}{\partial O_{C V}}=\frac{\beta}{4-\beta}>0, \frac{\partial \tilde{P}_{C V}^{N R}}{\partial O_{C V}}=\frac{\beta-2}{4-\beta}<0 . \\
& \frac{\partial \tilde{q}_{B E V}^{N R}}{\partial c e_{B E V}}=\frac{\beta-2}{(4-\beta)(1-\beta) \beta}<0, \quad \frac{\partial \tilde{q}_{C V}^{N R}}{\partial c e_{B E V}}=\frac{1}{(4-\beta)(1-\beta)}>0, \quad \frac{\partial \tilde{P}_{B E V}^{N R}}{\partial c e_{B E V}}=\frac{2}{4-\beta}>0, \quad \frac{\partial \tilde{P}_{C V}^{N R}}{\partial c e_{B E V}}=\frac{1}{4-\beta}>0, \\
& \frac{\partial \widetilde{\pi}_{B E V}^{N R}}{\partial c e_{B E V}}=-(2-\beta) \frac{2\left(\beta\left(\widetilde{K}_{1}+1-\beta+c e_{C V}\right)-(2-\beta)\left(K_{2}+c e_{B E V}\right)\right)}{(4-\beta)^{2}(1-\beta) \beta}-\frac{C R_{N E V}^{-} P_{C R}}{4-\beta}<0, \\
& \frac{\partial \widetilde{\pi}_{C V}^{N R}}{\partial c e_{B E V}}=\frac{2\left(2(1-\beta)-(2-\beta)\left(\widetilde{K}_{1}+c e_{C V}\right)+K_{2}+c e_{B E V}\right)}{(4-\beta)^{2}(1-\beta)}>0, \frac{\partial \widetilde{T C E}^{N R}}{\partial c e_{B E V}}=\frac{(2-\beta) c e_{B E V}+\beta c e_{C V}}{(4-\beta)(1-\beta) \beta}+\widetilde{q}_{B E V}^{N R} . \\
& \frac{\partial \tilde{q}_{B E V}^{N R}}{\partial c e_{C V}}=\frac{1}{(4-\beta)(1-\beta) \beta}>0, \frac{\partial \tilde{q}_{C V}^{N R}}{\partial c e_{C V}}=\frac{\beta-2}{(4-\beta)(1-\beta)}<0, \frac{\partial \tilde{P}_{B E V}^{N R}}{\partial c e_{C V}}=\frac{\beta}{4-\beta}>0, \frac{\partial \tilde{P}_{C V}^{N}}{\partial c e_{C V}}=\frac{2}{4-\beta}>0, \frac{\partial \widetilde{\pi}_{B E V}^{N}}{\partial c e_{C V}}= \\
& \frac{2\left(\beta\left(\widetilde{K}_{1}+1-\beta+c e_{C V}\right)-(2-\beta)\left(K_{2}+c e_{B E V}\right)\right)}{(4-\beta)^{2}(1-\beta)}-\frac{2 C R_{N E V}^{-} P_{C R}}{4-\beta}, \\
& \frac{\partial \widetilde{\pi}_{C V}^{N R}}{\partial c e_{C V}}=-(2-\beta) \frac{2\left(2(1-\beta)-(2-\beta)\left(\widetilde{K}_{1}+c e_{C V}\right)+K_{2}+c e_{B E V}\right)}{(4-\beta)^{2}(1-\beta)}<0, \frac{\partial \widetilde{T C E}^{N R}}{\partial c e_{C V}}=\frac{c e_{B E V}-(2-\beta) c e_{C V}}{(4-\beta)(1-\beta)}+\widetilde{q}_{C V}^{N R} .
\end{aligned}
$$

\section{Appendix B3}

The explicit expressions of the derivatives are as follow:

$$
\begin{aligned}
& \frac{\partial q_{B E V}^{C V R}}{\partial l}=\frac{1}{(4-\beta)(1-\beta)}>0, \frac{\partial q_{C V}^{C V R}}{\partial l}=\frac{\beta-2}{(4-\beta)(1-\beta)}<0, \frac{\partial P_{B E V}^{C V R}}{\partial l}=\frac{\beta}{4-\beta}>0, \frac{\partial P_{C V}^{C V R}}{\partial l}=\frac{\beta-2}{(4-\beta)\left(1+r_{V P T}\right)}<0, \\
& \frac{\partial \pi_{B E V}^{C V R}}{\partial l}=\frac{2\left(\beta\left(K_{1}+1-\beta+l\right)-(2-\beta) K_{2}\right)}{(4-\beta)^{2}(1-\beta)}-\frac{2 C R_{N E V}^{-}{ }^{P} C R}{4-\beta}, \quad \frac{\partial \pi_{C V}^{C V R}}{\partial l}=-(2-\beta) \frac{2\left(2(1-\beta)-(2-\beta)\left(K_{1}+l\right)+K_{2}\right)}{(4-\beta)^{2}(1-\beta)\left(1+r_{V P T}\right)}<0, \\
& \frac{\partial T C E C V R}{\partial l}=\frac{c e_{B E V}-(2-\beta) c e_{C V}}{(4-\beta)(1-\beta)}<0 .
\end{aligned}
$$




$$
\begin{aligned}
& \frac{\partial q_{B E V}^{C V R}}{\partial r_{V P T}}=\frac{C_{C V}+C R_{N E V}^{-} P_{C R}}{(4-\beta)(1-\beta)}>0, \quad \frac{\partial q_{C V}^{C V R}}{\partial r_{V P T}}=\frac{(\beta-2)\left(C_{C V}+C R_{N E V}^{-} P_{C R}\right)}{(4-\beta)(1-\beta)}<0, \quad \frac{\partial P_{B E V}^{C V R}}{\partial r_{V P T}}=\frac{\beta\left(C_{C V}+C R_{N E V}^{-} P_{C R}\right)}{4-\beta}>0, \\
& \frac{\partial T C E^{C V R}}{\partial r_{V P T}}=-\frac{C_{C V}+C R_{N E V}^{-} P_{C R}}{(4-\beta)}<0, \frac{\partial \pi_{B E V}^{C V R}}{\partial r_{V P T}}=\frac{2\left(C_{C V}+C R_{N E V}^{-} P_{C R}\right)\left[\Lambda_{2}-(4-\beta)(1-\beta) C R_{N E V}^{-} P_{C R}\right]}{(4-\beta)^{2}(1-\beta)}, \\
& \frac{\partial P_{C V}^{C V R}}{\partial r_{V P T}}=-\frac{K_{2}-(2-\beta)\left(O_{C V}+l\right)+2(1-\beta)}{(4-\beta)\left(1+r_{V P T}\right)^{2}}=-\frac{1}{1+r_{V P T}}\left[P_{C V}-\frac{2}{4-\beta}\left(C_{C V}+C R_{N E V}^{-} P_{C R}\right)\right]<0, \\
& \frac{\partial \pi_{C V}^{C V R}}{\partial r_{V P T}}=-\frac{\Lambda_{5}\left[2(2-\beta)\left(1+r_{V P T}\right)\left(C_{C V}+C R_{N E V}^{-} P_{C R}\right)+\Lambda_{5}\right]}{(4-\beta)^{2}(1-\beta)\left(1+r_{V P T}\right)^{2}}<0, \quad \text { where } \quad \Lambda_{2}=\beta\left(K_{1}+1-\beta+l\right)-(2- \\
& \beta) K_{2}, \Lambda_{5}=2(1-\beta)-(2-\beta)\left(K_{1}+l\right)+K_{2} \text {. } \\
& \frac{\partial q_{B E V}^{C V R}}{\partial O_{B E V}}=\frac{\beta-2}{(4-\beta)(1-\beta) \beta}<0, \frac{\partial q_{C V}^{C V R}}{\partial O_{B E V}}=\frac{1}{(4-\beta)(1-\beta)}>0, \frac{\partial P_{B E V}^{C V R}}{\partial O_{B E V}}=\frac{\beta-2}{4-\beta}<0, \\
& \frac{\partial P_{C V}^{C V R}}{\partial O_{B E V}}=\frac{1}{(4-\beta)\left(1+r_{V P T}\right)}>0, \quad \frac{\partial \pi_{B E V}^{C V R}}{\partial O_{B E V}}=-(2-\beta) \frac{2\left(\beta\left(K_{1}+1-\beta+l\right)-(2-\beta) K_{2}\right)}{(4-\beta)^{2}(1-\beta) \beta}-\frac{C R_{N E V}^{-} P_{C R}}{4-\beta}<0, \quad \frac{\partial \pi_{C V}^{C V R}}{\partial O_{B E V}}= \\
& \frac{2\left(2(1-\beta)-(2-\beta)\left(K_{1}+l\right)+K_{2}\right)}{(4-\beta)^{2}(1-\beta)\left(1+r_{V P T}\right)}>0, \frac{\partial T C E^{C V R}}{\partial O_{B E V}}=\frac{\beta c e_{C V}-(2-\beta) c e_{B E V}}{(4-\beta)(1-\beta) \beta} . \\
& \frac{\partial q_{B E V}^{C V R}}{\partial O_{C V}}=\frac{1}{(4-\beta)(1-\beta) \beta}>0, \frac{\partial q_{C V}^{C V R}}{\partial O_{C V}}=\frac{\beta-2}{(4-\beta)(1-\beta)}<0, \frac{\partial P_{B E V}^{C V R}}{\partial O_{C V}}=\frac{\beta}{4-\beta}>0, \\
& \frac{\partial P_{C V}^{C V R}}{\partial O_{C V}}=\frac{\beta-2}{(4-\beta)\left(1+r_{V P T}\right)}<0, \frac{\partial \pi_{B E V}^{C V R}}{\partial O_{C V}}=\frac{2\left(\beta\left(K_{1}+1-\beta+l\right)-(2-\beta) K_{2}\right)}{(4-\beta)^{2}(1-\beta)}-\frac{2 C R_{N E V}^{-} P_{C R}}{4-\beta}, \\
& \frac{\partial \pi_{C V}^{C V R}}{\partial O_{C V}}=-(2-\beta) \frac{2\left(2(1-\beta)-(2-\beta)\left(K_{1}+l\right)+K_{2}\right)}{(4-\beta)^{2}(1-\beta)\left(1+r_{V P T}\right)}<0, \frac{\partial T C E^{C V R}}{\partial O_{C V}}=\frac{c e_{B E V}-(2-\beta) c e_{C V}}{(4-\beta)(1-\beta)}<0 .
\end{aligned}
$$

\section{Appendix B4}

The explicit expressions of the derivatives are as follow:

$$
\begin{aligned}
& \frac{\partial \tilde{q}_{B E V}^{C V R}}{\partial l}=\frac{1}{(4-\beta)(1-\beta)}>0, \frac{\partial \tilde{q}_{C V}^{C V R}}{\partial l}=\frac{\beta-2}{(4-\beta)(1-\beta)}<0, \frac{\partial \tilde{P}_{B E V}^{C V R}}{\partial l}=\frac{\beta}{4-\beta}>0, \frac{\partial \tilde{P}_{C V}^{C V R}}{\partial l}=\frac{\beta-2}{4-\beta}<0, \\
& \frac{\partial \widetilde{\pi}_{B E V}^{C V R}}{\partial l}=\frac{2\left(\beta\left(\widetilde{K}_{1}+1-\beta+l+c e_{C V}\right)-(2-\beta)\left(K_{2}+c e_{B E V}\right)\right.}{(4-\beta)^{2}(1-\beta)}-\frac{2 C R_{N E V}^{-} P_{C R}}{4-\beta}, \\
& \frac{\partial \widetilde{\pi}_{C V}^{C V R}}{\partial t}=-(2-\beta) \frac{2\left(2(1-\beta)-(2-\beta)\left(\widetilde{K}_{1}+l+c e_{C V}\right)+K_{2}+c e_{B E V}\right)}{(4-\beta)^{2}(1-\beta)}<0, \quad \frac{\partial \widetilde{T C E}^{C V R}}{\partial t}=\frac{c e_{B E V}-(2-\beta) c e_{C V}}{(4-\beta)(1-\beta)}<0 . \\
& \frac{\partial \tilde{q}_{B E V}^{C V R}}{\partial O_{B E V}}=\frac{\beta-2}{(4-\beta)(1-\beta) \beta}<0, \quad \frac{\partial \tilde{q}_{C V}^{C V R}}{\partial O_{B E V}}=\frac{1}{(4-\beta)(1-\beta)}>0, \quad \frac{\partial \tilde{P}_{B E V}^{C V R}}{\partial O_{B E V}}=\frac{\beta-2}{4-\beta}<0, \quad \frac{\partial \tilde{P}_{C V}^{C V R}}{\partial O_{B E V}}=\frac{1}{4-\beta}>0, \\
& \frac{\partial \widetilde{\pi}_{B E V}^{C V R}}{\partial O_{B E V}}=-(2-\beta) \frac{2\left(\beta\left(\widetilde{K}_{1}+1-\beta+l+c e_{C V}\right)-(2-\beta)\left(K_{2}+c e_{B E V}\right)\right)}{(4-\beta)^{2}(1-\beta) \beta}-\frac{C R_{N E V}^{-} P_{C R}}{4-\beta}<0, \\
& \frac{\partial \widetilde{\pi}_{C V}^{C V R}}{\partial O_{B E V}}=\frac{2\left(2(1-\beta)-(2-\beta)\left(\widetilde{K}_{1}+l+c e_{C V}\right)+K_{2}+c e_{B E V}\right)}{(4-\beta)^{2}(1-\beta)}>0, \frac{\partial \widetilde{T C E}^{C V R}}{\partial O_{B E V}}=\frac{\beta c e_{C V}-(2-\beta) c e_{B E V}}{(4-\beta)(1-\beta) \beta} . \\
& \frac{\partial \tilde{q}_{B E V}^{C V R}}{\partial O_{C V}}=\frac{1}{(4-\beta)(1-\beta) \beta}>0, \frac{\partial \tilde{q}_{C V}^{C V R}}{\partial O_{C V}}=\frac{\beta-2}{(4-\beta)(1-\beta)}<0, \frac{\partial \tilde{P}_{B E V}^{C V R}}{\partial O_{C V}}=\frac{\beta}{4-\beta}>0, \frac{\partial \tilde{P}_{C V}^{C V R}}{\partial O_{C V}}=\frac{\beta-2}{4-\beta}<0, \frac{\partial \widetilde{\pi}_{B E V}^{C V R}}{\partial O_{C V}}=
\end{aligned}
$$




$$
\begin{aligned}
& \frac{2\left(\beta\left(\widetilde{K}_{1}+1-\beta+l+c e_{C V}\right)-(2-\beta)\left(K_{2}+c e_{B E V}\right)\right)}{(4-\beta)^{2}(1-\beta)}-\frac{2 C R_{N E V}^{-} P_{C R}}{4-\beta}, \\
& \frac{\partial \widetilde{\pi}_{C V}^{C V R}}{\partial O_{C V}}=-(2-\beta) \frac{2\left(2(1-\beta)-(2-\beta)\left(\widetilde{K}_{1}+l+c e_{C V}\right)+K_{2}+c e_{B E V}\right)}{(4-\beta)^{2}(1-\beta)}<0, \quad \frac{\partial T \widetilde{T C E}^{C V R}}{\partial O_{C V}}=\frac{c e_{B E V}-(2-\beta) c e_{C V}}{(4-\beta)(1-\beta)}<0 . \\
& \frac{\partial \tilde{q}_{B E V}^{C V R}}{\partial c e_{B E V}}=\frac{\beta-2}{(4-\beta)(1-\beta) \beta}<0, \quad \frac{\partial \tilde{q}_{C V}^{C V R}}{\partial c e_{B E V}}=\frac{1}{(4-\beta)(1-\beta)}>0, \quad \frac{\partial \tilde{P}_{B E V}^{C V R}}{\partial c e_{B E V}}=\frac{2}{4-\beta}>0, \quad \frac{\partial \tilde{P}_{C V}^{C V R}}{\partial c e_{B E V}}=\frac{1}{4-\beta}>0, \\
& \frac{\partial \widetilde{\pi}_{B E V}^{C V R}}{\partial c e_{B E V}}=-(2-\beta) \frac{2\left(\beta\left(\widetilde{K}_{1}+1-\beta+l+c e_{C V}\right)-(2-\beta)\left(K_{2}+c e_{B E V}\right)\right)}{(4-\beta)^{2}(1-\beta) \beta}-\frac{C R_{N E V}^{-} P_{C R}}{4-\beta}<0, \\
& \frac{\partial \widetilde{\pi}_{C V}^{C V R}}{\partial c e_{B E V}}=\frac{2\left(2(1-\beta)-(2-\beta)\left(\widetilde{K}_{1}+l+c e_{C V}\right)+K_{2}+c e_{B E V}\right)}{(4-\beta)^{2}(1-\beta)}>0, \quad \frac{\partial \widetilde{T C E}^{C V R}}{\partial c e_{B E V}}=\frac{(2-\beta) c e_{B E V}+\beta c e_{C V}}{(4-\beta)(1-\beta) \beta}+\widetilde{q}_{B E V}^{C V R} . \quad \frac{\partial \tilde{q}_{B E V}^{C V R}}{\partial c e_{C V}}= \\
& \frac{1}{(4-\beta)(1-\beta) \beta}>0, \quad \frac{\partial \tilde{q}_{C V}^{C V R}}{\partial c e_{C V}}=\frac{\beta-2}{(4-\beta)(1-\beta)}<0, \quad \frac{\partial \tilde{P}_{B E V}^{C V R}}{\partial c e_{C V}}=\frac{\beta}{4-\beta}>0, \quad \frac{\partial \tilde{P}_{C V}^{C V R}}{\partial c e_{C V}}=\frac{2}{4-\beta}>0, \quad \frac{\partial \widetilde{\pi}_{B E V}^{C V R}}{\partial c e_{C V}}= \\
& \frac{2\left(\beta\left(\widetilde{K}_{1}+1-\beta+l+c e_{C V}\right)-(2-\beta)\left(K_{2}+c e_{B E V}\right)\right)}{(4-\beta)^{2}(1-\beta)}-\frac{2 C R_{N E V}^{-} P_{C R}}{4-\beta}, \\
& \frac{\partial \widetilde{\pi}_{C V}^{C V R}}{\partial c e_{C V}}=-(2-\beta) \frac{2\left(2(1-\beta)-(2-\beta)\left(\widetilde{K}_{1}+l+c e_{C V}\right)+K_{2}+c e_{B E V}\right)}{(4-\beta)^{2}(1-\beta)}<0, \frac{\partial \widetilde{T C E}_{C V R}}{\partial c e_{C V}}=\frac{c e_{B E V}-(2-\beta) c e_{C V}}{(4-\beta)(1-\beta)}+\widetilde{q}_{C V}^{C V R} .
\end{aligned}
$$

\section{Appendix B5}

The explicit expressions of the derivatives are as follow:

$$
\begin{aligned}
& \frac{\partial q_{B E V}^{B R}}{\partial l}=\frac{1}{(4-\beta)(1-\beta)}>0, \quad \frac{\partial q_{C V}^{B R}}{\partial l}=\frac{\beta-2}{(4-\beta)(1-\beta)}<0, \quad \frac{\partial P_{B E V}^{B R}}{\partial l}=\frac{\beta}{4-\beta}>0, \quad \frac{\partial P_{C V}^{B R}}{\partial l}=\frac{\beta-2}{(4-\beta)\left(1+r_{V P T}\right)}<0, \\
& \frac{\partial \pi_{B E V}^{B R}}{\partial l}=\frac{2\left(\beta\left(K_{1}+1-\beta+l\right)-(2-\beta) K_{2}\right)}{(4-\beta)^{2}(1-\beta)}, \frac{\partial \pi_{C V}^{B R}}{\partial l}=-(2-\beta) \frac{2\left(2(1-\beta)-(2-\beta)\left(K_{1}+l\right)+K_{2}\right)}{(4-\beta)^{2}(1-\beta)\left(1+r_{V P T}\right)}<0, \\
& \frac{\partial T C E}{\partial l}=\frac{c e_{B E V}-(2-\beta) c e_{C V}}{(4-\beta)(1-\beta)}<0 . \\
& \frac{\partial q_{B E V}^{B R}}{\partial r_{V P T}}=\frac{C_{C V}+C R_{N E V}^{-} P_{C R}}{(4-\beta)(1-\beta)}>0, \quad \frac{\partial q_{C V}^{B R}}{\partial r_{V P T}}=\frac{(\beta-2)\left(C_{C V}+C R_{N E V}^{-} P_{C R}\right)}{(4-\beta)(1-\beta)}<0, \quad \frac{\partial P_{B E V}^{B R}}{\partial r_{V P T}}=\frac{\beta\left(C_{C V}+C R_{N E V}^{-} P_{C R}\right)}{4-\beta}>0, \\
& \frac{\partial \pi_{B E V}^{B R}}{\partial r_{V P T}}=\frac{2\left(C_{C V}+C R_{N E V}^{-} P_{C R}\right)\left[\Lambda_{3}-(4-\beta)(1-\beta) C R_{N E V}^{-} P_{C R}\right]}{(4-\beta)^{2}(1-\beta)}, \frac{\partial T C E^{B R}}{\partial r_{V P T}}=-\frac{C_{C V}+C R_{N E V}^{-} P_{C R}}{(4-\beta)}<0, \\
& \frac{\partial P_{C V}^{B R}}{\partial r_{V P T}}=-\frac{K_{2}-(2-\beta)\left(O_{C V}+l\right)+2(1-\beta)}{(4-\beta)\left(1+r_{V P T}\right)^{2}}=-\frac{1}{1+r_{V P T}}\left[P_{C V}-\frac{2}{4-\beta}\left(C_{C V}+C R_{N E V}^{-} P_{C R}\right)\right]<0, \\
& \frac{\partial \pi_{C V}^{B R}}{\partial r_{V P T}}=-\frac{\Lambda_{6}\left[2(2-\beta)\left(1+r_{V P T}\right)\left(C_{C V}+C R_{N E V}^{-} P C R+\Lambda_{6}\right]\right.}{(4-\beta)^{2}(1-\beta)\left(1+r_{V P T}\right)^{2}}<0, \quad \text { where } \quad \Lambda_{3}=\beta\left(K_{1}+1-\beta+l\right)-(2- \\
& \beta)\left(K_{2}+l\right), \Lambda_{6}=2(1-\beta)-(2-\beta)\left(K_{1}+l\right)+K_{2}+l . \\
& \frac{\partial q_{B E V}^{B R}}{\partial O_{B E V}}=\frac{\beta-2}{(4-\beta)(1-\beta) \beta}<0, \frac{\partial q_{C V}^{B R}}{\partial O_{B E V}}=\frac{1}{(4-\beta)(1-\beta)}>0, \frac{\partial P_{B E V}^{B R}}{\partial O_{B E V}}=\frac{\beta-2}{4-\beta}<0, \\
& \frac{\partial P_{C V}^{B R}}{\partial O_{B E V}}=\frac{1}{(4-\beta)\left(1+r_{V P T}\right)}>0, \frac{\partial \pi_{B E V}^{B R}}{\partial O_{B E V}}=-(2-\beta) \frac{2\left(\beta\left(K_{1}+1-\beta+l\right)-(2-\beta) K_{2}\right)}{(4-\beta)^{2}(1-\beta) \beta}-\frac{C R_{N E V}^{-} P_{C R}}{4-\beta}<0, \quad \frac{\partial \pi_{C V}^{B R}}{\partial O_{B E V}}=
\end{aligned}
$$




$$
\begin{aligned}
& \frac{2\left(2(1-\beta)-(2-\beta)\left(K_{1}+l\right)+K_{2}\right)}{(4-\beta)^{2}(1-\beta)\left(1+r_{V P T}\right)}>0, \quad \frac{\partial T C E^{B R}}{\partial O_{B E V}}=\frac{\beta c e_{C V}-(2-\beta) c e_{B E V}}{(4-\beta)(1-\beta) \beta} . \quad \frac{\partial q_{B E V}^{B R}}{\partial O_{C V}}=\frac{1}{(4-\beta)(1-\beta) \beta}>0, \quad \frac{\partial q_{C V}^{B R}}{\partial O_{C V}}= \\
& \frac{\beta-2}{(4-\beta)(1-\beta)}<0, \frac{\partial P_{B E V}^{B R}}{\partial O_{C V}}=\frac{\beta}{4-\beta}>0, \frac{\partial P_{C V}^{B R}}{\partial O_{C V}}=\frac{\beta-2}{(4-\beta)\left(1+r_{V P T}\right)}<0, \\
& \frac{\partial \pi_{B E V}^{B R}}{\partial O_{C V}}=\frac{2\left(\beta\left(K_{1}+1-\beta+l\right)-(2-\beta) K_{2}\right)}{(4-\beta)^{2}(1-\beta)}-\frac{2 C R_{N E V}^{-}{ }_{C R}}{4-\beta}, \quad \frac{\partial \pi_{C V}^{B R}}{\partial O_{C V}}=-(2-\beta) \frac{2\left(2(1-\beta)-(2-\beta)\left(K_{1}+l\right)+K_{2}\right)}{(4-\beta)^{2}(1-\beta)\left(1+r_{V P T}\right)}<0, \\
& \frac{\partial T C E^{B R}}{\partial O_{C V}}=\frac{c e_{B E V}-(2-\beta) c e_{C V}}{(4-\beta)(1-\beta)}<0 .
\end{aligned}
$$

\section{Appendix B6}

The explicit expressions of the derivatives are as follow:

$$
\begin{aligned}
& \frac{\partial \tilde{q}_{B E V}^{B R}}{\partial l}=\frac{1}{(4-\beta)(1-\beta)}>0, \frac{\partial \tilde{q}_{C V}^{B R}}{\partial l}=\frac{\beta-2}{(4-\beta)(1-\beta)}<0, \frac{\partial \tilde{P}_{B E V}^{B R}}{\partial l}=\frac{\beta}{4-\beta}>0, \frac{\partial \tilde{P}_{C V}^{B R}}{\partial l}=\frac{\beta-2}{4-\beta}<0, \\
& \frac{\partial \widetilde{\pi}_{B E V}^{B R}}{\partial l}=\frac{2\left(\beta\left(\widetilde{K}_{1}+1-\beta+l+c e_{C V}\right)-(2-\beta)\left(K_{2}+c e_{B E V}\right)\right)}{(4-\beta)^{2}(1-\beta)}-\frac{3 C R_{N E V}^{-} P_{C R}}{4-\beta}, \\
& \frac{\partial \widetilde{\pi}_{C V}^{B R}}{\partial l}=-(2-\beta) \frac{2\left(2(1-\beta)-(2-\beta)\left(\widetilde{K}_{1}+l+c e_{C V}\right)+K_{2}+c e_{B E V}\right)}{(4-\beta)^{2}(1-\beta)}<0, \quad \frac{\partial \widetilde{T C E}^{B R}}{\partial l}=\frac{c e_{B E V}-(2-\beta) c e_{C V}}{(4-\beta)(1-\beta)}<0 . \\
& \frac{\partial \tilde{q}_{B E V}^{B R}}{\partial O_{B E V}}=\frac{\beta-2}{(4-\beta)(1-\beta) \beta}<0, \quad \frac{\partial \tilde{q}_{C V}^{B R}}{\partial O_{B E V}}=\frac{1}{(4-\beta)(1-\beta)}>0, \quad \frac{\partial \tilde{P}_{B E V}^{B R}}{\partial O_{B E V}}=\frac{\beta-2}{4-\beta}<0, \quad \frac{\partial \tilde{P}_{C V}^{B R}}{\partial O_{B E V}}=\frac{1}{4-\beta}>0, \\
& \frac{\partial \widetilde{\pi}_{B E V}^{B R}}{\partial O_{B E V}}=-(2-\beta) \frac{2\left(\beta\left(\widetilde{K}_{1}+1-\beta+l+c e_{C V}\right)-(2-\beta)\left(K_{2}+c e_{B E V}\right)\right)}{(4-\beta)^{2}(1-\beta) \beta}-\frac{C R_{N E V}^{-} P_{C R}}{4-\beta}<0, \\
& \frac{\partial \widetilde{\pi}_{C V}^{B R}}{\partial O_{B E V}}=\frac{2\left(2(1-\beta)-(2-\beta)\left(\widetilde{K}_{1}+l+c e_{C V}\right)+K_{2}+c e_{B E V}\right)}{(4-\beta)^{2}(1-\beta)}>0, \frac{\partial \widetilde{T C E}^{B R}}{\partial O_{B E V}}=\frac{\beta c e_{C V}-(2-\beta) c e_{B E V}}{(4-\beta)(1-\beta) \beta} . \\
& \frac{\partial \tilde{q}_{B E V}^{B R}}{\partial O_{C V}}=\frac{1}{(4-\beta)(1-\beta) \beta}>0, \frac{\partial \tilde{q}_{C V}^{B R}}{\partial O_{C V}}=\frac{\beta-2}{(4-\beta)(1-\beta)}<0, \frac{\partial \tilde{P}_{B E V}^{B R}}{\partial O_{C V}}=\frac{\beta}{4-\beta}>0, \frac{\partial \tilde{P}_{C V}^{B R}}{\partial O_{C V}}=\frac{\beta-2}{4-\beta}<0, \\
& \frac{\partial \widetilde{\pi}_{B E V}^{B R}}{\partial O_{C V}}=\frac{2\left(\beta\left(\widetilde{K}_{1}+1-\beta+l+c e_{C V}\right)-(2-\beta)\left(K_{2}+c e_{B E V}\right)\right)}{(4-\beta)^{2}(1-\beta)}-\frac{2 C R_{N E V}^{-} P_{C R}}{4-\beta}, \\
& \frac{\partial \widetilde{\pi}_{C V}^{B R}}{\partial O_{C V}}=-(2-\beta) \frac{2\left(2(1-\beta)-(2-\beta)\left(\widetilde{K}_{1}+l+c e_{C V}\right)+K_{2}+c e_{B E V}\right)}{(4-\beta)^{2}(1-\beta)}<0, \quad \frac{\partial \widetilde{T C E}^{B R}}{\partial O_{C V}}=\frac{c e_{B E V}-(2-\beta) c e_{C V}}{(4-\beta)(1-\beta)}<0 . \\
& \frac{\partial \tilde{q}_{B E V}^{B R}}{\partial c e_{B E V}}=\frac{\beta-2}{(4-\beta)(1-\beta) \beta}<0, \quad \frac{\partial \tilde{q}_{C V}^{B R}}{\partial c e_{B E V}}=\frac{1}{(4-\beta)(1-\beta)}>0, \quad \frac{\partial \tilde{P}_{B E V}^{B R}}{\partial c e_{B E V}}=\frac{2}{4-\beta}>0, \quad \frac{\partial \tilde{P}_{C V}^{B R}}{\partial c e_{B E V}}=\frac{1}{4-\beta}>0, \\
& \frac{\partial \widetilde{\pi}_{B E V}^{B R}}{\partial c e_{B E V}}=-(2-\beta) \frac{2\left(\beta\left(\widetilde{K}_{1}+1-\beta+l+c e_{C V}\right)-(2-\beta)\left(K_{2}+c e_{B E V}\right)\right)}{(4-\beta)^{2}(1-\beta) \beta}-\frac{C R_{N E V}^{-} P_{C R}}{4-\beta}<0, \\
& \frac{\partial \widetilde{\pi}_{C V}^{B R}}{\partial c e_{B E V}}=\frac{2\left(2(1-\beta)-(2-\beta)\left(\widetilde{K}_{1}+l+c e_{C V}\right)+K_{2}+c e_{B E V}\right)}{(4-\beta)^{2}(1-\beta)}>0, \frac{\partial \widetilde{T C E}^{B R}}{\partial c e_{B E V}}=\frac{(2-\beta) c e_{B E V}+\beta c e_{C V}}{(4-\beta)(1-\beta) \beta}+\widetilde{q}_{B E V}^{B R} . \\
& \frac{\partial \tilde{q}_{B E V}^{B R}}{\partial c e_{C V}}=\frac{1}{(4-\beta)(1-\beta) \beta}>0, \frac{\partial \tilde{q}_{C V}^{B R}}{\partial c e_{C V}}=\frac{\beta-2}{(4-\beta)(1-\beta)}<0, \frac{\partial \tilde{P}_{B E V}^{B R}}{\partial c e_{C V}}=\frac{\beta}{4-\beta}>0, \frac{\partial \tilde{P}_{C V}^{B R}}{\partial c e_{C V}}=\frac{2}{4-\beta}>0, \\
& \frac{\partial \widetilde{\pi}_{B E V}^{B R}}{\partial c e_{C V}}=\frac{2\left(\beta\left(\widetilde{K}_{1}+1-\beta+l+c e_{C V}\right)-(2-\beta)\left(K_{2}+c e_{B E V}\right)\right)}{(4-\beta)^{2}(1-\beta)}-\frac{2 C R_{N E V}^{-} P_{C R}}{4-\beta},
\end{aligned}
$$


$\frac{\partial \widetilde{\pi}_{C V}^{B R}}{\partial c e_{C V}}=-(2-\beta) \frac{2\left(2(1-\beta)-(2-\beta)\left(\widetilde{K}_{1}+l+c e_{C V}\right)+K_{2}+c e_{B E V}\right)}{(4-\beta)^{2}(1-\beta)}<0, \frac{\partial \widetilde{T C E}^{B R}}{\partial c e_{C V}}=\frac{c e_{B E V}-(2-\beta) c e_{C V}}{(4-\beta)(1-\beta)}+\tilde{q}_{C V}^{B R}$ 


\section{Appendix C: Higher BEV Valuation}

When consumers value BEV higher than $\mathrm{CV}$, the demand functions in Lemmas 1, 2, and 3 yield

the optimal retail prices, sales volumes, and manufacturers profits as summarized in the following Lemmas.

\section{Lemma C1: No restrictions}

$$
\begin{aligned}
P_{B E V}^{N R}= & \frac{\beta\left(K_{1}+2 \beta-2+2 K_{2}\right)}{4 \beta-1}-O_{B E V}+s, \\
q_{B E V}^{N R} & =\frac{\beta\left(K_{1}+2 \beta-2\right)-(2 \beta-1) K_{2}}{(4 \beta-1)(\beta-1)}, \\
\pi_{B E V}^{N R} & =\frac{\left[\beta\left(K_{1}+2 \beta-2\right)-(2 \beta-1) K_{2}\right]^{2}}{(4 \beta-1)^{2}(\beta-1)} \\
& +C R_{N E V}^{-} P_{C R} \frac{3 \beta-2 K_{1}-K_{2}}{4 \beta-1}, \\
P_{C V}^{N R}= & \frac{\left(2 \beta K_{1}+\beta-1+K_{2}\right)}{(4 \beta-1)\left(1+r_{V P T}\right)}-\frac{O_{C V}}{1+r_{V P T}}, \\
q_{C V}^{N R} & =\frac{\beta\left[\beta-1-(2 \beta-1) K_{1}+K_{2}\right]}{(4 \beta-1)(\beta-1)}, \\
\pi_{C V}^{N R}= & \frac{\beta^{2}\left[2(\beta-1)-(2 \beta-1) K_{1}+K_{2}\right]^{2}}{(4 \beta-1)^{2}(\beta-1)\left(1+r_{V P T}\right)} .
\end{aligned}
$$

Note: $K_{1}=\left(1+r_{V P T}\right)\left(C_{C V}+C R_{N E V}^{-} P_{C R}\right)+O_{C V}$ and $K_{2}=C_{B E V}+C R_{N E V}^{-} P_{C R}+O_{B E V}-s$.

\section{Lemma C2: Restricting CV}




$$
\begin{aligned}
P_{B E V}^{C V R}= & \frac{\beta\left(K_{1}+l+2 \beta-2+2 K_{2}\right)}{4 \beta-1}-O_{B E V}+s, \\
q_{B E V}^{C V R} & =\frac{\beta\left(K_{1}+2 \beta-2+l\right)-(2 \beta-1) K_{2}}{(4 \beta-1)(\beta-1)}, \\
\pi_{B E V}^{C V R} & =\frac{\left[\beta\left(K_{1}+2 \beta-2+l\right)-(2 \beta-1) K_{2}\right]^{2}}{(4 \beta-1)^{2}(\beta-1)} \\
& +\mathrm{CR}_{\mathrm{NEV}}^{-} P_{C R} \frac{3 \beta-2 K_{1}-K_{2}-2 l}{4 \beta-1} \\
P_{C V}^{C V R}= & \frac{\left(2 \beta\left(K_{1}+l\right)+\beta-1+K_{2}\right)}{(4 \beta-1)\left(1+r_{V P T}\right)}-\frac{O_{C V}+l}{1+r_{V P T}}, \\
q_{C V}^{C V R} & =\frac{\beta\left[\beta-1-(2 \beta-1)\left(K_{1}+l\right)+K_{2}\right]}{(4 \beta-1)(\beta-1)}, \\
\pi_{C V}^{C V R}= & \frac{\beta^{2}\left[2(\beta-1)-(2 \beta-1)\left(K_{1}+l\right)+K_{2}\right]^{2}}{(4 \beta-1)^{2}(\beta-1)\left(1+r_{V P T}\right)} .
\end{aligned}
$$

Note: $K_{1}=\left(1+r_{V P T}\right)\left(C_{C V}+C R_{N E V}^{-} P_{C R}\right)+O_{C V}$ and $K_{2}=C_{B E V}+C R_{N E V}^{-} P_{C R}+O_{B E V}-s$.

\section{Lemma C3: Restricting both BEV and CV}

$$
\begin{aligned}
P_{B E V}^{B R}= & \frac{\beta\left(K_{1}+3 l+2 \beta-2+2 K_{2}\right)}{4 \beta-1}-O_{B E V}+s-l, \\
q_{B E V}^{B R} & =\frac{\beta\left(K_{1}+2 \beta-2+l\right)-(2 \beta-1)\left(K_{2}+l\right)}{(4 \beta-1)(\beta-1)}, \\
\pi_{B E V}^{B R}= & \frac{\left[\beta\left(K_{1}+2 \beta-2+l\right)-(2 \beta-1)\left(K_{2}+l\right)\right]^{2}}{(4 \beta-1)^{2}(\beta-1)} \\
& +\mathrm{CR}_{\mathrm{NEV}}^{-} P_{C R} \frac{3 \beta-2 K_{1}-K_{2}-3 l}{4 \beta-1}, \\
P_{C V}^{B R}= & \frac{\left(2 \beta\left(K_{1}+l\right)+\beta-1+K_{2}+l\right)}{(4 \beta-1)\left(1+r_{V P T}\right)}-\frac{O_{C V}+l}{1+r_{V P T}}, \\
q_{C V}^{B R} & =\frac{\beta\left[\beta-1-(2 \beta-1)\left(K_{1}+l\right)+K_{2}+l\right]}{(4 \beta-1)(\beta-1)}, \\
\pi_{C V}^{B R}= & \frac{\beta^{2}\left[2(\beta-1)-(2 \beta-1)\left(K_{1}+l\right)+K_{2}+l\right]^{2}}{(4 \beta-1)^{2}(\beta-1)\left(1+r_{V P T}\right)} .
\end{aligned}
$$

Note: $K_{1}=\left(1+r_{V P T}\right)\left(C_{C V}+C R_{N E V}^{-} P_{C R}\right)+O_{C V}$ and $K_{2}=C_{B E V}+C R_{N E V}^{-} P_{C R}+O_{B E V}-s$.

\section{Proposition C1}

(a) Based on Lemmas $\mathrm{C} 1, \mathrm{C} 2$, and $\mathrm{C} 3$, there are:

$$
\begin{aligned}
q_{B E V}^{C V R}-q_{B E V}^{N R}=\frac{\beta l}{(4 \beta-1)(\beta-1)} & >0, q_{B E V}^{B R}-q_{B E V}^{N R}=\frac{-l}{(4-\beta)}<0, \\
& q_{B E V}^{C V R}-q_{B E V}^{B R}=q_{B E V}^{C V R}-q_{B E V}^{N R}-\left(q_{B E V}^{B R}-q_{B E V}^{N R}\right)>0 .
\end{aligned}
$$


Based on Lemmas C1, C2, and C3, there are:

$q_{C V}^{C V R}-q_{C V}^{N R}=-l \frac{(2 \beta-1) \beta}{(4 \beta-1)(\beta-1)}<0, q_{C V}^{B R}-q_{C V}^{N R}=\frac{-2 \beta l}{4 \beta-1}<0, q_{C V}^{C V R}-q_{C V}^{B R}=\frac{-\beta l}{(4 \beta-1)(\beta-1)}<0$.

(b) Based on Lemmas C1, C2, and C3, there are:

$$
\begin{gathered}
\pi_{B E V}^{B R}-\pi_{B E V}^{N R}=-l \frac{\Lambda_{1}+\Lambda_{3}}{(4 \beta-1)^{2}}-\frac{3 l C R_{N E V}^{-} P_{C R}}{4 \beta-1}<0, \\
\pi_{B E V}^{C V R}-\pi_{B E V}^{B R}=(2 \beta-1) l \frac{\Lambda_{2}+\Lambda_{3}}{(4 \beta-1)^{2}(\beta-1)}+\frac{l C R_{N E V}^{-} P_{C R}}{4 \beta-1}>0 \\
\pi_{B E V}^{C V R}-\pi_{B E V}^{N R}=\beta l \frac{\Lambda_{1}+\Lambda_{2}}{(4 \beta-1)^{2}(\beta-1)}-\frac{2 l C R_{N E V}^{-} P_{C R}}{4 \beta-1}
\end{gathered}
$$

Therefore, $\pi_{B E V}^{C V R}-\pi_{B E V}^{N R}>0$ if and only if $\frac{\beta l}{2}>C R_{N E V}^{-} P_{C R}(4 \beta-1)(\beta-1)-\beta \Lambda_{1}$, where $\Lambda_{1}=\beta\left(K_{1}+2 \beta-2\right)-(2 \beta-1) K_{2}>0, \Lambda_{2}=\beta\left(K_{1}+2 \beta-2+l\right)-(2 \beta-1) K_{2}>0$, and $\Lambda_{3}=\beta\left(K_{1}+2 \beta-2+l\right)-(2 \beta-1)\left(K_{2}+l\right)>0$.

Based on Lemmas C1, C2, and C3, there are:

$$
\begin{gathered}
\pi_{C V}^{C V R}-\pi_{C V}^{N R}=-(2 \beta-1) \beta^{2} l \frac{\Lambda_{4}+\Lambda_{5}}{(4 \beta-1)^{2}(\beta-1)\left(1+r_{V P T}\right)}<0, \\
\pi_{C V}^{B R}-\pi_{C V}^{N R}=-l 2 \beta^{2} \frac{\Lambda_{4}+\Lambda_{6}}{(4 \beta-1)^{2}\left(1+r_{V P T}\right)}<0, \pi_{C V}^{C V R}-\pi_{C V}^{B R}=-l \beta^{2} \frac{\Lambda_{5}+\Lambda_{6}}{(4 \beta-1)(\beta-1)\left(1+r_{V P T}\right)}<0,
\end{gathered}
$$

where $\Lambda_{4}=2(\beta-1)-(2 \beta-1) K_{1}+K_{2}>0, \Lambda_{5}=2(\beta-1)-(2 \beta-1)\left(K_{1}+l\right)+K_{2}>0$, and $\Lambda_{6}=2(\beta-1)-(2 \beta-1)\left(K_{1}+l\right)+K_{2}+l>0$.

(c) Substituting Demands in Lemmas C1, C2, and C3 into Equation (6) yields the total carbon emission under different traffic restriction policies:

$$
\begin{gathered}
T C E^{N R}=\frac{\beta\left(K_{1}+2 \beta-2\right)-(2 \beta-1) K_{2}}{(4 \beta-1)(\beta-1)} e_{B E V} \\
+\frac{\beta\left[\beta-1-(2 \beta-1) K_{1}+K_{2}\right]}{(4 \beta-1)(\beta-1)} e_{C V}, \\
T C E^{C V R}=\frac{\beta\left(K_{1}+2 \beta-2+l\right)-(2 \beta-1) K_{2}}{(4 \beta-1)(\beta-1)} e_{B E V} \\
+\frac{\beta\left[\beta-1-(2 \beta-1)\left(K_{1}+l\right)+K_{2}\right]}{(4 \beta-1)(\beta-1)} e_{C V},
\end{gathered}
$$




$$
\begin{gathered}
T C E^{B R}=\frac{\beta\left(K_{1}+2 \beta-2+l\right)-(2 \beta-1)\left(K_{2}+l\right)}{(4 \beta-1)(\beta-1)} e_{B E V} \\
+\frac{\beta\left[\beta-1-(2 \beta-1)\left(K_{1}+l\right)+K_{2}+l\right]}{(4 \beta-1)(\beta-1)} e_{C V},
\end{gathered}
$$

Based on Lemmas $\mathrm{C} 1, \mathrm{C} 2$, and $\mathrm{C} 3$, there are:

$$
\begin{gathered}
T C E^{C V R}-T C E^{N R}=\frac{l}{(4 \beta-1)(\beta-1)}\left(\beta e_{B E V}-(2 \beta-1) e_{C V}\right)<0, \\
T C E^{B R}-T C E^{N R}=-\frac{l}{4 \beta-1}\left(e_{B E V}+2 \beta e_{C V}\right)<0, \\
T C E^{C V R}-T C E^{B R}=\frac{l}{(4 \beta-1)(\beta-1)}\left((2 \beta-1) e_{B E V}-\beta e_{C V}\right) .
\end{gathered}
$$

Therefore, $T C E^{C V R}<T C E^{B R}$ if and only if $e_{B E V}<\frac{\beta}{2 \beta-1} e_{C V}$. 


\section{Appendix D: Regulatory Fines}

When the regulatory fines are introduced, the profit functions in Lemmas 1, 2, and 3 yield the optimal retail prices, sales volumes, and manufacturers profits as summarized in the following Lemmas.

\section{Lemma D1}

$$
\begin{gathered}
P_{B E V}^{N R}=\frac{\beta\left(K_{1}+1-\beta\right)+2 K_{2}}{4-\beta}-O_{B E V}+s, \\
q_{B E V}^{N R}=\frac{\beta\left(K_{1}+1-\beta\right)-(2-\beta) K_{2}}{(4-\beta)(1-\beta) \beta}, \\
\pi_{B E V}^{N R}=\frac{\left[\beta\left(K_{1}+1-\beta\right)-(2-\beta) K_{2}\right]^{2}}{(4-\beta)^{2}(1-\beta) \beta}, \\
P_{C V}^{N R}=\frac{2\left(K_{1}+1-\beta\right)+K_{2}}{(4-\beta)\left(1+r_{V P T}\right)}-\frac{O_{C V}}{1+r_{V P T}}, \\
q_{C V}^{N R}=1-\frac{(2-\beta)\left(K_{1}+1-\beta\right)-K_{2}}{(4-\beta)(1-\beta)}, \\
\pi_{C V}^{N R}=(m-1) C R_{N E V}^{+} P C R \frac{K_{1}+1-\beta+2 K_{2}}{4-\beta} \\
+\frac{\left[2(1-\beta)-(2-\beta) K_{1}+K_{2}\right]^{2}}{(4-\beta)^{2}(1-\beta)\left(1+r_{V P T}\right)} .
\end{gathered}
$$

Note: $\quad K_{1}=\left(1+r_{V P T}\right)\left\{C_{C V}+\left[m C R_{N E V}^{-}+(m-1) C R_{N E V}^{+}\right] P_{C R}\right\}+O_{C V}$ and $K_{2}=C_{B E V}-$ $C R_{N E V}^{+} P_{C R}+O_{B E V}-s$. 


\section{Lemma D2}

$$
\begin{gathered}
P_{B E V}^{C V R}=\frac{\beta\left(K_{1}+1-\beta+l\right)+2 K_{2}}{4-\beta}-O_{B E V}+s, \\
q_{B E V}^{C V R}=\frac{\beta\left(K_{1}+1-\beta+l\right)-(2-\beta) K_{2}}{(4-\beta)(1-\beta) \beta}, \\
\pi_{B E V}^{C V R}=\frac{\left[\beta\left(K_{1}+1-\beta+l\right)-(2-\beta) K_{2}\right]^{2}}{(4-\beta)^{2}(1-\beta) \beta}, \\
P_{C V}^{C V R}=\frac{2\left(K_{1}+1-\beta+l\right)+K_{2}}{(4-\beta)\left(1+r_{V P T}\right)}-\frac{O_{C V}+l}{1+r_{V P T}}, \\
q_{C V}^{C V R}=1-\frac{(2-\beta)\left(K_{1}+1-\beta+l\right)-K_{2}}{(4-\beta)(1-\beta)}, \\
\pi_{C V}^{C V R}=(m-1) C R_{N E V}^{+} P_{C R} \frac{K_{1}+1-\beta+l+2 K_{2}}{4-\beta} \\
+\frac{\left[2(1-\beta)-(2-\beta)\left(K_{1}+l\right)+K_{2}\right]^{2}}{(4-\beta)^{2}(1-\beta)\left(1+r_{V P T}\right)} .
\end{gathered}
$$

Note: $\quad K_{1}=\left(1+r_{V P T}\right)\left\{C_{C V}+\left[m C R_{N E V}^{-}+(m-1) C R_{N E V}^{+}\right] P_{C R}\right\}+O_{C V}$ and $K_{2}=C_{B E V}-$ $C R_{N E V}^{+} P_{C R}+O_{B E V}-S$.

\section{Lemma D3}

$$
\begin{gathered}
P_{B E V}^{B R}=\frac{\beta\left(K_{1}+1-\beta+l\right)+2\left(K_{2}+l\right)}{4-\beta}-O_{B E V}-l+s, \\
q_{B E V}^{B R}=\frac{\beta\left(K_{1}+1-\beta+l\right)-(2-\beta)\left(K_{2}+l\right)}{(4-\beta)(1-\beta) \beta}, \\
\pi_{B E V}^{B R}=\frac{\left[\beta\left(K_{1}+1-\beta+l\right)-(2-\beta)\left(K_{2}+l\right)\right]^{2}}{(4-\beta)^{2}(1-\beta) \beta}, \\
P_{C V}^{B R}=\frac{2\left(K_{1}+1-\beta+l\right)+K_{2}+l}{(4-\beta)\left(1+r_{V P T}\right)}-\frac{O_{C V}+l}{1+r_{V P T}}, \\
q_{C V}^{B R}=1-\frac{(2-\beta)\left(K_{1}+1-\beta+l\right)-K_{2}-l}{(4-\beta)(1-\beta)}, \\
\pi_{C V}^{B R}=(m-1) C R_{N E V}^{+} P C R \frac{K_{1}+1-\beta+2 K_{2}+3 l}{4-\beta} \\
+\frac{\left[2(1-\beta)-(2-\beta)\left(K_{1}+l\right)+K_{2}+l\right]^{2}}{(4-\beta)^{2}(1-\beta)\left(1+r_{V P T}\right)} .
\end{gathered}
$$

Note: $\quad K_{1}=\left(1+r_{V P T}\right)\left\{C_{C V}+\left[m C R_{N E V}^{-}+(m-1) C R_{N E V}^{+}\right] P_{C R}\right\}+O_{C V} \quad$ and $\quad K_{2}=C_{B E V}-$ $C R_{N E V}^{+} P_{C R}+O_{B E V}-S$.

\section{Proposition D1}


(a) Based on Lemmas D1, D2, and D3, there are:

$$
\begin{aligned}
& q_{B E V}^{C V R}-q_{B E V}^{N R}=\frac{l}{(4-\beta)(1-\beta)}>0, q_{B E V}^{B R}-q_{B E V}^{N R}=\frac{-2 l}{(4-\beta) \beta}<0, \\
& q_{B E V}^{C V R}-q_{B E V}^{B R}=q_{B E V}^{C V R}-q_{B E V}^{N R}-\left(q_{B E V}^{B R}-q_{B E V}^{N R}\right)>0 .
\end{aligned}
$$

Based on Lemmas D1, D2, and D3, there are:

$q_{C V}^{C V R}-q_{C V}^{N R}=-l \frac{2-\beta}{(4-\beta)(1-\beta)}<0, q_{C V}^{B R}-q_{C V}^{N R}=\frac{-l}{4-\beta}<0, q_{C V}^{C V R}-q_{C V}^{B R}=\frac{-l}{(4-\beta)(1-\beta)}<0$.

(b) Based on Lemmas D1, D2, and D3, there are:

$$
\begin{array}{r}
\pi_{B E V}^{C V R}-\pi_{B E V}^{N R}=l \frac{\Lambda_{1}+\Lambda_{2}}{(4-\beta)^{2}(1-\beta)}>0, \pi_{B E V}^{B R}-\pi_{B E V}^{N R}=-2 l \frac{\Lambda_{1}+\Lambda_{3}}{(4-\beta)^{2} \beta}<0 \\
\pi_{B E V}^{C V R}-\pi_{B E V}^{B R}=\pi_{B E V}^{C V R}-\pi_{B E V}^{N R}-\left(\pi_{B E V}^{B R}-\pi_{B E V}^{N R}\right)>0,
\end{array}
$$

where $\Lambda_{1}=\beta\left(K_{1}+1-\beta\right)-(2-\beta) K_{2}>0, \Lambda_{2}=\beta\left(K_{1}+1-\beta+l\right)-(2-\beta) K_{2}>0$, and $\Lambda_{3}=\beta\left(K_{1}+1-\beta+l\right)-(2-\beta)\left(K_{2}+l\right)>0$.

Based on Lemmas D1, D2, and D3, there are:

$$
\begin{gathered}
\pi_{C V}^{C V R}-\pi_{C V}^{N R}=-(2-\beta) l \frac{\Lambda_{4}+\Lambda_{5}}{(4-\beta)^{2}(1-\beta)\left(1+r_{V P T}\right)}+\frac{(m-1) C R_{N E V}^{+} P_{C R} l}{4-\beta}, \\
\pi_{C V}^{B R}-\pi_{C V}^{N R}=-l \frac{\Lambda_{4}+\Lambda_{6}}{(4-\beta)^{2}\left(1+r_{V P T}\right)}+\frac{3(m-1) C R_{N E V}^{+} P_{C R} l}{4-\beta}, \\
\pi_{C V}^{C V R}-\pi_{C V}^{B R}=-l \frac{\Lambda_{5}+\Lambda_{6}}{(4-\beta)(1-\beta)\left(1+r_{V P T}\right)}-\frac{2(m-1) C R_{N E V}^{+} P_{C R} l}{4-\beta}<0
\end{gathered}
$$

where $\Lambda_{4}=2(1-\beta)-(2-\beta) K_{1}+K_{2}>0, \Lambda_{5}=2(1-\beta)-(2-\beta)\left(K_{1}+l\right)+K_{2}>0$, and $\Lambda_{6}=2(1-\beta)-(2-\beta)\left(K_{1}+l\right)+K_{2}+l>0$.

(c) Substituting Equations (D.1), (D.2), and (D.3) into Equation (6) yields the total economic cost of emissions under different traffic restriction policies, as shown below:

$$
\begin{gathered}
T C E^{N R}=\frac{\beta\left(K_{1}+1-\beta\right)-(2-\beta) K_{2}}{(4-\beta)(1-\beta) \beta} e_{B E V} \\
+\left(1-\frac{(2-\beta)\left(K_{1}+1-\beta\right)-K_{2}}{(4-\beta)(1-\beta)}\right) e_{C V} \\
T C E^{C V R}=\frac{\beta\left(K_{1}+1-\beta+l\right)-(2-\beta) K_{2}}{(4-\beta)(1-\beta) \beta} e_{B E V} \\
+\left(1-\frac{(2-\beta)\left(K_{1}+1-\beta+l\right)-K_{2}}{(4-\beta)(1-\beta)}\right) e_{C V},
\end{gathered}
$$




$$
\begin{aligned}
& T C E^{B R}=\frac{\beta\left(K_{1}+1-\beta+l\right)-(2-\beta)\left(K_{2}+l\right)}{(4-\beta)(1-\beta) \beta} e_{B E V} \\
& \quad+\left(1-\frac{(2-\beta)\left(K_{1}+1-\beta+l\right)-K_{2}-l}{(4-\beta)(1-\beta)}\right) e_{C V},
\end{aligned}
$$

Based on Equations (D.4), (D.5), and (D.6), there are:

$$
\begin{gathered}
T C E^{C V R}-T C E^{N R}=\frac{l}{(4-\beta)(1-\beta)}\left(e_{B E V}-(2-\beta) e_{C V}\right)<0, \\
T C E^{B R}-T C E^{N R}=\frac{-l}{(4-\beta) \beta}\left(2 e_{B E V}+\beta e_{C V}\right)<0, \\
T C E^{C V R}-T C E^{B R}=\frac{l}{(4-\beta)(1-\beta) \beta}\left((2-\beta) e_{B E V}-\beta e_{C V}\right) .
\end{gathered}
$$

Therefore, $T C E^{C V R}<T C E^{B R}$ if and only if $e_{B E V}<\frac{\beta}{2-\beta} e_{C V}$.

$$
\begin{gathered}
\widetilde{T C E}^{C V R}-\widetilde{T C E}^{N R}=\frac{l}{(4-\beta)(1-\beta)}\left(e_{B E V}-(2-\beta) e_{C V}\right)<0, \\
\widetilde{T C E}^{B R}-\widetilde{T C E}^{N R}=\frac{-l}{(4-\beta) \beta}\left(2 e_{B E V}+\beta e_{C V}\right)<0, \\
\widetilde{T C E}^{C V R}-\widetilde{T C E}^{B R}=\frac{l}{(4-\beta)(1-\beta) \beta}\left((2-\beta) e_{B E V}-\beta e_{C V}\right) .
\end{gathered}
$$

Therefore, $\widetilde{T C E}^{C V R}>\widetilde{T C E}^{B R}$ if and only if $e_{B E V}<\frac{\beta}{2-\beta} e_{C V}$.

\section{Appendix E. Higher Operating Cost of Some NEV}

When the operating cost of $\mathrm{NEV}$ (i.e., $\mathrm{FCEV}$ ) is higher than that of $\mathrm{CV}, O_{F C E V}>O_{C V}$, we recalculate and yield the optimal retail prices, sales volumes, and manufacturers profits as summarized in the following Lemmas. Appendix $\mathrm{E}$ identifies the threshold, $\bar{O}_{F C E V}=$ $\frac{\beta\left(K_{1}+1-\beta+l\right)}{2-\beta}-C_{F C E V}-\beta C R_{N E V}^{-} P_{C R}+s$. When the operating cost of FCEVs exceeds the threshold, $O_{F C E V} \geq \bar{O}_{F C E V}$, uncompetitive FCEVs lose their market share. The extremely high operating cost of FCEV also explains why BEV and PHEV adoptions are promoted, while FCEV performs unexpectedly, when all three types of NEVs are exempted from restrictions in China. When the operating cost of FCEVs only exceeds the operating cost of CVs but not the threshold, $O_{C V} \leq O_{F C E V} \leq \bar{O}_{F C E V}$, the analysis is summarized in the following Lemmas and Proposition.

\section{Lemma E1}




$$
\begin{gathered}
P_{F C E V}^{N R}=\frac{\beta\left(K_{1}+1-\beta\right)+2 K_{2}}{4-\beta}-O_{F C E V}+s, \\
q_{F C E V}^{N R}=\frac{\beta\left(K_{1}+1-\beta\right)-(2-\beta) K_{2}}{(4-\beta)(1-\beta) \beta}, \\
\pi_{F C E V}^{N R}=\frac{\left[\beta\left(K_{1}+1-\beta\right)-(2-\beta) K_{2}\right]^{2}}{(4-\beta)^{2}(1-\beta) \beta} \\
+C R_{N E V}^{-} P_{C R} \frac{2+\beta-2 K_{1}-K_{2}}{4-\beta}, \\
P_{C V}^{N R}=\frac{2\left(K_{1}+1-\beta\right)+K_{2}}{(4-\beta)\left(1+r_{V P T}\right)}-\frac{O_{C V}}{1+r_{V P T}} \\
q_{C V}^{N R}=1-\frac{(2-\beta)\left(K_{1}+1-\beta\right)-K_{2}}{(4-\beta)(1-\beta)}, \\
\pi_{C V}^{N R}=\frac{\left[2(1-\beta)-(2-\beta) K_{1}+K_{2}\right]^{2}}{(4-\beta)^{2}(1-\beta)\left(1+r_{V P T}\right)} .
\end{gathered}
$$

Note: $K_{1}=\left(1+r_{V P T}\right)\left(C_{C V}+C R_{N E V}^{-} P_{C R}\right)+O_{C V}$ and $K_{2}=C_{F C E V}+\beta C R_{N E V}^{-} P_{C R}+O_{F C E V}-s$.

\section{Lemma E2}

$$
\begin{gathered}
P_{F C E V}^{C V R}=\frac{\beta\left(K_{1}+1-\beta+l\right)+2 K_{2}}{4-\beta}-O_{F C E V}+s, \\
q_{F C E V}^{C V R}=\frac{\beta\left(K_{1}+1-\beta+l\right)-(2-\beta) K_{2}}{(4-\beta)(1-\beta) \beta}, \\
\pi_{F C E V}^{C V R}=\mathrm{CR}_{\mathrm{NEV}}^{-} P_{C R} \frac{2+\beta-2 K_{1}-2 l-K_{2}}{4-\beta} \\
+\frac{\left[\beta\left(K_{1}+1-\beta+l\right)-(2-\beta) K_{2}\right]^{2}}{(4-\beta)^{2}(1-\beta) \beta}, \\
P_{C V}^{C V R}=\frac{2\left(K_{1}+1-\beta+l\right)+K_{2}}{(4-\beta)\left(1+r_{V P T}\right)}-\frac{O_{C V}+l}{1+r_{V P T}}, \\
q_{C V}^{C V R}=1-\frac{(2-\beta)\left(K_{1}+1-\beta+l\right)-K_{2}}{(4-\beta)(1-\beta)}, \\
\pi_{C V}^{C V R}=\frac{\left[2(1-\beta)-(2-\beta)\left(K_{1}+l\right)+K_{2}\right]^{2}}{(4-\beta)^{2}(1-\beta)\left(1+r_{V P T}\right)} .
\end{gathered}
$$

Note: $K_{1}=\left(1+r_{V P T}\right)\left(C_{C V}+C R_{N E V}^{-} P_{C R}\right)+O_{C V}$ and $K_{2}=C_{F C E V}+\beta C R_{N E V}^{-} P_{C R}+O_{F C E V}-s$.

\section{Lemma E3}




$$
\begin{gathered}
P_{F C E V}^{B R}=\frac{\beta\left(K_{1}+1-\beta+l\right)+2\left(K_{2}+l\right)}{4-\beta}-O_{F C E V}-l+s, \\
q_{F C E V}^{B R}=\frac{\beta\left(K_{1}+1-\beta+l\right)-(2-\beta)\left(K_{2}+l\right)}{(4-\beta)(1-\beta) \beta}, \\
\pi_{F C E V}^{B R}=\mathrm{CR}_{\mathrm{NEV}}^{-} P_{C R} \frac{2+\beta-2 K_{1}-K_{2}-3 l}{4-\beta} \\
+\frac{\left[\beta\left(K_{1}+1-\beta+l\right)-(2-\beta)\left(K_{2}+l\right)\right]^{2}}{(4-\beta)^{2}(1-\beta) \beta}, \\
P_{C V}^{B R}=\frac{2\left(K_{1}+1-\beta+l\right)+K_{2}+l}{(4-\beta)\left(1+r_{V P T}\right)}-\frac{O_{C V}+l}{1+r_{V P T}}, \\
q_{C V}^{B R}=\frac{1-\frac{(2-\beta)\left(K_{1}+1-\beta+l\right)-K_{2}-l}{(4-\beta)(1-\beta)},}{\left.(4-\beta)\left(K_{1}+l\right)+K_{2}+l\right]^{2}} . \\
\pi_{C V}^{B R}=\frac{\left[2(1-\beta)-(1-\beta)\left(1+r_{V P T}\right)\right.}{(4-\beta)^{2}(1-\beta)}
\end{gathered}
$$

Note: $K_{1}=\left(1+r_{V P T}\right)\left(C_{C V}+C R_{N E V}^{-} P_{C R}\right)+O_{C V}$ and $K_{2}=C_{F C E V}+\beta C R_{N E V}^{-} P_{C R}+O_{F C E V}-s$.

\section{Proposition E1}

(a) According to Lemma E1, E2, E3, we have

$$
\begin{gathered}
q_{F C E V}^{C V R}-q_{F C E V}^{N R}=\frac{l}{(4-\beta)(1-\beta)}>0, q_{F C E V}^{B R}-q_{F C E V}^{N R}=\frac{-2 l}{(4-\beta) \beta}<0, \\
q_{F C E V}^{C V R}-q_{F C E V}^{B R}=q_{F C E V}^{C V R}-q_{F C E V}^{N R}-\left(q_{F C E V}^{B R}-q_{F C E V}^{N R}\right)>0 .
\end{gathered}
$$

According to Lemma E1, E2, E3, we have

$$
q_{C V}^{C V R}-q_{C V}^{N R}=-l \frac{2-\beta}{(4-\beta)(1-\beta)}<0, q_{C V}^{B R}-q_{C V}^{N R}=\frac{-l}{4-\beta}<0, q_{C V}^{C V R}-q_{C V}^{B R}=\frac{-l}{(4-\beta)(1-\beta)}<0 .
$$

(b) According to Lemma E1, E2, E3, we have

$$
\pi_{F C E V}^{C V R}-\pi_{F C E V}^{N R}=l \frac{\Lambda_{1}+\Lambda_{2}}{(4-\beta)^{2}(1-\beta)}-\frac{2 l C R_{N E V}^{-} P_{C R}}{4-\beta},
$$

Therefore $\pi_{F C E V}^{C V R}-\pi_{F C E V}^{N R}>0$ if and only if $\frac{l}{2 \beta}>C R_{N E V}^{-} P_{C R}(4-\beta)(1-\beta)-\Lambda_{1}$.

$$
\begin{gathered}
\pi_{F C E V}^{B R}-\pi_{F C E V}^{N R}=-2 l \frac{\Lambda_{1}+\Lambda_{3}}{(4-\beta)^{2} \beta}-\frac{3 l C R_{N E V}^{-} P_{C R}}{4-\beta}<0, \\
\pi_{F C E V}^{C V R}-\pi_{F C E V}^{B R}=(2-\beta) l \frac{\Lambda_{2}+\Lambda_{3}}{(4-\beta)^{2}(1-\beta) \beta}+\frac{l C R_{N E V}^{-} P_{C R}}{4-\beta}>0 .
\end{gathered}
$$

where $\Lambda_{1}=\beta\left(K_{1}+1-\beta\right)-(2-\beta) K_{2}>0, \Lambda_{2}=\beta\left(K_{1}+1-\beta+l\right)-(2-\beta) K_{2}>0$, and $\Lambda_{3}=$ $\beta\left(K_{1}+1-\beta+l\right)-(2-\beta)\left(K_{2}+l\right)>0$.

According to Lemma E1, E2, E3, we have

$$
\pi_{C V}^{C V R}-\pi_{C V}^{N R}=-(2-\beta) l \frac{\Lambda_{4}+\Lambda_{5}}{(4-\beta)^{2}(1-\beta)\left(1+r_{V P T}\right)}<0
$$




$$
\pi_{C V}^{B R}-\pi_{C V}^{N R}=-l \frac{\Lambda_{4}+\Lambda_{6}}{(4-\beta)^{2}\left(1+r_{V P T}\right)}<0, \pi_{C V}^{C V R}-\pi_{C V}^{B R}=-l \frac{\Lambda_{5}+\Lambda_{6}}{(4-\beta)(1-\beta)\left(1+r_{V P T}\right)}<0,
$$

where $\Lambda_{4}=2(1-\beta)-(2-\beta) K_{1}+K_{2}>0, \Lambda_{5}=2(1-\beta)-(2-\beta)\left(K_{1}+l\right)+K_{2}>0$, and $\Lambda_{6}=$ $2(1-\beta)-(2-\beta)\left(K_{1}+l\right)+K_{2}+l>0$.

(c) By substituting Equations (E.1), (E.2), (E.3) into Equation (6) yields the total economic cost of emissions under different traffic restriction policies, as shown below

$$
\begin{gathered}
T C E^{N R}=\frac{\beta\left(K_{1}+1-\beta\right)-(2-\beta) K_{2}}{(4-\beta)(1-\beta) \beta} e_{F C E V}+\left[1-\frac{(2-\beta)\left(K_{1}+1-\beta\right)-K_{2}}{(4-\beta)(1-\beta)}\right] e_{C V}, \\
T C E^{C V R}=\frac{\beta\left(K_{1}+1-\beta+l\right)-(2-\beta) K_{2}}{(4-\beta)(1-\beta) \beta} e_{F C E V}+\left[1-\frac{(2-\beta)\left(K_{1}+1-\beta+l\right)-K_{2}}{(4-\beta)(1-\beta)}\right] e_{C V}, \\
T C E^{B R}=\frac{\beta\left(K_{1}+1-\beta+l\right)-(2-\beta)\left(K_{2}+l\right)}{(4-\beta)(1-\beta) \beta} e_{F C E V}+\left[1-\frac{(2-\beta)\left(K_{1}+1-\beta+l\right)-K_{2}-l}{(4-\beta)(1-\beta)}\right] e_{C V},(E .6)
\end{gathered}
$$

According to Equations (E.4), (E.5), and (E.6), we have

$$
\begin{gathered}
T C E^{C V R}-T C E^{N R}=\frac{l}{(4-\beta)(1-\beta)}\left[e_{F C E V}-(2-\beta) e_{C V}\right]<0, \\
T C E^{B R}-T C E^{N R}=\frac{-l}{(4-\beta) \beta}\left(2 e_{F C E V}+\beta e_{C V}\right)<0, \\
T C E^{C V R}-T C E^{B R}=\frac{l}{(4-\beta)(1-\beta) \beta}\left[(2-\beta) e_{F C E V}-\beta e_{C V}\right] .
\end{gathered}
$$

Therefore, $T C E^{C V R}<T C E^{B R}$ if and only if $e_{F C E V}<\frac{\beta}{2-\beta} e_{C V}$. 